Portland State University

PDXScholar

\title{
Modeling Spawning Habitat Potential for Chum (Onchorhynchus keta) and Pink Salmon (0. gorbuscha) in Relation to Landscape Characteristics in Coastal Southeast Alaska
}

Bernard Timothy Romey

Portland State University

Follow this and additional works at: https://pdxscholar.library.pdx.edu/open_access_etds

Part of the Natural Resources Management and Policy Commons Let us know how access to this document benefits you.

\section{Recommended Citation}

Romey, Bernard Timothy, "Modeling Spawning Habitat Potential for Chum (Onchorhynchus keta) and Pink Salmon (O. gorbuscha) in Relation to Landscape Characteristics in Coastal Southeast Alaska" (2018). Dissertations and Theses. Paper 4252.

https://doi.org/10.15760/etd.6136

This Thesis is brought to you for free and open access. It has been accepted for inclusion in Dissertations and Theses by an authorized administrator of PDXScholar. Please contact us if we can make this document more accessible: pdxscholar@pdx.edu. 
Modeling Spawning Habitat Potential for Chum (Oncorhynchus keta) and Pink Salmon

(O. gorbuscha) in Relation to Landscape Characteristics in Coastal Southeast Alaska

by

Bernard Timothy Romey

A thesis submitted in partial fulfillment of the requirements for the degree of

Master of Science

in

Environmental Science and Management

Thesis Committee:

Yangdong Pan, Chair

Angela Strecker

Eugene Foster

Douglas Martin

Portland State University

2018 


\begin{abstract}
In response to the increasing need for ecosystem services throughout the Southeast Alaska region, decision makers are tasked with balancing the need for natural resources with salmon conservation. However, accurate historical and current information on salmonid population abundance, freshwater distribution, and habitat quality are sparse with limited resolution for large portions of this remote and rugged landscape. Here, I created Intrinsic Potential (IP) models for chum and pink salmon to predict the potential for portions of coastal rivers to provide high-quality spawning habitat. I developed IP models for both species from field redd surveys and synthetic habitat variables derived from 1-m resolution digital elevation models. The surveys were performed at 49 study reaches in five coastal drainage basins on the north end of Chichagof Island, Southeast Alaska. I used a spatially balanced random sampling design that included field surveys for redds during two field seasons with contrasting precipitation patterns and disparate adult salmon escapements. The IP models predict probable spawning habitat for both species based on persistent landform characteristics and hydrologic processes that control the formation and distribution of spawning habitat across the landscape. Selection of persistent reach variables for both species IP models was informed by principal component analysis (PCA), resource selection ratios, random forest modeling, and regression models of field and synthetic variable comparisons. I observed primarily one spawning strategy by chum salmon associated with mainstem channels, and two distinct spawning strategies for pink salmon related to small moderategradient channels and tributaries, and lower drainage basin mainstem channels. The
\end{abstract}


relationships suggest that chum and pink salmon primarily selected for unconstrained channel types in large-and small-size channels, with chum salmon being more selective toward the larger mainstem channels, and pink salmon selecting for smaller channels and tributaries. The prediction of chum salmon redd presence within a specific reach for both high and low streamflow regimes was explained by channel gradient, floodplain width, and mean annual flow in order of importance. In general, chum salmon redds were observed in larger unconstrained low-gradient floodplain reaches where accumulation of deposited gravels and adequate flow produce habitat heterogeneity suitable for spawning. Pink salmon redd presence for both survey years was explained by channel gradient, reach elevation, and mean annual flow, in order of importance. Specifically, when flows allowed upstream access, spawning pink salmon utilized smaller moderate-gradient channels where substrate size and flows were better suited to their smaller body size. Remotely sensed persistent fish habitat data is valuable information for helping understand fish population distributions across the landscape. These synthetic metrics enabled the identification and evaluation of persistent landscape features as probable predictors of IP. Validation of LiDAR-derived channel characteristics indicated channel lengths measured from the DEM were $12 \%$ longer than field measured channel length, primarily for channels wider than 10 meters. Thus, understanding the limitations of the data is important so that decision makers do not unintentionally set unrealistic objectives. This research highlights the utility of using IP models with high resolution remote sensing to expand known distributions and quality of spawning habitat for these two species in Southeast Alaska coastal streams. 


\section{Acknowledgements}

First and foremost, I would like to thank my advisor Yangdong Pan, for the patience and guidance through the graduate school process with unwavering dedication to the mentorship, freely sharing his knowledge and perspective, and the encouragement in the face of challenges that helped me become a better scientist. I would also like to thank my committee members Angela Strecker and Eugene Foster for their insight, support, and willingness to serve. An enormous amount of gratitude is extended to Doug Martin, not only for his role as an honorary committee member, but also for encouragement as a mentor and friend, and for making this research opportunity possible. Additionally, many thanks to my lab mates and fellow graduate students who offered feedback and encouragement during the research process.

In addition to committee and graduate students, I also thank Lee Benda, Dan Miller, and Kevin Andras at Terrain Works for their GIS and NetMap knowledge and expertise. Multiple years of data collection would not have been possible without field assistance supplied by the Hoonah Indian Association and the Forest Service; these dedicated folks from the local community of Hoonah Alaska helped collect the data that I examined, and at times during inclement weather and challenging field conditions. Field equipment, office support, and lodging was provided by Sealaska, Hoonah Indian Association, and the Forest Service. This research was supported by the Natural Resource Conservation Service (NRCS) Regional Conservation Partnership Program (RCPP) to promote landscape scale watershed planning (Grant Number 68-0150-15-010). 
Finally, making it through graduate school would not have been possible without the support of family, friends, and mentors who encouraged me to pursue my educational goals with purpose and persistence regardless of the many obstacles that blocked my path along the way. 


\section{Table of Contents}

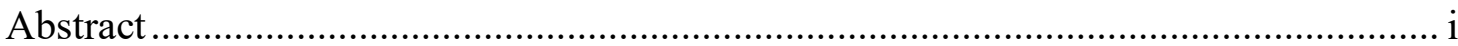

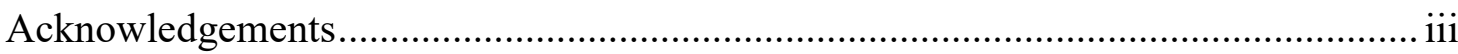

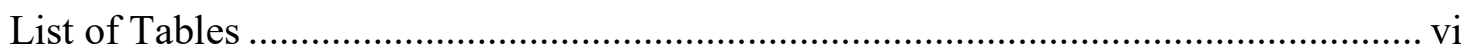

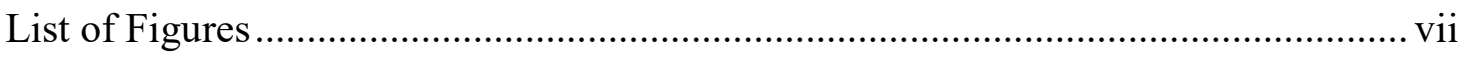

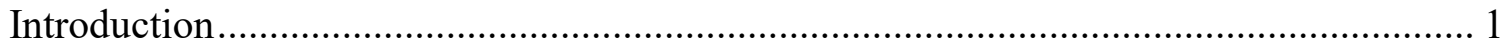

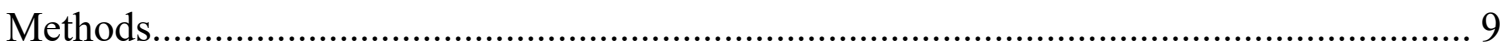

Study Area

Chum and Pink Salmon Freshwater Life Histories ................................................ 12

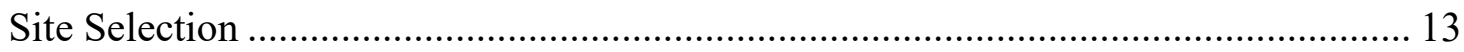

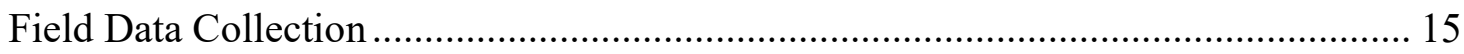

Synthetic Landscape Attributes .................................................................. 21

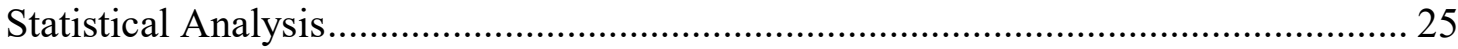

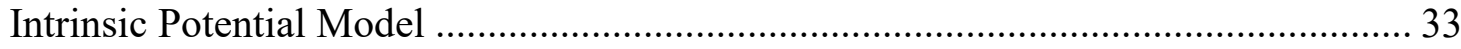

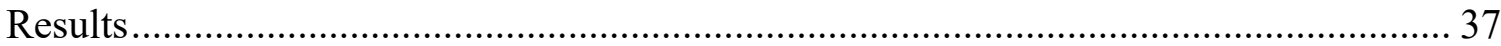

Spatial and Temporal Variation of Redds............................................................ 37

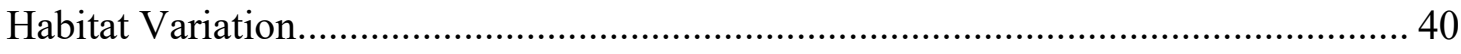

Persistent Habitat Predictors of Redd Density........................................................ 44

Relationship Between Redds and Process Types ................................................ 47

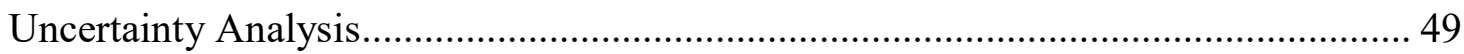

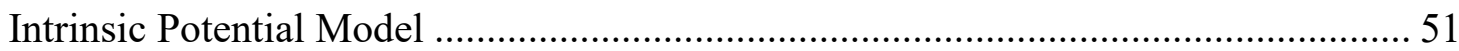

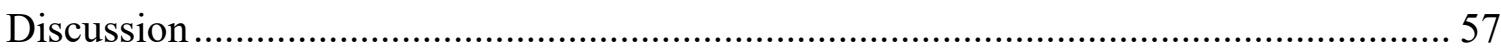

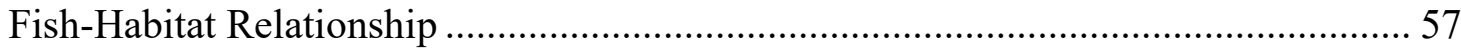

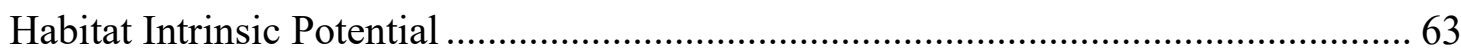

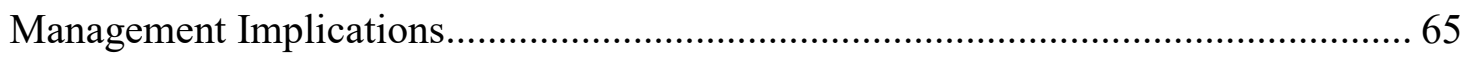

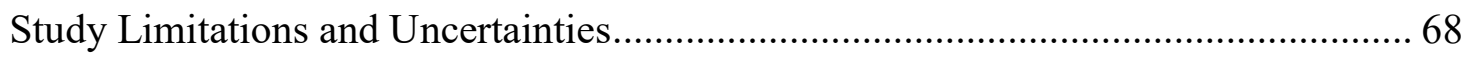

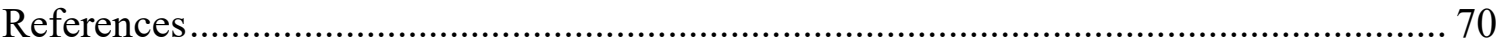

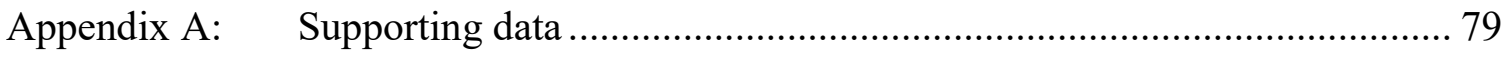




\section{List of Tables}

Table 1. Synthetic habitat characteristics of mainstem, tributary, channel size, constraint, and geology reach segment types in Game Creek, Gartina Creek, Seagull Creek, Spasski Creek, and Suntaheen Creek, Alaska. Channel reach types are unconstrained valleys (UV) and constrained canyons (CC) (adapted from Frissell et al. 1992), tributary and mainstem, small and large, and alluvium deposit and dolerite formation geology. Derived from 1-m pixel LiDAR digital elevation models (DEM).

Table 2. List of 26 synthetic persistent reach-level habitat predictors calculated in NetMap from light detection and ranging (LiDAR) digital elevation models (DEM) derived channel network.

Table 3. Principal component analysis (PCA) eigenvectors and associated loading for first 3 axes. Loadings $>0.35$ considered significant for axis interpretation. All 13 persistent reach habitat variables included in analysis. Reference Table 1 for variable description.

Table 4. Random forest classification tree observed versus predicted accuracy measures for presence (Sensitivity), absence (Specificity), and overall model percent correctly classified (PCC) for chum and pink salmon redds in the study area on Chichagof Island, Southeast Alaska $(\mathrm{n}=49)$.

Table 5. Field and synthetic (model) channel morphology characteristics comparison at cross sections $\left(\mathrm{BFW}=\right.$ Bank-full width, $\mathrm{BFD}=$ Bank-full depth, $\mathrm{D}_{50}=$ Median particle size), and longitudinal channel profiles ( $\mathrm{LPL}=$ Longitudinal profile length, Gradient $=$ Reach gradient at $20 \times$ BFW) during 2015 field season $(n=48)$. 


\section{List of Figures}

Figure 1. Map showing the locations of five study drainages (Seagull, Game, Gartina, Spasski and Suntaheen creeks) on the northeast side of Chichagof Island, and study reaches (white lines are stream channels, black lines are sampled reaches, and circles indicate natural upstream migration barriers).

Figure 2. Diagram representing the flow of geospatial and field observed biological information into the analysis and selection of persistent landscape attributes used in the fish-habitat suitability index curves of the intrinsic potential analyses.

Figure 3. Historical mean monthly precipitation (boxplots) from 1941 to 2016, with spawning period for chum and pink salmon in green, and 2015 and 2016 mean monthly precipitation for gauging station located within the project area (58.107 latitude, -135.428 longitude) near Hoonah, Alaska. Boxes designate the 25 th and 75 th percentiles, the solid line indicates the median, whiskers denote the nearest data point within 1.5 times the interquartile range, and outliers are shown by disconnected points.

Figure 4. Distribution of relative redd density (redds $/ 100 \mathrm{~m}^{2}$ ) for each study reach during rainy 2015 and lack of rainfall 2016 redd survey field season. Density range for pink salmon (2015 and 2016 range: 0-29.2 and 0-6.7, respectively) and chum salmon (2015 and 2016 range: 0-3.5 and 0-1.1, respectively) for both years indicated by size of circle. Grey line is watershed boundary and blue line is stream.

Figure 5. Principal component analysis (PCA) biplot of synthetic reach factors with overlaid pink and chum salmon redd present (P) and absent (A) for all study reaches during 2015 (rainy) and 2016 (lack of rainfall) spawning periods. (a) Pink salmon present during 2015 and (b) 2016, and chum salmon present during (c) 2015 and (d) 2016. Standardized PC1 $(25.2 \%)$ is comprised primarily of channel size related to flow and channel gradient, while standardize PC2 $(22.0 \%)$ is a channel constraint and debris transport, or deposition gradient.

Figure 6. Random forest synthetic variable importance plots for (a) 2015 and (b) 2016 pink and (c) 2015 and (d) 2016 chum salmon redd presence/absence. Higher variable importance increase node splitting homogeneity (purity), while variables closest to absolute value of lowest purity are relatively unimportant (Mean decrease Gini index). 46

Figure 7. Selection ratios of adult chum salmon (C) and pink salmon (P) during 2015 and 2016 field season for: (a) unconstrained valleys (UV) and constrained canyons (CC); (b) glacial deposit (Dv) and volcanic dolerite (Qs) formations; (c) mainstem and tributary channels; (d) and small and large channel types. A selection ratio was not significant if the Bonferroni-adjusted confidence interval $(\alpha=0.1 / 2)$ included one. Selection ratios were significantly different for a given year by species $(\alpha=0.1)$ if their confidence interval did not overlap. 
Figure 8. Fish-habitat relationship between values of the three synthetic persistent reach attributes and the index scores based on chum and pink salmon redd density used to calculate intrinsic potential for: (a, b) mean annual flow, $(c, d)$ channel gradient, and (e, f) valley-width index, respectively.

Figure 9. Map showing (a) chum and (b) pink salmon IP modeled reaches across the study area landscape. White lines represent riverscape patterns for stream segments having IP scores $<0.50$ (Low potential), green lines represent IP scores between 0.50 and 0.75 (moderate potential), and red lines represent IP scores $\geq 0.75$ (high potential) for uncorrected channel length. 


\section{Introduction}

All five species of Pacific salmon utilize the coastal rivers of Southeast Alaska and are important culturally, socially, and economically for the people who have shared these coastal landscapes for thousands of years. Anthropogenic factors contributing to changes in wild salmonid abundance for this region regularly include commercial, recreational, and subsistence fisheries (Piston and Heinl 2011; Heinl et al. 2014; Piston and Heinl 2014), hatchery-based stock releases (Ruggerone et al. 2010; 2012), and alteration of freshwater habitat (Murphy 1995; Martin and Shelly 2017). In response to the increasing need for ecosystem services throughout the region, decision makers are tasked with balancing the need for natural resources with salmon conservation. To better understand this balance, managers require accurate information to evaluate population structure and habitat requirements across heterogeneous landscapes used by salmonids in these rugged and remote riverscapes. Understanding the historical fish-habitat requirements for a viable population is a critical first step because the historical population structure and underlying persistent habitat template is the foundation for each salmonid species long-term success (McElhany et al. 2000).

Salmonid population productivity and survival are intrinsically linked to freshwater habitat in coastal watersheds in Southeast Alaska. Although, accurate historical and current information on chum salmon (Oncorhynchus keta) and pink salmon (O. gorbuscha) population abundance and freshwater distribution for this region are sparse with limited resolution. In addition, the exorbitant costs associated with conducting accurate population and habitat surveys for large areas of remote and rugged 
Southeast Alaska are prohibitive. Therefore, decision makers are turning to a GIS-based modeling approach based on remote sensing data to predict the quantity and quality of freshwater habitat as a function of watershed hydrogeomorphic features (Sheer et al. 2009). These coarse-scale habitat models are a useful method for describing persistent habitat heterogeneity across the landscape, and can provide the initial information necessary for assessing habitat potential and informing conservation strategies to protect populations of salmonids.

Over the last decade, models for analyzing river landscapes have been proliferating due to the increasing accessibility of geospatial data used to model coarse synthetic stream habitat characteristics derived from high resolution digital elevation models (DEMs), and the predictive ability of these models to effectively describe riverscape patterns of high-quality habitat important to salmonids (Benda et al. 2007). Intrinsic potential (IP) models are one such GIS-based approach that uses fish habitat preferences as a function of synthetic persistent geomorphic and hydrologic processes to predict the potential of a reach to produce suitable freshwater habitat for a particular salmonid life-history (Agrawal 2005; Burnett et al. 2007; Busch et al. 2011; Flitcroft et al. 2014). The foundation of IP models are thus based on the immutable physical characteristics and processes (landform, lithology, hydrology) that form important stream habitat for salmonids, and are not easily altered by anthropogenic influences (Steel et al. 2016).

IP modeling was originally developed to estimate potential high-quality rearing habitat suitable for juvenile coho salmon (O. kisutch) and steelhead (O. mykiss) along the Coast Province of Oregon (Burnett et al. 2003, 2007). The geomorphic and hydrological 
characteristics Burnett (2007) selected as the best predictors of IP were valley constraint, reach gradient, and mean annual flow. IP modeling has also been used in northern California to prioritize stream channels important for the conservation and restoration of freshwater habitat for Chinook salmon (O. tshawytscha), coho salmon, and steelhead (Agrawal 2005). Agrawal (2005) adapted the approach used by Burnett (2003) by implementing the same synthetic reach attributes for coho salmon and steelhead with a few slight modifications to the index curves to fit the northern California region, and added juvenile Fall-run Chinook salmon based on expert opinion. Busch (2011) used valley confinement, reach gradient, and stream width for an IP model to identify potential Chinook salmon spawning habitat in the lower Columbia River basin. In addition, Bidlack (2014) developed an IP model to identify potential high-quality rearing habitat for juvenile Chinook salmon for conservation and management planning. Bidlack (2014) used reach gradient, mean annual flow, and glacial influence to encompass the geomorphic and hydrologic processes that generate suitable habitat for juvenile Chinook salmon in the Copper River drainage basin in Alaska. Furthermore, the IP index from some of these published models has also been used indirectly as a predictor to inform other models of fish distribution or fish-habitat relationships (Firman et al. 2011; Steel et al. 2012; Beeson 2014; Flitcroft et al. 2014; May et al. 2016; Steel et al. 2016). Currently, IP analysis has been used to inform the prioritization of stream sites for conservation or restoration, species recovery planning, and potential historic or future species distributions.

Only a few studies have validated the efficacy of an IP model to predict potential habitat accurately or calibrated the IP fish-habitat relationship curves for a model. For 
example, Bidlack (2014) created a preliminary IP model using the Delphi system (Crance 1987), then used juvenile fish density data to calibrate the model. Sensitivity analysis is another way of evaluating model performance; while less robust than field validation, it is informative for understanding how the strength of the correlation between the IP model results (response) and the fish-habitat suitability threshold functions (predictors) change the model results (Van Horne and Wiens 1991). Busch (2011) created an IP model that was informed by the Burnett (2007) and Agrawal (2005) IP models for juvenile Chinook salmon to predict spawning habitat for the lower Columbia River basin, then used a Monte Carlo approach to evaluate the sensitivity of their model. This approach used by Busch (2011) is problematic because even though some juvenile Chinook salmon stay near their natal habitat after emerging from the spawning gravel, and there is some overlap in habitat use at the reach scale between juveniles and spawners, juveniles usually migrate to rearing habitat that is distinctly different than spawning habitat after emerging from the gravel (Steel et al. 2016). Hence, the processes that drive the distribution of juveniles during their freshwater rearing should not be used to infer the same relationship as those associated with adult salmon during spawning.

Currently, there are no empirically derived IP models for the five Pacific Salmon species present in Southeast Alaska and no IP models for chum and pink salmon, which are the most abundant species in the region. To develop IP models for these two species, a better understanding is needed of the immutable geomorphic and hydrologic processes that form and maintain spawning habitat critical for the sustainability of both populations.

Salmonid populations are structured by the spatial and temporal patterns of habitat formation and the persistence of that habitat. The capacity of a stream to generate 
suitable habitat for spawning salmonids originates from a hierarchical perspective of a fish-habitat relationship (Frissell et al. 1986; Montgomery and Buffington 1998). From this perspective, the interaction of large scale geomorphic processes (lithology, landform) with hydrology control the transport and deposition of sediment and wood, control channel movement within the confines of the valley, and therefore shape the diversity of habitat at the unit scale along the river network (Miller et al. 2008). These processes within the confines of a drainage basin, in combination with stream network configuration, create the habitat heterogeneity across the riverscape that is reflected by the diversity of salmonid species that are able to persist (Benda et al. 2004; Zarnetske et al. 2017). Differences in spawning habitat preferences by chum and pink salmon are a result of this spatial habitat heterogeneity, and Beechie (2008) proposed that larger-scale geomorphic processes are a reflection of adaptive traits while smaller scale patterns at the habitat unit scale are likely a reflection of phenotype plasticity response to local shortterm environmental variation.

Persistent habitat selection by chum and pink salmon during their freshwater upstream migration and spawning is dependent primarily on hydromorphological factors. Chum and pink salmon have a similar freshwater life history, and populations are generally limited by the amount of available spawning habitat (Wickett 1958; Manhard et al. 2017). These two species have adapted to specific spawning site characteristics, leading to spatial and temporal segregation over thousands of years (Taylor 1991). For populations of both species to persist, they must successfully deposit their gametes in the gravel, and the eggs must survive detrimental high flow events and associated scour (Montgomery et al. 1996), fine sediment suffocation (Chapman 1988), and predation 
during incubation (Reed 1967; Dittman et al. 1998). Habitat characteristics associated with spawning site selection by chum and pink salmon is typically a reflection of female body size (Kondolf and Wolman 1993; Buffington et al. 2004; Riebe et al. 2014; Overstreet et al. 2016). The body size of a female salmon is related to the size of gravel used for spawning, in addition to water depths and flow velocities conducive for digging a redd (Montgomery et al. 1996; Overstreet et al. 2016). In general, larger substrate tends to be associated with higher flow velocities, therefore they are not independent. The water depth needs to be deep enough for a female salmon to excavate a redd with adequate velocity for both holding position in the water column and transporting excavated substrate away from the egg pocket. Larger-bodied salmonids, such as chum salmon, spawn in larger gravels with deeper egg pocket, while smaller salmonids, such as pink salmon, utilize shallower streams with smaller gravels (Burner 1951; Bjornn and Reiser 1991; Beechie et al. 2008). Therefore, gravel size, water depth, and water velocity make up the selective environment utilized by chum and pink salmon, and are physically interrelated and controlled by larger channel forming processes such as mean annual flow, channel gradient, and channel constraint (Buffington et al. 2004; Beechie et al. 2008).

Flow events have a strong influence on upstream migration and timing of peak spawning. Montgomery et al. (1999) hypothesized that anadromous salmonids have adapted to timing and distribution patterns of scour depth within accessible reaches of a drainage basin that impose spatial and temporal restrictions on different species. In Southeast Alaska, chum salmon spawn primarily in July and August, while the majority of pink salmon spawn in late August and September (Alaska Department of Fish and 
Game unpublished data). Both of these species are fall spawners with spawning success linked to peak seasonal flows and associated scour depths occurring during winter storm events (Montgomery et al. 1996). Therefore, the differences in site selection by these species are linked to the availability of suitable habitat, the distribution of gravel sizes transported by habitat forming flows, and associated scour depths produced over time by the larger valley controlling geomorphic processes (Montgomery and Buffington 1997; Montgomery 1999; Beechie et al. 2008).

For chum and pink salmon, we have substantial knowledge of how spawning site attributes, at the habitat unit scale, influence site selection and optimize the survival of progeny (Wolman 1954; McNeil 1964, 1966; Raleigh and Nelson 1985; Hale et al. 1985; Crisp and Carling 1989, 1989; Kondolf and Wolman 1993; Montgomery et al. 1996; Fukushima and Smoker 1997; Dickerson et al. 2002, 2005; Buffington et al. 2004; Riebe et al. 2014; Overstreet et al. 2016). In contrast, there has been relatively little research concerning how reach-to landscape-scale factors influence the spatial distribution and selection of spawning habitat for these two species, and how these habitat use patterns are reflective of long-term adaptive survival strategies that are associated with persistent hydrologic and geomorphic characteristics. (Montgomery et al. 1999; Beechie et al. 2008; Sloat et al. 2016).

The goal of this research was to better understand reach-level persistent geomorphic and hydrologic characteristics that indicate spawning habitat intrinsic to chum and pink salmon by using synthetic variables derived from 1-m resolution Digital Elevation Models (DEMs) across coastal landscapes of Southeast Alaska. Specific objectives were to: 1) evaluate spawning habitat selectivity by chum and pink salmon 
among different channel types and varying seasonal stream flows; 2) determine the most important synthetic persistent habitat predictors for chum and pink salmon spawning habitat; and 3) use the results from these fish-habitat analyses to create an IP model for these two species in coastal riverscapes typical of Southeast Alaska. 


\section{Methods}

\section{Study Area}

The study area is broadly defined as coastal river drainage basins within the temperate rainforest island chain of Southeast Alaska (Figure 1). The study region includes the northeast end of Chichagof Island, extending from Icy Strait Point in the north to the headwaters of Game Creek in the south, and bordered on the west by Port Fredrick and on the east by Suntaheen Creek watershed. The study area has similar geology that includes alluvial deposit and dolerite formation that are characterized by mountainous terrain with steep slopes and glacially carved U-shaped valleys. The area covers $374 \mathrm{~km}^{2}$ and is characterized by large variations in topography (from sea level to $1,140 \mathrm{~m}$ ), with water sources from ground, snow, and rain. Annual precipitation averages 1,680 $\mathrm{mm}$ and reaches a peak in October and decreases to a low in May and June (NOAA 2016). This study was conducted at five watersheds during the summer field season of 2015 and 2016, including Game, Seagull, Gartina, Spasski, and Suntaheen creeks. These streams range in drainage area from 36 to $135 \mathrm{~km}^{2}$, flow directly to the ocean; primarily north into Port Fredrick and Icy Strait, and are unregulated. Stream types range from low-gradient floodplain to steep confined channels, and average stream size is $<20 \mathrm{~km}$ in this transition from low gradient wetland forest to rugged mountainous terrain. The majority of spawning habitat occurs in low gradient channel reaches at lower elevations.

Forests in the study area are actively managed on both private and public lands. Land ownership is dominated by lands managed by the Unites States Forest Service (USFS, $250 \mathrm{~km}^{2}$ ) as part of the Tongass National Forest (TNF), and private land holdings 
$\left(124 \mathrm{~km}^{2}\right)$. Forested areas reach an elevation of $500 \mathrm{~m}$, and are dominated by western red cedar (Thuja plicata), sitka spruce (Picea sitchensis), and western hemlock (Tsuga heterophylla), with riparian areas frequently comprised of red alder (Alnus rubra). The study area is located within the range of numerous salmonids, including chum salmon $(O$. keta), coho salmon (O. kisutch), sockeye (O. nerka), pink salmon (O. gorbuscha), steelhead trout (O. mykiss), cutthroat trout (O. clarki), and Dolly Varden (Salvelinus malma) (Alaska Department of Fish and Game (ADFG) 2016 anadromous waters catalog (AWC) (ADFG 2008)). 

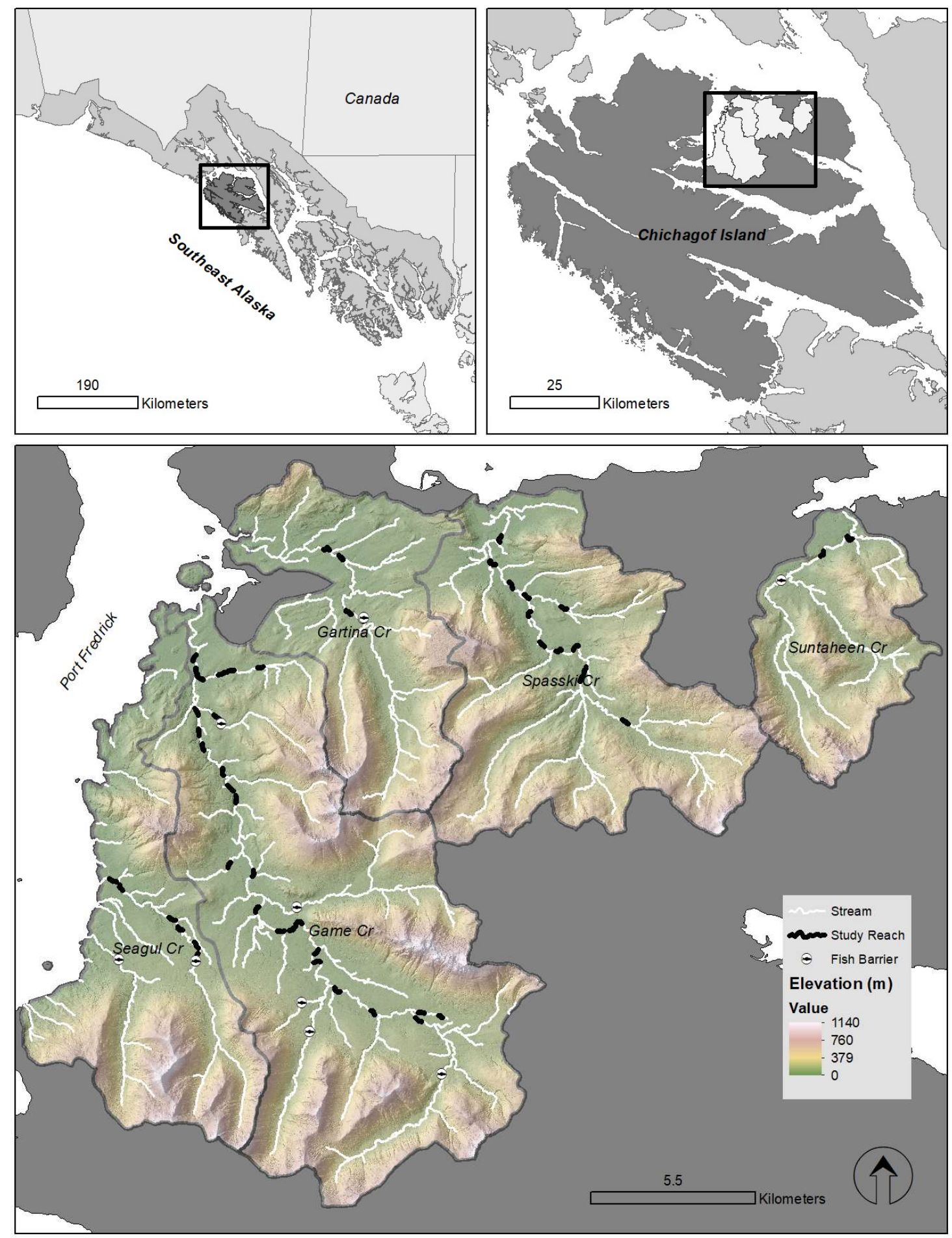

Figure 1. Map showing the locations of five study drainages (Seagull, Game, Gartina, Spasski and Suntaheen creeks) on the northeast side of Chichagof Island, and study reaches (white lines are stream channels, black lines are sampled reaches, and circles indicate natural upstream migration barriers). 


\section{Chum and Pink Salmon Freshwater Life Histories}

Chum salmon - Chum salmon (O. keta) have the widest distribution of the five anadromous Pacific salmon species found in Alaska. They range as far south as the Sacramento River in California, and in the north to the Mackenzie River in Canada. They are also found east to the Sea of Japan and northeast to rivers in Siberia. In Alaska, chum salmon spend primarily 4 to 5 years at sea before reaching maturity (Bakkala 1970; Pauley et al. 1988). Upon returning to their natal streams to spawn, Alaskan adult chum salmon will reach a length of about 60 to $75 \mathrm{~cm}$, second only to chinook salmon $(O$. tshawytcha), and have been reported to reach lengths up to $108 \mathrm{~cm}$ (Groot and Margolis 1991). In Southeast Alaska chum salmon migrate upstream to spawn primarily in July and August (ADFG unpublished data). The female will spend about 11 to 18 days selecting a mate, constructing a redd with an average area of $2.3 \mathrm{~m}^{2}$, and guarding the redd until death after spawning is complete (Pauley et al. 1988; Groot and Margolis 1991). Juvenile chum salmon migrate to the estuary during their first spring (usually before June) instead of spending their first year in freshwater, unlike coho salmon $(O$. kisutch), sockeye salmon (O. nerka), and Chinook salmon (O. tshawytscha). Chum salmon are the second most abundantly harvested salmon species in Southeast Alaska and are primarily caught by purse seines and drift gillnets. The study area is located within the ADFG designated Alaska inside adult salmon escapement monitoring subregion, and for 2015 and 2016 the adult chum escapement for this subregion was estimated at 166,000 and 66,000 fish, respectively, with a 60\% decline between 2015 and 2016, (Unpublished data from ADFG 2016 PSTF). 
Pink salmon - Pink salmon (O. gorbuscha) are the most abundant of the Pacific salmon in Alaska and range from the Russian River in California, north through the Bering Strait, past the northern tip of Alaska, and east to the Mackenzie River in Canada (Groot and Margolis 1991). Pink salmon populations are distributed along the coast of Alaska and the majority of spawning is typically observed in short coastal streams, including a portion of the intertidal area (Dickerson et al. 2002). In Southeast Alaska, adult pink salmon enter freshwater streams primarily in late July to middle September (ADFG unpublished data). Unlike the other four Pacific salmon, pink salmon mature in 2 years with a distinct and genetically isolated even-and odd-year run (Heard 1991). Once the female arrives at the spawning grounds, a mate is found and a redd constructed with a mean area of $1.5 \mathrm{~m}^{2}$ (Dickerson et al. 2002; Overstreet et al. 2016). After spawning is complete, the female guards the redd until death. Similar to juvenile chum salmon that depend heavily on the estuarine ecosystem for growth, juvenile pink salmon migrate directly to the estuary in spring, spending very little time in freshwater. Pink salmon are the most abundant commercially caught salmon in Southeast Alaska, and the estimated adult escapement for the 2015 and 2016 northern Southeast Alaska adult salmon escapement subregion monitoring index area was 5.3 and 1.8 million fish, respectively, with a 66\% decline between 2015 and 2016 (Unpublished data from ADFG 2016 PSTF).

\section{Site Selection}

This study looked at stream channels on the northeast end of Chichagof Island in Southeast Alaska (Figure 1). Five catchment drainages were chosen on the east side of 
Port Fredrick with both chum and pink salmon present. Possible sample sites within each drainage were then identified using a geographic information system (GIS) to isolate stream reaches below known barriers to anadromous migration, and within identified distributions of both chum and pink salmon, as indicated by the ADFG 2015 anadromous waters catalog (AWC) for waters important for spawning, rearing or migration of anadromous fishes. The GIS stream layer for the study area was created and partitioned into 100-m long reaches using the NetMap tool in ArcGIS (Miller 2003; Benda et al. 2007). A generalized random-tessellation stratified sampling design (GRTS) using the $\mathrm{R}$ programming language (Stevens and Olsen 2004; R Core Team 2017) was used to randomly select sample reaches from the target population that were spatially distributed across the study area. One of the advantages of GRTS sampling is that it provides a simple approach to adding or deleting sampling units from the sample pool while still maintaining spatial balance. This is accomplished by randomly placing a grid over the known species distribution (i.e., sample space), assigning a randomized hierarchical address to each of the cells, and then systematically sampling from these addresses. The result is a spatially balanced sample that is evenly dispersed across the stream network (Stevens and Olsen 2004). With a representative spatially random sample, it is then possible to minimize spatial autocorrelation and accurately infer conditions in the rest of the study area.

The total number of reaches surveyed was based on the availability of field crews and the duration of freshwater residence (stream life) for adult female spawners. The average stream life for chum salmon is estimated to be 11 to 18 days (Pauley et al. 1988), and approximately 12 for pink salmon (Fukushima and Smoker 1997; Bue et al. 1998; 
Dickerson et al. 2002). Because field crew can generally survey approximately 3 to $5 \mathrm{~km}$ of stream hiking on foot per day, I determined that three crews comprised of two field technicians were able to survey 51 reaches within a 12-day rotation interval. The rotation interval included enough time for delays such as high water, or limited visibility due to turbidity and tannins in the water that blocked view of redds, thus requiring a site revisit once the conditions improved. I initially selected 51 study sites from a sample frame of 75 random sites in GRTS. However, two sites were subsequently excluded from further sampling after I found a temporary log barrier to chum and pink salmon below the survey reach, leaving a total of 49 study reaches for analysis.

Each survey reach was 250-m long and were initially located with the use of GPS and digital maps that showed the GRTS location on a handheld mobile device. At each GRTS location, a 250-meter reach of stream was measured to the nearest meter so that the GRTS site was included within the study reach. All survey reach lengths were 250-m long, regardless of channel width, and the study reaches surveyed during the 2015 field season were the same during the 2016 field season, therefore the synthetic channel characteristics are the same for the two years. Furthermore, all study reaches were at least $50 \mathrm{~m}$ away from any bridge or culvert crossing, or major tributary.

\section{Field Data Collection}

Redd Survey - Crews of two walked three to four study reaches per day during six biweekly rotations in 2015 and two rotations in 2016 looking for redds, live fish, and carcasses. Biweekly surveys occurred from early July 2015 to early September 2015, and 
from middle August 2016 to early September 2016. This included times when high flows created unsafe and/or turbid conditions that limited streambed visibility. Biweekly survey rotations were frequent enough to detect the peak redd count of the spawning run, and I used the 2015 run timing to inform when to conduct peak run surveys for 2016. All observations were conducted along a 250-m stream reach that included both mainstem and side channels; with latter including only side channels that started and ended within $50 \mathrm{~m}$ of the main channel. Survey reaches were sub-divided and marked with a Tyvek tree tag every $50 \mathrm{~m}$ to allow reach identification on subsequent rotation visits, and allow surveyors to record approximate channel location of all observations.

Redd surveys were performed by trained surveyors that were proficient at distinguishing the difference between chum and pink salmon redds, and adult salmon identification as spawner timing overlaps between species. The criterion used for species distinction of redds for both chum and pink salmon were based primarily on whether live fish were actively using (digging or courtship) or guarding the redd, an ocular estimate of mean redd size (Riebe et al. 2014), and an ocular estimate of threshold substrate particle size (ADFG 1985; Riebe et al. 2014) observed in the redd tailspill. Female chum and pink salmon length data from streams in the study area (Dickerson et al. 2002 \& unpublished data from Eric Knudsen 2016 for Game Creek) were used to overcome the limitation of not knowing the species specific redd metrics. The ocular estimated redd size used in the field to identify redds for each species was based on the calculation:

$$
A_{\text {REDD }}=3.3\left[\frac{L}{600}\right]^{2.3}
$$


where area of redd $\left(A_{R E D D}\right)$ is measured in $\mathrm{m}^{2}$, and $L$ is length of female fish in $\mathrm{mm}$.

The ocular estimated species-specific tailspill threshold particle size diameter used in the field to identify redds for each species was based on the calculation:

$$
D_{T}=115\left[\frac{L}{600}\right]^{0.62}
$$

where $D_{T}$ is the threshold between movable and immovable grains in the tailspill as a function of fish length $(L)$.

Criterion for field ocular estimate of redd size and threshold tailspill particle size identification of chum and pink salmon for the project area were estimated to be $2.3 \mathrm{~m}^{2}$ and $1.5 \mathrm{~m}^{2}$, and $104 \mathrm{~mm}$ and $92 \mathrm{~mm}$, respectively. Since there was only chum and pink salmon spawning in the study area during the surveys, it was convenient for surveyors identifying redds without fish present to focus on a relative threshold between both species for a redd size of $1.5 \mathrm{~m}^{2}$, and $92 \mathrm{~mm}$ for particle size in the tailspill. Live fish behavior used for redd classification for each species was predominantly digging, courtship, and guarding the redd from other fish.

To ensure consistency in data collection and identification of redds and fish, surveyors were provided with one day of laboratory training and one day of field training at the beginning of the 2015 season. The same surveyors were used for the 2016 season, thus only $4 \mathrm{~h}$ of field training were required for a refresher. In addition, an effort was made so that experienced and inexperienced surveyors were paired. Redd identification for both species when fish are absent the redd is subjective, and the number of redds 
observed is dependent on surveyor accuracy and among surveyor variability (Gallagher and Gallagher 2005). Source of surveyor error associated with redd counts can be due to test redds, multiple redds from a single female, redd superimposition, inability of the surveyor to distinguish the difference between redd size for different species, and inexperience or poor training (Dunham et al. 2001; Gallagher and Gallagher 2005; Wright 2011). Due to limited resources during both years of the study, redd count variation between sets of surveyors was not investigated with double-blind surveys.

Live fish and carcasses were also counted during each survey so they could be used as an additional reference to the peak of the run. Live fish were identified to species and counted, otherwise they were estimated by group when large schools in deep pools indicated prudence. Carcasses were initially identified to species, but after the third biweekly survey it quickly became apparent that counting all carcasses to species was imposing a time constraint on completing the rotation in the 12-day period. Instead, total carcasses per reach were recorded.

Study reach wet area was measured for all channels accessible to adult salmon. The start of a 250-m study reach was identified as a transition between channel habitat unit types, and the reach length was then measured upstream using a hip-chain metric distance measurement box. Each 250-m reach was further subdivided into 50-m subreaches and a wetted channel width was taken within the 50,150, and 250-meter subreaches for an overall reach mean channel wetted width. Channel wetted widths were measured only in riffle habitat so as not to skew the channel width toward the wider pool habitat wetted widths. Side channel length and width was measured for each section of channel associated with the main channel and was also marked with a Teflon tree tag. A 
GPS waypoint, and a photograph was taken at the start and end of each 250-meter study reach, and a trail map showing access to the reach was created from GPS tracking points for subsequent rotation return visits.

Starting at the downstream end of a reach, a two-person crew would proceed upstream counting number of redds by species, number of live fish by species, and total number of dead fish. Surveys were usually performed from the bank of the river so not to disturb spawning fish and to facilitate the identification of species associated with each redd. For sections of stream channel where observations of fish presence and activity were not possible from the river bank, the observer would enter the active channel and proceed upstream in a fashion to optimize channel viewable area and minimize fish disturbance. Redd counts were only completed for a study reach when water visibility allowed a clear view to the stream bottom in riffle habitat.

When superimposition of redds occurred in a spawning habitat area, and efficiently counting the number of redds was not practical, the area of redd disturbance was visually estimated using a graduated rod or measuring tape. The number of redds per area was then calculated based on total area of redd superimposition divided by average redd size (Riebe et al. 2014). The calculated number of redds per area was then multiplied by a factor of 0.36 (Gallagher and Gallagher 2005; Wright 2011) to calibrate for observer bias when counting redds. This is a conservative calibration since research suggests that surveyor bias of redd counts is often negated by false positives and missed observations (Dunham et al. 2001; Muhlfeld et al. 2006; Wright 2011), and that it is unlikely that 100 percent of the estimated spawning area was seeded. Difficulties 
counting redds due to superimposition of redds only occurred for pink salmon during the 2015 survey at 4 of the 49 study reaches.

Channel Morphology Survey - Measures of stream channel morphology were taken at 30 redd study reaches and an additional 19 reaches near road crossings. The objective of conducting channel morphology surveys was to collect field data to compare with synthetic habitat data derived from a light detection and ranging (LiDAR) digital elevation model (DEM). Using a survey level, a field crew of three surveyed channel reaches for wetted channel width, bank-full width, bank-full depth, channel slope, and longitudinal channel length at 20-x the channel width (Harrelson et al. 1994). Low channel gradient sites were selected from the redd survey reaches, while higher gradient reaches were opportunistically selected near road crossings within the study area. Redd survey reaches were selected starting at the first downstream reach and progressing upstream so that there was no overlap in reach selection (reach length 20-x channel width) with the next available reach upstream. Channel morphology measurements were primarily taken in straight riffle channel reaches that were free of obstructions to water flow to facilitate identification of left and right bank-full depth. Channel bankfull was identified visually as the point on both left and right banks where the flow of water starts to leave the main channel and enters the adjacent floodplain. For confined channels, bank-full was identified by undercuts, stain lines, vegetation changes, substrate changes, and height of depositional features (Harrelson et al. 1994). 
The channel cross section profile length measured in the field was limited to 100$\mathrm{m}$ long based on the length of the fiberglass tape used to measure the distance from left to right valley slope break. Therefore, only valley widths $<100$-m wide were measured in the field. Valley width not measured in the field was measured optically from the DEM using the measure tool in ArcGIS 10.4.1. At each field cross section location, a distance perpendicular to the channel was measured out to the left and right valley wall slope break with the valley floor.

Substrate - At each channel morphology site, grain-size distributions was measured for a representative frequency of stream bed particle size (Wolman 1954; Bunte and Abt 2001). A total of 100 substrate measurements using a gravelometer were taken systematically and evenly along five active channel-spanning transects, 20 measurements per transect, centered at the channel morphology cross section.

\section{Synthetic Landscape Attributes}

In Southeast Alaska, the current capacity to evaluate salmon population distributions and instream habitat quality across riverscapes and landscapes is challenging due to limited and inconsistent field data that is generally only available for a small fraction of a species range. As part of a project supported by the Natural Resource Conservation Service (NRCS), high resolution 1-m LiDAR imagery was taken in the fall of 2015 for a large area of northeast Chichagof Island, including the study area. From these images a DEM was created and a consistent synthetic stream channel network was 
derived for each study drainage basin (Davies et al. 2007). In addition, synthetic reachlevel stream channel geomorphology and hydrology characteristics derived from the digital elevation and precipitation data was used to populate any reach of interest using models in GIS based NetMap tools (Miller 2003; Benda et al. 2007) (Table 2). Hence, stream reach is the unit of analysis for this study, and twenty-six persistent reach habitat characteristics associated with the 49 study reaches (Table A-1) were matched with the high resolution DEM stream network in ArcGIS and parameter averages for each reach were calculated for all continuous synthetic habitat variables in R (R Core Team 2017). Hereafter, synthetic habitat refers to reach-level habitat variables derived from the 1-m resolution LiDAR DEM, and field habitat refers to reach-level habitat measured during the 2015 and 2016 field season.

Mean Annual Stream Flow - Mean annual flow for each stream reach was derived from a regional flow model that is based on mean annual precipitation and basin area (Parks and Madison 1985) and calibrated for Southeast Alaska. Historical mean annual precipitation data were derived from a $2 \times 2 \mathrm{~km}$ resolution grid based on Parameterelevation Regressions on Independent Slopes Model (PRISM) data obtained from the Scenarios Network for Alaska and Arctic Planning (SNAP). Mean annual flow coefficients were based on 66 field gauged stream flow stations, and flow for each synthetic stream reach was calculated as:

$$
Q=-0.46 \times A^{1.01} \times P^{0.68},
$$


where $Q$ is mean annual flow $\left(\mathrm{m}^{3} / \mathrm{s}\right), A$ is drainage area $\left(\mathrm{km}^{2}\right)$, and $P$ is mean annual precipitation ( $\mathrm{mm})$.

Channel Type - Channel reaches are sections of stream utilized by anadromous salmonids as they migrate upstream to spawn. Four categorical descriptors for geomorphic variables were used to classify types of synthetic channel reaches and evaluated for habitat selection by both species, including constraint, geology, tributary, and channel size. Valley constraint is a measure of control the valley has over a channels capacity to move laterally within the floodplain. The valley constraint for each reach were classified as either Constrained Canyon (CC) or Unconstrained Valley (UV) types (Table 1, Table A-4), adapted from Frissell (1992). Channel constraint is imposed primarily by hillslopes or adjacent floodplain terraces, inactive floodplain terraces due to river denudation, abandoned terrace from lateral channel migration, and remnant terrace from underfit streams as a result of glacial retreat. Valley width index (VWI) is a measure of channel constraint and compares how much valley floor distance a stream channel is capable of moving laterally proportional to channel width (Grant and Swanson 1995 ) measured out from the middle of the channel at $5 \mathrm{x}$ bank-full depth. Reaches in unconstrained valleys were dispersed throughout the study drainages and are defined by stream channels that are typically lower gradient with a valley floor or floodplain that are $>2.9$ times the active channel width (i.e., VWI $>2.9$ ) (Grant and Swanson 1995). Constrained canyons encompass stream channels that are confined by valley hillslopes and usually have a higher gradient with a valley floor width that is $<2.9$ times the active 
channel width (i.e., VWI $<2.9)$. Drainage area was not significantly different $(\mathrm{p}>0.05)$

between valley reach types (CC \& UV).

Table 1. Synthetic habitat characteristics of mainstem, tributary, channel size, constraint, and geology reach segment types in Game Creek, Gartina Creek, Seagull Creek, Spasski Creek, and Suntaheen Creek, Alaska. Channel reach types are unconstrained valleys (UV) and constrained canyons (CC) (adapted from Frissell et al. 1992), tributary and mainstem, small and large, and alluvium deposit and dolerite formation geology. Derived from 1-m pixel LiDAR digital elevation models (DEM).

\begin{tabular}{lcrrrc}
\hline & & & Mean (SD) & Drainage & Number of \\
Type & Code & Length $(\mathrm{m})$ & \% gradient & area $\left(\mathrm{km}^{2}\right)$ & $\begin{array}{c}\text { reaches } \\
\text { Constrained Canyon }\end{array}$ \\
CC & 8,000 & $1.1(0.009)$ & 1,384 & 32 \\
Unconstrained Valley & UV & 4,250 & $0.7(0.006)$ & 932 & 17 \\
Mainstem & $\mathrm{m}$ & 9,500 & $0.7(0.006)$ & 2,251 & 38 \\
Tributary & $\mathrm{t}$ & 2,750 & $1.9(0.010)$ & 65 & 11 \\
Large channel & $\mathrm{I}$ & 7,000 & $0.5(0.002$ & 2,037 & 28 \\
Small channel & $\mathrm{S}$ & 5,250 & $1.7(0.009$ & 278 & 21 \\
*Alluvial deposit & Qs & 6,500 & $0.8(0.006)$ & 1,120 & 26 \\
*Dolerite formation & Dv & 4,750 & $1.0(0.010)$ & 1,066 & 19 \\
\hline
\end{tabular}

* Not derived from DEM

Classification of channel reaches for the two main geology types found in the project area included surficial sedimentary (glacial/fluvial) deposits (Qs) and Devonian volcanic andesite or ryolite (Dv) (Gehrels and Berg 1992). Two reaches on Suntaheen Creek fell within a Silurian turbidite deposit (Ss) classification and were excluded from the geology analysis due to the sample size $>5$ requirement for each classification type (Manly et al. 2002). Drainage area was not significantly different $(p>0.05)$ between valley geology types.

Channel reaches were also classified into size type as either mainstem or tributaries with the mainstem channel of all five drainages ranging from 5 th to 6 th order (Strahler 1957). Habitat size types for small and large channels were defined as the 
difference between a threshold habitat size capable of transporting a mean annul flow of $2.5 \mathrm{cms}$. Of the forty-nine channel reaches surveyed (Table 1); six are in Seagull Creek, 26 are in Game Creek, 3 are in Gartina Creek, 12 are in Spasski Creek, and 2 are in Suntaheen Creek.

\section{Statistical Analysis}

All statistical analyses presented in this study were achieved with R statistical software version 3.4.2 (R Core Team 2017) with significance determined at $\alpha=0.05$. The main library of analysis and modeling packages includes "randomForest" (Liaw and Wiener 2002) for the random forest models, "boot" (Canty 2002) for the bootstrapped resource selection ratio models, "MASS" and "vegan" for PCA models, and "spsurvey" for the linear network generalized random tessellation stratified (GRTS) spatially random sampling design. Visualizations and sampling location analysis were made with ArcGIS 10.4.1 (ESRI 2017, Redmond, California), Terrain Works NetMap GIS tools 3.1.0 (2016), and the "maptools", "sp", and "GISTools" packages in R.

Data Reduction - A Pearson's correlation analysis (Table A-1) was performed on all 26 synthetic persistent habitat characteristics (Table 2) to limit the redundancy of persistent variables used to describe the conditions of each reach sampled. The distribution of each synthetic persistent variable was first checked for normality and linearity using frequency distributions, boxplots, q-q plots, and Shapiro-Wilks normality tests. All continuous reach variables were transformed to maximize multivariate 
normality using natural log transformation. If a pair of variables were highly collinear, or a linear combination (i.e., $r=$ absolute value $>0.8$ ), the variable with the most ecological relevance would be retained for interpretation. This process led to the selection of thirteen synthetic persistent habitat variables including five related to flow, two measures of gradient, four related to valley constraint, and one elevation (Table 2, Table A-3). 
Table 2. List of 26 synthetic persistent reach-level habitat predictors calculated in NetMap from light detection and ranging (LiDAR) digital elevation models (DEM) derived channel network.

\begin{tabular}{|c|c|c|}
\hline Variable & Model Name & Description \\
\hline Basin area & AREA_SQKM & Drainage area above the reach $\left(\mathrm{km}^{2}\right)$ \\
\hline * Out distance & OUT_DIST & Distance from reach to the estuary $(\mathrm{m})$ \\
\hline Source distance & SRC_DIST & $\begin{array}{l}\text { Distance from reach continuing upstream to the origin of the channel } \\
\text { (m) }\end{array}$ \\
\hline Channel width & WIDTH_M & Bankfull width for reach $(\mathrm{m})$ \\
\hline Channel depth & DEPTH_M & Bankfull depth for reach $(\mathrm{m})$ \\
\hline * Mean annual precipitation & MNANPRC_M & $\begin{array}{l}\text { Mean annual precipitation contributing to flow above the reach }(\mathrm{m}) \text {, } \\
\text { PRISM grid }\end{array}$ \\
\hline * Mean annual flow & MEANANNCMS & $\begin{array}{l}\text { Mean annual flow (cms), based on regional flow equation using } \\
\text { drainage area and PRISM precipitation data (Clarke et al. 2008) }\end{array}$ \\
\hline * Bank full flow & BFQ & Amount of water flowing through a reach at bankfull height (cms) \\
\hline * P at tributary junction & p_trib & $\begin{array}{l}\text { Tributary confluence effects: the probability a tributary will have a } \\
\text { geomorphic effect in the channel it enters, and near channels. Based } \\
\text { on contributing and receiving basin area }\end{array}$ \\
\hline * Channel gradient & GRADIENT & Reach gradient, rise over run $(\mathrm{m} / \mathrm{m})$ \\
\hline * Gradient downstream & GRAD_D & Maximum gradient change downstream of the reach $(\mathrm{m} / \mathrm{m})$ \\
\hline Flow velocity & FlowVel & $\begin{array}{l}\text { Speed of water flowing through reach }\left(\mathrm{m}^{2} / \mathrm{s}\right) \text {, based on Manning } \\
\text { equation using bankfull width, depth, and gradient }\end{array}$ \\
\hline Stream power & StrmPow & $\begin{array}{l}\text { Amount of water energy exerted on the channel (a function of } \\
\text { gradient multiplied by drainage area) }\end{array}$ \\
\hline Median substrate size & d50 & $\begin{array}{l}\text { Median channel cross section substrate size }(\mathrm{cm}) \text {, as a function of } \\
\text { shear stress (gradient based) }\end{array}$ \\
\hline Channel substrate shear stress & Shear & Calculated based on bankfull depth-gradient product \\
\hline * Floodplain width & FP_WIDTH & $\begin{array}{l}\text { Distance from center of channel out to edge of floodplain ( } 2 x \text { bankfull } \\
\text { depth, } m \text { ) }\end{array}$ \\
\hline Valley width & VAL_WIDTH & $\begin{array}{l}\text { Distance from center of channel out to edge of valley ( } 5 x \text { bankfull } \\
\text { depth, } m \text { ) }\end{array}$ \\
\hline * Valley Width Index (VWI) & VWI_Floor & Valley width divided by channel width \\
\hline * Generic erosion potential & GEP & $\begin{array}{l}\text { Based on topographic wetness index for drainage wings adjacent to } \\
\text { channel; potential for hillslopes in a reach to route sediment to } \\
\text { channel (hillslope gradient and slope convergence) }\end{array}$ \\
\hline \multicolumn{2}{|c|}{ * Cumulative generic erosion potentialGEP_Cum } & Cumulative GEP upstream of reach \\
\hline Generic erosion potential delivery & GEP_DEL & $\begin{array}{l}\text { Potential delivery of sediment from mass wasting to channel. Based } \\
\text { on hillslope channel delivery gradient threshold via GEP }\end{array}$ \\
\hline Valley constraint $(\mathrm{m} / \mathrm{m})$ & ValCnstrnt & Floodplain width divided by channel width $(\mathrm{m} / \mathrm{m})$ \\
\hline * Channel sinuosity & SINUOSITY & $\begin{array}{l}\text { Actual channel distance divided by shortest path distance; a function } \\
\text { of gradient, flow, and constraint }\end{array}$ \\
\hline * Elevation (m) & ELEV_M & Reach elevation above mean sea level $(\mathrm{m})$ \\
\hline Fit elevation $(\mathrm{m})$ & FitElev & Smoothed elevation based on polynomial function using gradient (m) \\
\hline Azimuth in degrees & AZIMTH_DEG & Azimuth direction of the reach looking downstream in degrees \\
\hline
\end{tabular}

* Reduced number of variables used in PCA and random forest analysis

Principal Component Analysis - The main purpose for using principal component analysis (PCA) was to consolidate information for the large number of synthetic persistent habitat variables into a few independent linear combinations (principal 
components), with the least amount of information loss, and that explain the majority of the habitat variance. This reduction in large multivariate datasets facilitates interpretation of complex ecological data by emphasizing broad habitat relationships among study reaches. PCA was performed on the correlation matrix of 13 synthetic persistent reach-level habitat variables comprised of 49 study reaches. All 13 habitat variables were natural log transformed to maximize multivariate normality, even though they did not strictly meet the multivariate normality assumption required for inferential testing of hypothesis with principal components. Because PCA was being used for descriptive purposes to explore covariance patterns, a 3:1 ratio of study reaches to synthetic variables was deemed adequate (Johnson 1981). Since the correlation matrix was used, the eigenvectors are directly proportional to the loadings so the principal components are therefore weighted linear combinations of the original persistent habitat variables that represent maximum variation in the habitat data. The principal components with observed eigenvalues $>$ eigenvalues expected under the Broken Stick distribution were retained for interpretation (Frontier 1976). Furthermore, variables were considered ecologically significant and used to interpret the axes if their loading on the component axes had an absolute value $>0.35$ (Hair et al. 1987).

Understanding Fish-habitat Association - To relate pattern in redd presence with groups of persistent habitat variables with the largest amount of variance, the presence of redds were compared with principal components by matching redd presence with PCA eigenvalues. Associated patterns of redd presence at each study reach could then be 
compared with independent groups of synthetic habitat variables associated with each principal component axis in an ordination plot. In this comparison the overall persistent habitat characteristic change between study sites, expressed as eigenvalues, is the response variable and redd presence is the predictor of important habitat for the target species. Therefore, patterns expressed in the ordination plot of redd presence for chum and pink salmon indicate the inter-site relationship change in habitat due to variance contribution by groups of important persistent habitat variables at each study reach that load on the principal component axis.

Resource Selection Ratio - Spawning chum and pink salmon may be selecting for reach habitat due to availability instead of selecting based on reach habitat quality (Burnett 2001; Manly et al. 2002). Statistical methods to quantify habitat selection of a resource defined by several categories (type) were developed by Manley et al. (2002) where the ratio is proportional to the probability of use for each habitat type, assuming fish making the selection have access to all available habitat types. Burnett (2001) demonstrated resource selection ratio using bootstrapping and associated standard errors methods for salmonid habitat selection in the Elk River, Oregon. I followed this approach to address normality distribution assumptions associated with synthetic reach types.

Synthetic reach type selection by both chum and pink salmon was evaluated using a selection ratio function (Manly et al. 2002) calculated with a bootstrapping method (Manly 2006). For each of the two years and for each species, selection ratios were 
calculated for each of the two types of stream systems (i.e., mainstem and tributaries); for both reach segment types (i.e., unconstrained valleys, and constrained canyons); for the two geology types that dominated the project area (Dv - dolerite formation, Qs - alluvial deposit); and for small and large channels. For channel constraint, I chose not to use an intermediate constraint class based on findings by Burnett (2001) that there is no significant difference in habitat selection ratios between alluviated canyons and constrained canyons for salmon due to their geomorphic similarity, and because of the small sample size a third category would generate. For each species, type, and year, 5,000 bootstrap samples were drawn with replacement from the original data to achieve comparable distributions for estimate consistency. The sample size used for the bootstrap sampling was the total number of study reaches surveyed for each type and year. Because spawning salmon are territorial, habitat selection for spawning within a reach may be influenced by the size of the adult escapement and not independent of the selection made by other spawning salmon. Therefore, a survey reach was considered an observation instead of a single redd. The total number of redds observed and the total area observed for each reach were determined for each of the 5,000 samples for each species, type, and year. For both chum and pink salmon, and for both years, selection ratios by type were calculated (Manly et al. 2002):

$$
w_{i}=\frac{o_{i}}{\pi_{i}}
$$

where $i$ was the type,

$\mathrm{o}_{i}$ was the number of redds observed in type $i$ divided by the total number of redds observed in all types, 
and $\pi_{\mathrm{i}}$ was the reach area surveyed of type $i$ divided by the total area surveyed of all types.

For comparison, the pairwise difference between selection ratios $\left(\mathrm{w}_{\mathrm{i}}-\mathrm{w}_{\mathrm{j}}\right)$ was also calculated.

Means and confidence intervals were derived from the bootstrap selection ratios for each species, type, and year. Confidence intervals for each bootstrapped sample distribution were determined with the $100(\alpha / 2)$ and $100(1-\alpha / 2)$ percentiles. I used $\alpha=0.1$ and a Bonferroni adjustment of $\alpha / 2 \mathrm{I}$, where $\mathrm{I}=$ number of resource category types. Since all types were evaluated with two selection ratios, the lower and upper confidence limits were 2.5 and 97.5 percentiles. When using the percentile method to estimate a category type confidence interval for a bootstrapped distribution, the mean is used to estimate selection instead of the median and may be inaccurate; infrequent for this selection ratio analysis.

Selection ratios can range from zero to infinity with a value of one suggesting no selection preference for a particular channel type. The null hypothesis that salmonid species are randomly using reach habitat for redds in proportion to availability was rejected when the confidence interval did not contain the value of one (Manly et al. 2002). This means that a selection ratio significantly $<1$ indicates avoidance for a habitat type, and a selection ratio significantly $>1$ indicated selection for that habitat type.

Persistent Habitat Predictors of Redd Density - To identify the most important predictors of redd density, I used a classification tree for evaluating non-normal data 
distributions and unequal variance for synthetic habitat predictors (Strobl et al. 2009a, 2009b). Classification models use binary recursive partitioning to identify binary splits in the predictor variables to classify categorical presence or absence of redds. Classification tree models are therefore a form of threshold analysis that evaluate each predictor individually and attempts to maximize homogeneous clusters of observation that explain maximum differences in redd presence-absence. For both years of chum salmon redd surveys, and for the 2016 pink salmon redd survey, nearly half of the study reaches had zero redd observations. The redd density response variable was therefore converted to binary presence-absence for analysis.

The classification tree model used was a random forest model that utilizes bootstrapped samples to generate a collection (forest) of decision trees and the samples that are not selected are referred as the out-of-bag (OOB) and used for cross-validation (Breiman 2001). First, random forest fits many redd classification trees $(5,000$ bootstrapped trees) to the reach habitat dataset, and then combines the predictions from all the trees. Variables are deemed important predictors if their variables importance score is greater than the absolute value of the lowest predictor (Strobl et al. 2009b). Variable importance score is acquired by adding up the total amount that the Gini index (total model variance of classification error rate for node purity) has decreased by splits for a given predictor, and then averaged over all 5000 bootstrapped trees.

Random forest uses ensemble learning methods to reduce the inclusion error rate for classification tree binary redd presence-absence data. It does so by bootstrapping a number (B) of training samples (usually about $2 / 3$ of the data) using a randomly selected 
subset of predictors for each tree model to minimize correlation among tree models. The limited number of predictors used at each split is the square root of the number of predictors. The remaining $1 / 3$ of the data is used for OOB error estimates so the model is not over-fitted, as long as the size of B is large enough so that the error rate stabilizes. A cross validation OOB error plot was used to make sure the error rate stabilized for the sample size used. For interpretation of classification tree accuracy, comparisons were made of overall percentage correctly classified (PCC) with observed versus predicted error sensitivity (percent redd presence correctly classified), and specificity (percent redd absence correctly classified). The best model for habitat evaluation should have a high sensitivity and a low false positive rate (Guy and Brown 2007). The final interpretation of the classification model is a summary of all random trees generated as to the importance of each predictor using the Gini index for redd presence-absence. Random forest classification was applied for each year to test the null hypothesis that adult chum and pink salmon presence in a reach was unrelated to synthetic reach features. Partial dependence plots were also used to evaluate individual predictor importance for redd presence while holding all other predictors in the model constant (Hastie et al. 2009).

\section{Intrinsic Potential Model}

Model Building-Assumption for the intrinsic potential (IP) model are that three persistent habitat characteristics are adequate indicators of landform and hydrology, can be quantified with remote sensing, and are therefore a good representation of the potential for a reach of stream to produce the habitat heterogeneity utilized by a species of 
salmonid during a particular life stage. The persistence of these three landscape characteristics over a long temporal period is the basis for predicting the potential habitat under historical conditions and the potential for future conditions without anthropogenic influences. Intrinsic Potential models are built using habitat suitability index (HSI) curves (Raleigh and Nelson 1985; Hale et al. 1985; Crance 1987), and the index curves for these two models were developed based on empirical non-linear relationships from this study between stream reach attributes and redd density for both species (Figure 2). The purpose of using HSI curves is to develop threshold relationships between redd density and persistent habitat variables that represent the total habitat quality of a study reach for a species of interest compared with optimal persistent conditions for that species. Based on redd densities plotted against a given persistent characteristic, a range of values were identified that yields favorable reach spawning habitat in addition to the range of values for unfavorable reach habitat. With seasonal variability associated with intermediate values, a linear relationship is used to span the distance between favorable and unfavorable reach potential. Persistent reach attribute values were then translated into intrinsic potential index scores by standardizing the range of redd density values from 0 to 1 . Intrinsic potential index scores therefore indicate the relationship between mean annual flow, gradient, valley width index, and redd density for both species. Intrinsic potential was then calculated for each reach with the NetMap tool in ArcGIS (Benda et al. 2007) using the geometric mean of the three species-specific IP Index scores (Burnett et al. 2003, 2007; Sheer et al. 2009), then mapped across the study area:

(4) Intrinsic Potential $\left(I P_{R E D D}\right)=\left(I P_{M A F} \cdot I P_{G} \cdot I P_{V W I}\right)^{\frac{1}{3}}$ 
where $I P_{R E D D}$ is the intrinsic potential based on redd density for a species,

$I P_{M A F}$ is the IP index for mean annual flow,

$I P_{G}$ is the IP index for channel gradient,

and $I P_{V W I}$ is the IP index for valley width index.

The assumptions associated with using the geometric mean to estimate overall habitat intrinsic potential are that each of the synthetic persistent attributes are nearly equal in importance, only partially compensatory, and that the overall suitability index is weighted by the smallest habitat suitability score (Van Horne and Wiens 1991; Guy and Brown 2007). Since the IP is calculated from the three intrinsic potential index scores, it too will range from 0 to 1 with larger values $\geq 0.75$ indicating a high potential for a reach to provide high-quality spawning habitat (USFWS 1981). Stream reaches below naturally occurring barriers to adult fish passage were used to report intrinsic potential, and were identified based on the ADFG AWC and field observations. Stream reaches with a gradient $>8 \%$ over a $200-\mathrm{m}$ reach were also excluded from IP analysis as barriers to adult chum and pink salmon upstream migration (Hall et al. 2007). 


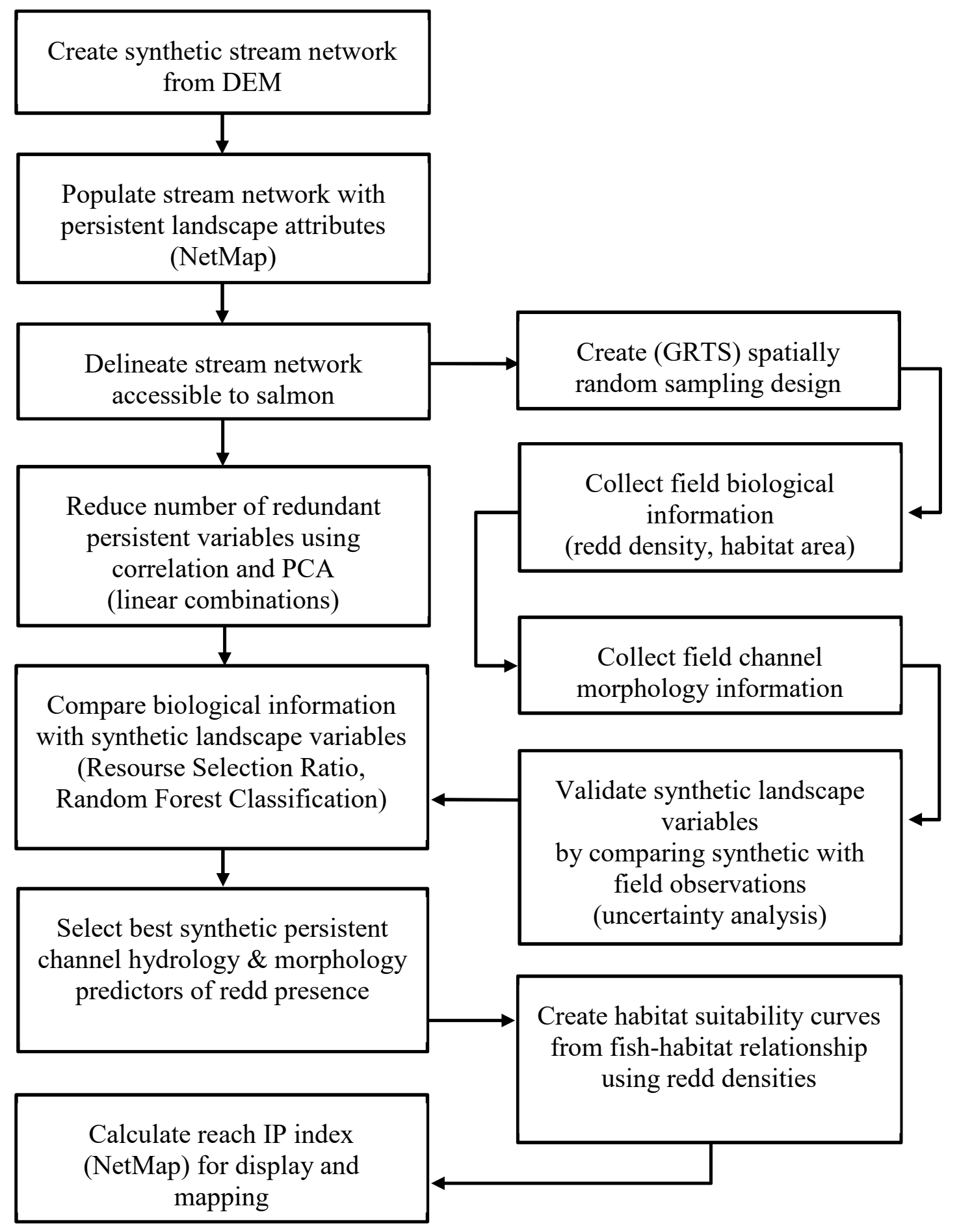

Figure 2. Diagram representing the flow of geospatial and field observed biological information into the analysis and selection of persistent landscape attributes used in the fish-habitat suitability index curves of the intrinsic potential analyses. 


\section{Results}

\section{Spatial and Temporal Variation of Redds}

Precipitation and associated stream flows for all study drainage basins between both years of field surveys was substantially different. The 2015 field season had above normal rainfall compared to historical median for the spawning period surveyed (NOAA 2016), with many days of heavy rain that hindered water visibility, and elevated flows that restricted survey crew access to some reaches during multiple rotations (Figure 3). In contrast, the 2016 field season had below normal rainfall compared to the historical median for the spawning period. The amount of total in-channel wet area surveyed during the 2015 spawning period was $175,514 \mathrm{~m}^{2}$, and $150,018 \mathrm{~m}^{2}$ during the 2016 period, a 15\% decline in measured wet channel area for all study reaches combined. 


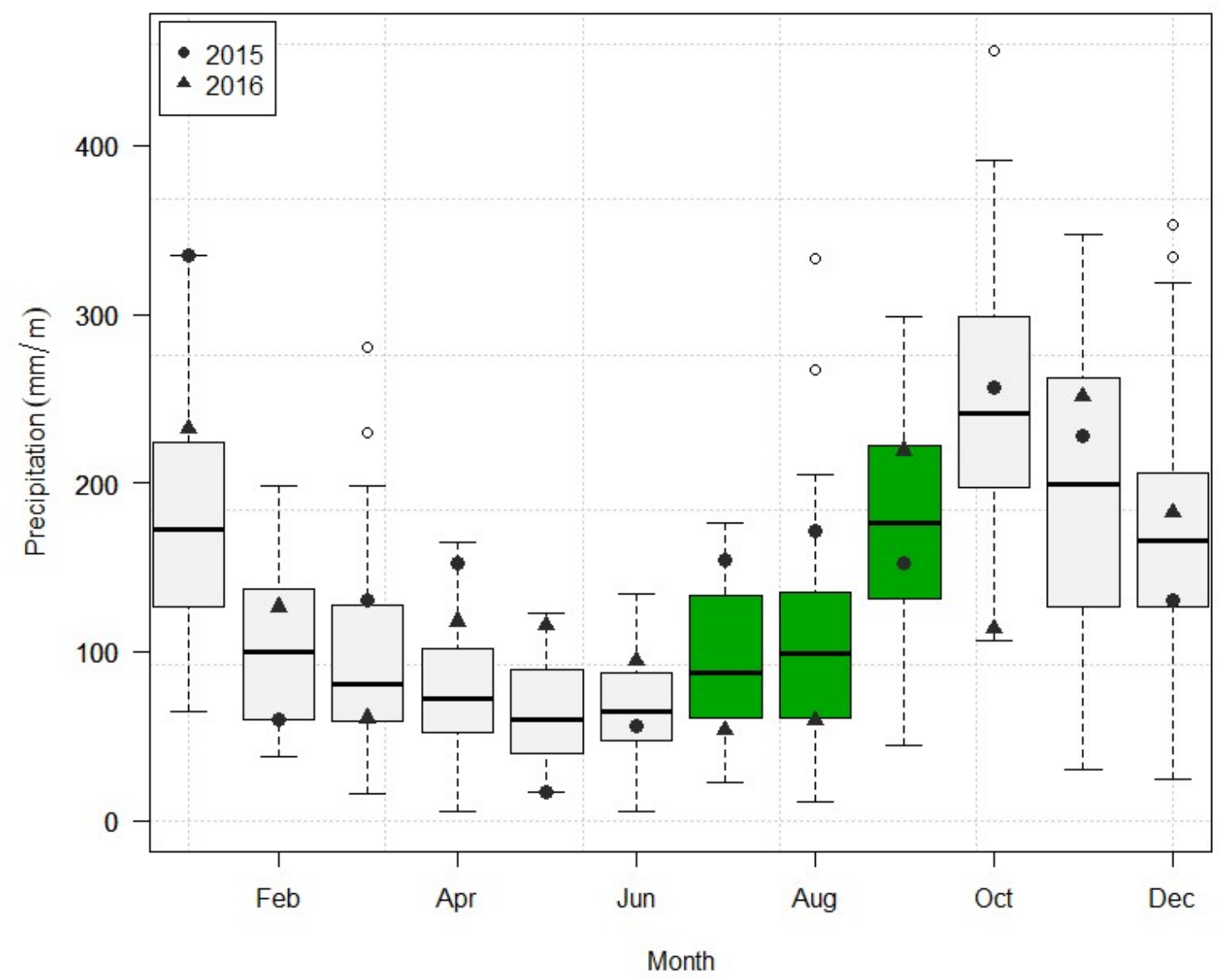

Figure 3. Historical mean monthly precipitation (boxplots) from 1941 to 2016, with spawning period for chum and pink salmon in green, and 2015 and 2016 mean monthly precipitation for gauging station located within the project area (58.107 latitude, -135.428 longitude) near Hoonah, Alaska. Boxes designate the 25 th and 75 th percentiles, the solid line indicates the median, whiskers denote the nearest data point within 1.5 times the interquartile range, and outliers are shown by disconnected points.

Redd Density - Peak redd count seasonal trends were similar for both species and for both years. During the 2015 spawning period, the peak of the chum salmon run occurred during the last two weeks of July (second rotation), while the peak of the pink salmon run was observed during the first two weeks of August (third rotation). During each rotation, $12.3 \mathrm{~km}$ of stream were surveyed for a total of 6 rotations during the 2015 spawning period and two rotations during the peak of the 2016 spawning period. As a 
reference to the peak of the 2016 chum and pink salmon runs, two reaches (Reach 73 in Game Creek, and 56 in Spasski Creek where high density of spawning occurred) were revisited a third time to verify that spawning activity and number of redds were declining. For the 2015 and 2016 spawning period there was a total peak redd count for chum salmon of 893 and 617 , respectively, a decrease in total redds of $31 \%$ for chum salmon. In comparison, the 2015 and 2016 pink salmon spawning period had a total peak redd count of 7,623 and 1,619, respectively, a decrease in total redds of 79\%.

Density of redds for each species varied primarily by field season and location within the drainage basin. The number of redds by species within the study reach wetted area was used to calculate relative redd density per $100 \mathrm{~m}^{2}$ (Table A-4). The comparative spatial distribution of redd density for the 2015 and 2016 spawning periods were similar for chum salmon, while pink salmon redd densities changed from a wide-spread distribution in 2015 to a high concentration toward the low-gradient floodplain channel near the estuary for each drainage in 2016 (Figure 4). The highest densities of chum salmon redds were observed in the large floodplain reaches of mainstem channels throughout all drainages for both rainy and lack of rainfall spawning periods of study. The highest densities of pink salmon redds during the rainy 2015 spawning period were located in small tributary channels, then shifted to lower-drainage floodplain channels during the low rainfall 2016 spawning period. 

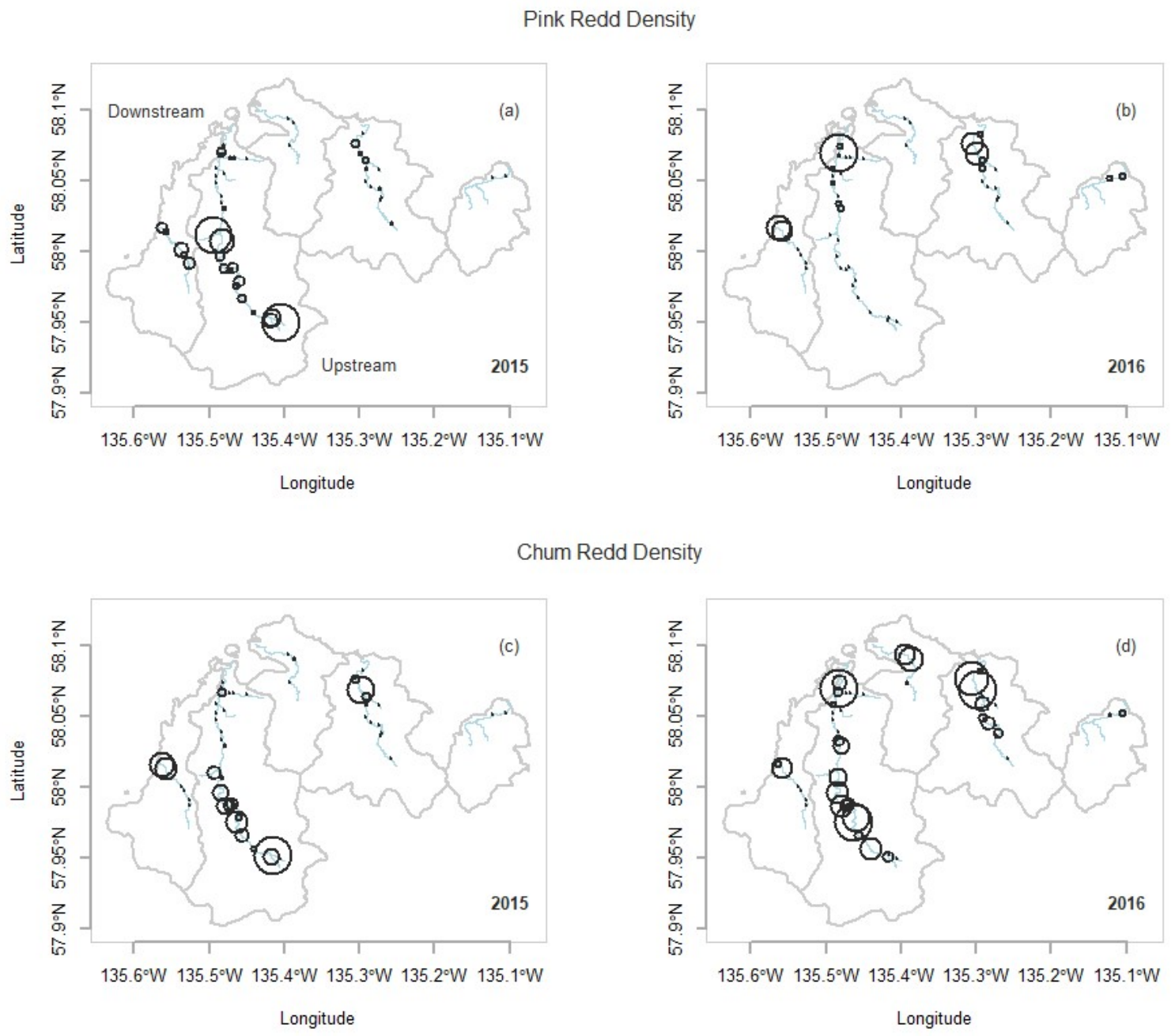

Figure 4. Distribution of relative redd density (redds $/ 100 \mathrm{~m}^{2}$ ) for each study reach during rainy 2015 and lack of rainfall 2016 redd survey field season. Density range for pink salmon (2015 and 2016 range: 0-29.2 and 0-6.7, respectively) and chum salmon (2015 and 2016 range: 0-3.5 and 01.1 , respectively) for both years indicated by size of circle. Grey line is watershed boundary and blue line is stream.

\section{Habitat Variation}

DEM Derived Channel Attributes - Synthetic channel habitat attributes varied considerably among the 49 redd survey study reaches. Bankfull width ranged from $5.9 \mathrm{~m}$ to $27.0 \mathrm{~m}$, gradient varied from $0.05 \%$ to $4.40 \%$ with an average of $1.00 \%$ and elevation from mean sea level ranged from $3.8 \mathrm{~m}$ up to 114.4 meters, with an average of 40.1 
meters (Table A-3). Channel constraint as modeled by valley width index (VWI) ranged from 1.4 to 19.5 , with low gradient floodplain channels having the largest VWI. In addition, drainage area above each study reach varied from $1.1 \mathrm{~km}^{2}$ to $131.1 \mathrm{~km}^{2}$, the largest of which were located in Game and Spasski creeks, whilst the smaller were also located in tributaries of the same drainages.

Principal Component Analysis - The principal component analysis reduced to three principal components through the broken-stick model and explained a total variance of $65.9 \%$ across sampled reaches. The first component explained $25.2 \%$ of the variation and was weighted positively by predictors related to gradient, and negatively by habitat size and flow predictors (Table 3, Figure A-1). The positive weighting for the first axis were reach gradient and maximum gradient downstream of reach, whereas mean annual flow and floodplain width weighted the negative. The second axis explained an additional $22.0 \%$ of the variation in channel habitat and was weighted negatively with debris delivery comprised of mean annual precipitation, cumulative generic erosion potential upstream of reach, and elevation. The third principal component contributed an additional $18.7 \%$ of the total variance and was loaded positive with channel constraint variables that included valley width index, distance to estuary and elevation, whereas the loadings negative related to sediment transport and included bank full flow and generic erosion potential. 
Table 3. Principal component analysis (PCA) eigenvectors and associated loading for first 3 axes. Loadings $>0.35$ considered significant for axis interpretation. All 13 persistent reach habitat variables included in analysis. Reference Table 1 for variable description.

\begin{tabular}{lcrr}
\hline Variable & \multicolumn{3}{l}{ Principal component } \\
\cline { 2 - 4 } & PC 1 & PC 2 & PC 3 \\
\hline GRADIENT & 0.48 & 0.01 & 0.08 \\
GRAD_D & 0.36 & 0.23 & 0.17 \\
GEP & 0.26 & -0.30 & -0.35 \\
ELEV_M & 0.13 & -0.38 & 0.41 \\
GEP_Cum & -0.03 & -0.45 & -0.05 \\
P_trib & -0.08 & 0.06 & -0.03 \\
BFQ & -0.09 & -0.24 & -0.37 \\
OUT_DIST & -0.13 & -0.32 & 0.44 \\
SINUOSITY & -0.18 & 0.19 & -0.09 \\
MNANPRC_M & -0.21 & -0.49 & 0.15 \\
VWI_Floor & -0.26 & 0.19 & 0.47 \\
FP_WIDTH & -0.42 & 0.21 & 0.10 \\
MEANANNCMS & -0.45 & -0.08 & -0.30 \\
\hline Component & Eigenvalues & & \\
\cline { 2 - 4 } & Total & $\%$ Var. & $\%$ Cum. \\
\hline PC1 & 3.28 & 25.20 & 25.20 \\
PC2 & 2.86 & 22.02 & 47.23 \\
PC3 & 2.43 & 18.65 & 65.88 \\
\hline
\end{tabular}

Combining redd presence with ordination results showed that the distribution of both species is primarily related to flow, channel size and gradient (Figure 5). The presence of chum salmon redds was associated with larger low gradient channels during both rainy and dry spawning season surveys. Chum redd presence across all reaches indicates a similar distribution for the 2015 rainy period with adequate flows and the 2016 lack of rainfall period with low flows, as related to precipitation measured in the project area (Figure 5c, d). In addition, three of the small unconfined channels used by chum salmon during the rainy period in 2015 were not used during the dry period in 2016. Pink salmon redd presence for the rainy spawning period in 2015 showed a wide distribution of redds for the majority of study reaches with no discernable pattern (Figure 
5a, b). During the 2016 dry spawning period, the PCA analysis indicates that pink salmon showed a preference for large-channel-low-gradient habitat over the smallchannel-high-gradient habitat.

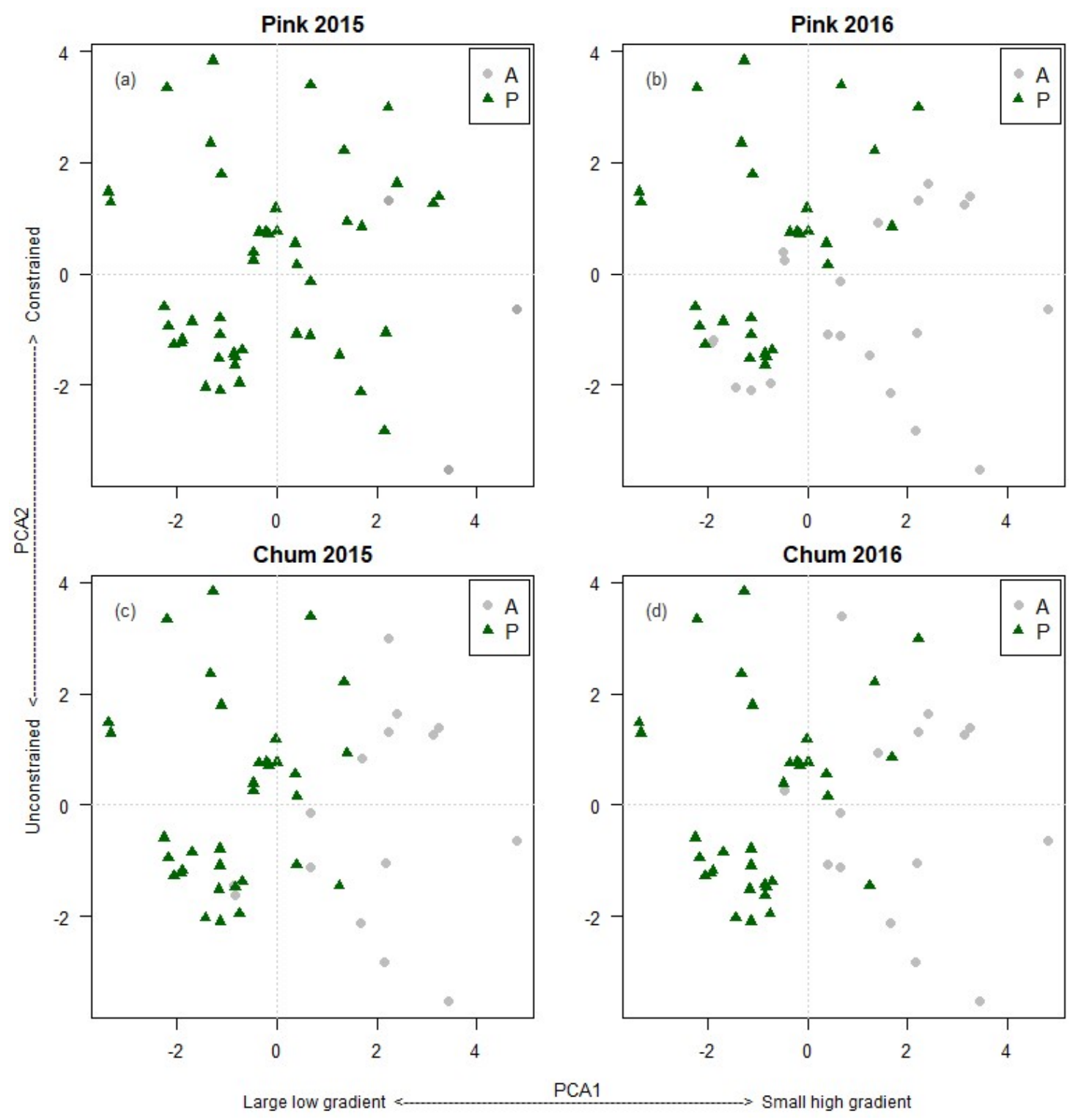

Figure 5. Principal component analysis (PCA) biplot of synthetic reach factors with overlaid pink and chum salmon redd present (P) and absent (A) for all study reaches during 2015 (rainy) and 2016 (lack of rainfall) spawning periods. (a) Pink salmon present during 2015 and (b) 2016, and chum salmon present during (c) 2015 and (d) 2016. Standardized PC1 (25.2\%) is comprised primarily of channel size related to flow and channel gradient, while standardize PC2 $(22.0 \%)$ is a channel constraint and debris transport, or deposition gradient. 
The overall patterns in redd presence for both chum and pink salmon is not the same for both years. The transition in habitat pattern for pink salmon from absent to present is diagonal, indicating a habitat change from high-gradient confined channels to low-gradient unconfined channels with both PC1 and PC2 axis having an equal contribution of variance to redd presence. In contrast to pink salmon, redd presence for chum salmon during both years show a horizontal transition from high-gradient small channels to low-gradient large channels indicating that habitat variance from the PC1 axis contributes the most variance to the detectable pattern of redd presence.

\section{Persistent Habitat Predictors of Redd Density}

Random Forest Classification - The random forest model with 13 predictors was used to evaluate synthetic predictor importance for habitat factors related to redd presence for each species, and for both years. The random forest classification model for chum salmon during 2015 had an overall percent correct classification (PCC) accuracy of $85.7 \%$ (Table 4), with a confusion matrix for observed versus predicted classification error for presence and absence at 8.8\% (91.2\% sensitivity) and 26.7\% (73.3\% specificity), respectively. The Gini index variable importance plot for the first three predictors were dominated by habitat and flow predictors, with channel gradient as the most important predictor of redd presence (Figure 6c). The classification model for 2016 chum salmon showed a slight increase in overall model accuracy over the 2015 model with a PCC accuracy of $94.1 \%$, a sensitivity of $94.1 \%$, and $86.7 \%$ specificity. The model Gini index variable importance plot for the first 3 predictors indicates that flow and 
habitat size are the most important, with mean annual flow as the primary predictor of chum redd presence (Figure 6d).

Table 4. Random forest classification tree observed versus predicted accuracy measures for presence (Sensitivity), absence (Specificity), and overall model percent correctly classified (PCC) for chum and pink salmon redds in the study area on Chichagof Island, Southeast Alaska $(n=49)$.

\begin{tabular}{lccc}
\hline Species (year) & PCC & Sensitivity & Specificity \\
\hline Chum salmon 2015 & 85.7 & 91.2 & 73.3 \\
Chum salmon 2016 & 91.8 & 94.1 & 86.7 \\
Pink salmon 2015 & 93.9 & 100.0 & 0.0 \\
Pink salmon 2016 & 89.8 & 92.9 & 85.7 \\
\hline
\end{tabular}

Variable importance for pink salmon was similar to chum salmon for the 2015 and 2016 field season. The random forest classification model for 2015 pink salmon correctly classified $100 \%$ of redd presence and $0 \%$ of redd absence. The low specificity for the 2015 pink salmon model was due to the small sample size containing only three reaches with no redds observed (Table 4). The Gini index variable importance plot from the random forest model indicates that the three most important variables are associated with channel gradient, with reach gradient as the primary predictor (Figure 6a). The random forest classification model for 2016 pink salmon was a better model than 2015 and correctly classified $92.9 \%$ of the redd presence and $85.7 \%$ of red absence. The model variable importance plot indicates that the top three predictors of pink salmon redd 
presence during 2016 were factors related primarily to elevation, gradient, and mean annual flow, with elevation as the primary predictor (Figure 6b).

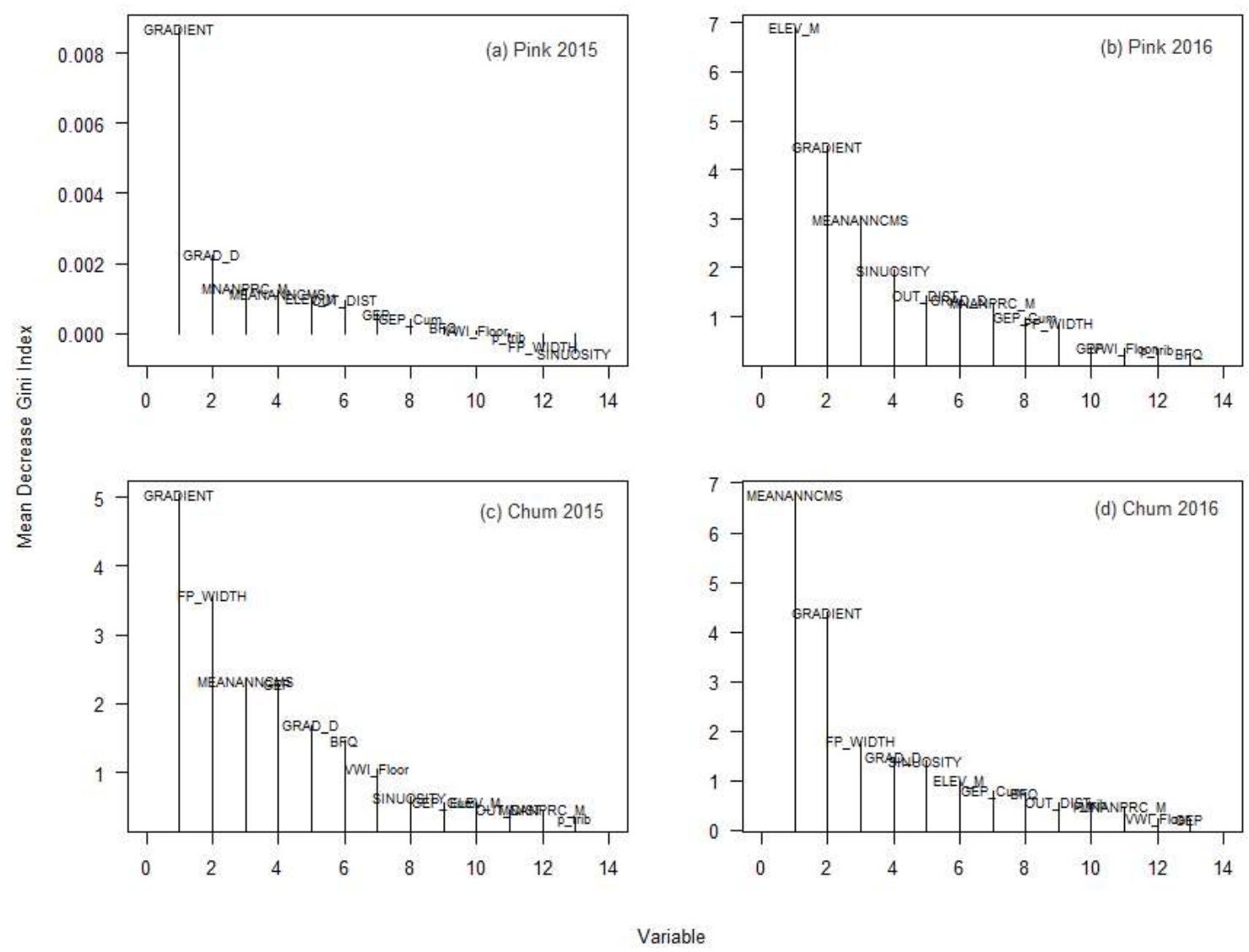

Figure 6. Random forest synthetic variable importance plots for (a) 2015 and (b) 2016 pink and (c) 2015 and (d) 2016 chum salmon redd presence/absence. Higher variable importance increase node splitting homogeneity (purity), while variables closest to absolute value of lowest purity are relatively unimportant (Mean decrease Gini index).

Partial dependency plots of the most important variables for all four models (Figure A-2) indicate that the relationship between these predictors and probability of redd presence is nonlinear. The probability of there being a redd present drops rapidly for both pink salmon years (gradient $>0.02$ and elevation $>40 \mathrm{~m}$, respectively), and for the 2015 chum salmon gradient variable $(>0.01)$. The 2016 chum salmon partial 
dependency plot indicates that the probability of redd presence increases rapidly after flows exceed $1.5 \mathrm{~m}^{3} / \mathrm{s}$.

\section{Relationship Between Redds and Process Types}

Landform and Geology Types - Habitat selection by spawning chum and pink salmon did not differ in their selection of channel constraint types (Figure 7a). In comparison, geology types were different (Figure 7b). Based on confidence intervals derived from bootstrapped distributions of selection ratios, both chum and pink salmon underutilized constrained canyons during both 2015 and 2016 spawning season, selected unconstrained valleys in proportion to availability in 2016, and selected for unconstrained valleys in 2015. Chum salmon selected for glacial deposit formation during spawning in 2015 at a higher proportion to their availability and underutilized the dolerite formation during the 2016 spawning period. Pink salmon underutilized the volcanic dolerite and selected for glacial deposits during the 2015 spawning period, and both geology types were selected for in proportion to availability during the 2016 spawning period.

Stream System and Size Type - Chum and pink salmon selected for different size channels and stream system types. Chum salmon primarily used tributaries and mainstem channel types in proportion to availability, with the exception of the 2016 season when tributaries were underutilized (Figure 7c). Small and large channels were used in proportion to availability during 2015 spawning, while large channels where being selected for and small channels underutilized during the 2016 season. Pink salmon 
selected for small and large channels in proportion to availability for both years of spawning (Figure 7d). Tributaries and mainstem channels were selected for in proportion to their availability for both years, with the exception of tributaries being underutilized during 2016.

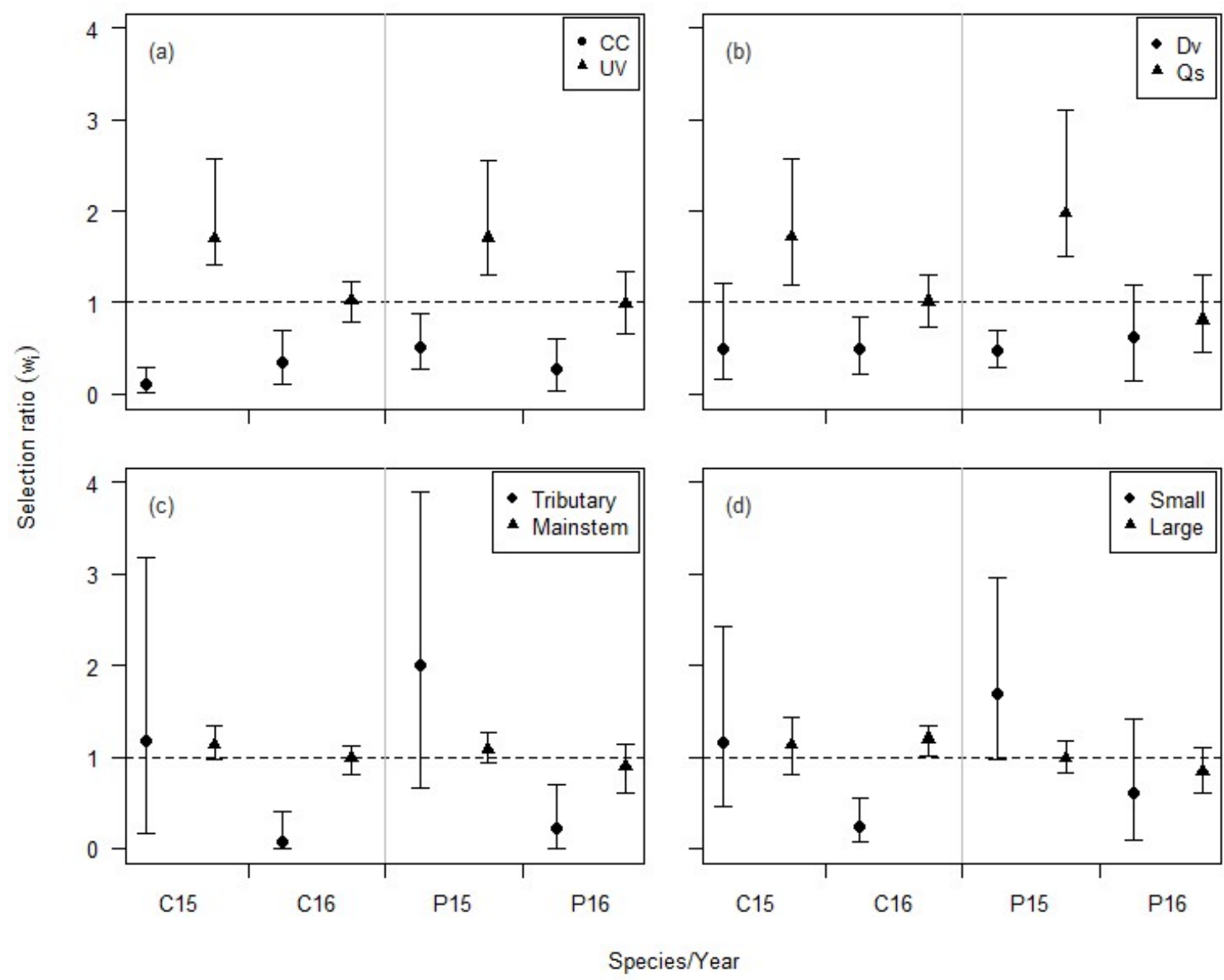

Figure 7. Selection ratios of adult chum salmon (C) and pink salmon (P) during 2015 and 2016 field season for: (a) unconstrained valleys (UV) and constrained canyons (CC); (b) glacial deposit (Dv) and volcanic dolerite (Qs) formations; (c) mainstem and tributary channels; (d) and small and large channel types. A selection ratio was not significant if the Bonferroni-adjusted confidence interval $(\alpha=0.1 / 2)$ included one. Selection ratios were significantly different for a given year by species $(\alpha=0.1)$ if their confidence interval did not overlap. 


\section{Uncertainty Analysis}

Field vs. Synthetic Persistent Channel Characteristics - The accuracy and variability of synthetic and field measured channel morphology during the 2015 field season depended on metric (Table 5)

Table 5. Field and synthetic (model) channel morphology characteristics comparison at cross sections $\left(\mathrm{BFW}=\right.$ Bank-full width, $\mathrm{BFD}=$ Bank-full depth, $\mathrm{D}_{50}=$ Median particle size $)$, and longitudinal channel profiles $(\mathrm{LPL}=$ Longitudinal profile length, Gradient $=$ Reach gradient at 20 $\mathrm{x}$ BFW) during 2015 field season $(\mathrm{n}=48)$.

\begin{tabular}{llccccccc}
\hline & Code & Mean & Std.Dev & Median & Min & Max & 25th & 75th \\
\hline Field & & & & & & & & \\
& Gradient $(\mathrm{m} / \mathrm{m})$ & 0.029 & 0.036 & 0.013 & 0.002 & 0.169 & 0.006 & 0.043 \\
& LPL (m) & 307.6 & 240.6 & 275.1 & 50.0 & 843.0 & 69.2 & 479.2 \\
& BFW (m) & 14.4 & 12.2 & 11.3 & 0.7 & 41.5 & 3.0 & 22.4 \\
& BFD (m) & 0.4 & 0.2 & 0.3 & 0.1 & 0.8 & 0.2 & 0.5 \\
& D50 (cm) & 34.3 & 14.5 & 33.7 & 10.5 & 65.1 & 20.7 & 42.6 \\
Model & & & & & & & & \\
& Gradient $(\mathrm{m} / \mathrm{m})$ & 0.030 & 0.042 & 0.009 & 0.001 & 0.192 & 0.005 & 0.039 \\
& LPL (m) & 350.5 & 292.7 & 298.9 & 44.1 & 1016.4 & 71.3 & 564.7 \\
& BFW (m) & 14.6 & 7.8 & 14.6 & 3.3 & 26.9 & 8.0 & 21.5 \\
& BFD (m) & 0.6 & 0.1 & 0.6 & 0.3 & 0.7 & 0.5 & 0.7 \\
& D50 (cm) & 49.3 & 39.9 & 31.4 & 4.8 & 181.8 & 21.2 & 71.7 \\
\hline
\end{tabular}

A measure of how well the synthetic factors predicted field measured habitat was compared by performing polynomial and linear regression with field versus synthetic reach habitat variables. Synthetic channel gradients were highly correlated with, but slightly over estimated field-measured channel gradient $\left(\mathrm{p}<0.001, \mathrm{R}^{2}=0.95\right)$ for steeper channels (Figure A-3, Table A-2). As the slope of the channel exceeds 5\%, the synthetic gradient deviates from 1:1 toward larger gradients, as indicated by a regression slope of 1.13. The coefficient of determination indicates that the accuracy of the comparison is high, and the slope indicates that the precision decreases as slope increases. 
Synthetic and field channel lengths were more similar for small bank-full width channels than large bank-full width channels. Field channel length was compared with synthetic channel length and found to have a significantly strong positive correlation ( $p<$ $0.001, \mathrm{R}^{2}=0.99$ ). Furthermore, as synthetic channel length increases above $200 \mathrm{~m}$ the relationship deviates from a 1:1 ratio leading to a longer synthetic channel length by a factor of 1.21 (regression slope) for every one-unit increase in field channel length (Figure A-4). For all measured reaches combined, there was a 12.0\% increase in synthetic length compared to field measured channel length, and there was a 13.8\% model channel length increase for channels $>10 \mathrm{~m}$ wide. These results show that even though the precision is high, the accuracy (regression slope) decreases with wider channels, and the error is cumulative.

Comparing field and synthetic bank-full width indicates that synthetic bank-full width is not a linear function of field measured bank-full width for all surveyed channels ranging from $0.7 \mathrm{~m}$ to $41.5 \mathrm{~m}$ (Figure A-5). Although, fitting a non-linear model to the data resulted in a significant correlation $\left(\mathrm{p}<0.001, \mathrm{R}^{2}=0.95\right)$. The non-linear pattern in the bank-full width data indicates that smaller channels $<20 \mathrm{~m}$ wide are similar in width to synthetic channels, and synthetic channels $>20 \mathrm{~m}$ decrease in width as field channel width increases.

Field measured bank-full depth was a significant predictor of synthetic bank-full depth $\left(p<0.001, R^{2}=0.77\right)$. Although, similar to bank-full width, the relationship was not linear, nor was it 1:1 (Figure A-6). For all paired synthetic and field correlations, 
synthetic bank-full depth had the lowest correlation with field measured habitat while still being significantly correlated.

\section{Intrinsic Potential Model}

Mean Annual Stream Flow - Index curves for mean annual stream flow (Figure $8 \mathrm{a}, \mathrm{b})$ were derived from synthetic mean annual flow relative to field observed chum and pink salmon redd densities in the study area. Based on field data of redd densities, the index curve for chum salmon linearly increased from zero to $0.25 \mathrm{~m}^{3} / \mathrm{s}$, then declined linearly from 5.5 to $11.5 \mathrm{~m}^{3} / \mathrm{s}$, and was then extended beyond the upper limit of field data to encompass the range of synthetic flows fish would encounter in the study area. The index curve for pinks salmon was also based on field data, started at zero and sharply increased linearly to $0.15 \mathrm{~m}^{3} / \mathrm{s}$, then linearly declined from 0.5 to $11.5 \mathrm{~m}^{3} / \mathrm{s}$ where the index curve was extended past the upper limit of field data to encompass the range of synthetic flows in the study area.

Gradient - Channel gradient index curves (Figure 8c, d) were based on field observations of redd density for both species relative to synthetic channel gradient. A field survey for upper limits of chum salmon distribution was not performed for the study area, therefore I extended the channel gradient upper limit based on criterion from Washington state (WDFW 2009). I gave channels with a gradient between 3\% and 6\% a very low suitability score of 0.05 . This led to an index curve for chum salmon that declined linearly from a slope near $0 \%$ to a low near 3\% channel gradient, and assumes 
no use upstream of reaches $>6 \%$. During the 2015 field season when flows allowed fish access to all channels, a field crew surveyed for upper limits of pink salmon distribution. These field observations were used to set the gradient upper limit for pink salmon. Pink salmon were observed in habitat up to $7.5 \%$ gradient, suggesting that pockets of potential habitat for spawning can occur in these higher gradient reaches. Similar to Busch (2011), channels with a gradient between $4.5 \%$ and $8 \%$ were given a very low suitability score of 0.05 . The index curve for pink salmon started to linearly decline near $1.5 \%$ channel gradient to a low near $4.5 \%$, then assumes no use upstream of reaches $>8 \%$.

Valley Constraint - Index curves for reach valley constraint (Figure 8e, f) were based on synthetic VWI and redd density for both species. Based on professional judgment, the upper limit index scores for valley constraint were also extended past the limit of the field data to encompass the range of synthetic VWI in the study area. For chum salmon, the index curve started to increase linearly for VWI $>3$ and reached an optimal index for channel constraint $>8.5$. Pink salmon VWI index started to increase linearly near 2.2 and reached an optimal use for this species for channel constraint $>5.5$. 

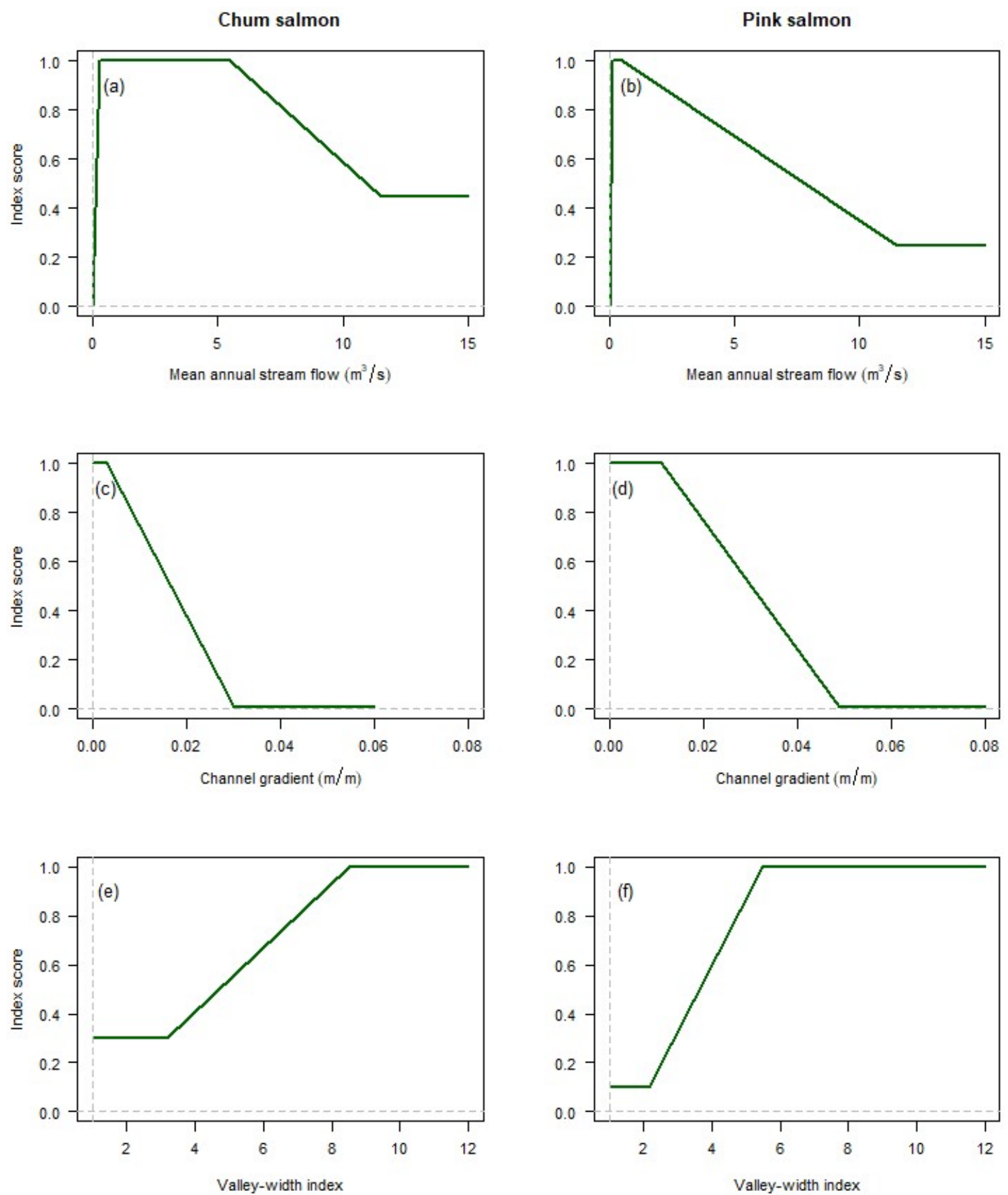

Figure 8. Fish-habitat relationship between values of the three synthetic persistent reach attributes and the index scores based on chum and pink salmon redd density used to calculate intrinsic potential for: $(\mathrm{a}, \mathrm{b})$ mean annual flow, $(\mathrm{c}, \mathrm{d})$ channel gradient, and $(\mathrm{e}, \mathrm{f})$ valley-width index, respectively. 
Chum salmon tended to prefer stream channels with gradients $<3.5 \%$, and channel constraint $>8.5$. This species preferred mean annual flows that ranged from 0.25 to $5.5 \mathrm{~m}^{3} / \mathrm{s}$, and would tolerate flows that exceeded $11 \mathrm{~m}^{3} / \mathrm{s}$. These habitat characteristics indicate that chum salmon primarily use larger low-gradient floodplain channels in open valleys for spawning and avoid small tributaries and headwater streams.

Pink salmon preferred channel gradients up to $4.5 \%$, and channel constraint $>7.5$. Optimal flows for pink salmon were near $1.0 \mathrm{~m}^{3} / \mathrm{s}$ and preference steadily declined as flows increased. These habitat characteristics for pink salmon indicated a spawning habitat preference for smaller stream channels and tributaries with low gradient in unconfined valleys.

The IP model for both species (Figure 9a, b) indicated a low proportion of the channel network in the study drainage basins provided potential suitable spawning habitat for chum and pink salmon. Chum and pink salmon had access to an estimated $255 \mathrm{~km}$ of the total $(2,012 \mathrm{~km})$ synthetic stream network (Figure 9). Stream reaches with IP values $\geq 0.75$ for chum salmon comprised $18 \%$ of streams accessible to adult migration, while $31 \%$ of this same synthetic stream network was classified as high intrinsic potential for pink salmon. Both species predicted high IP stream lengths were allocated primarily to mainstem for chum salmon, with more pink salmon high IP extending into smaller channel habitat and tributaries (Figure 9a, b). 

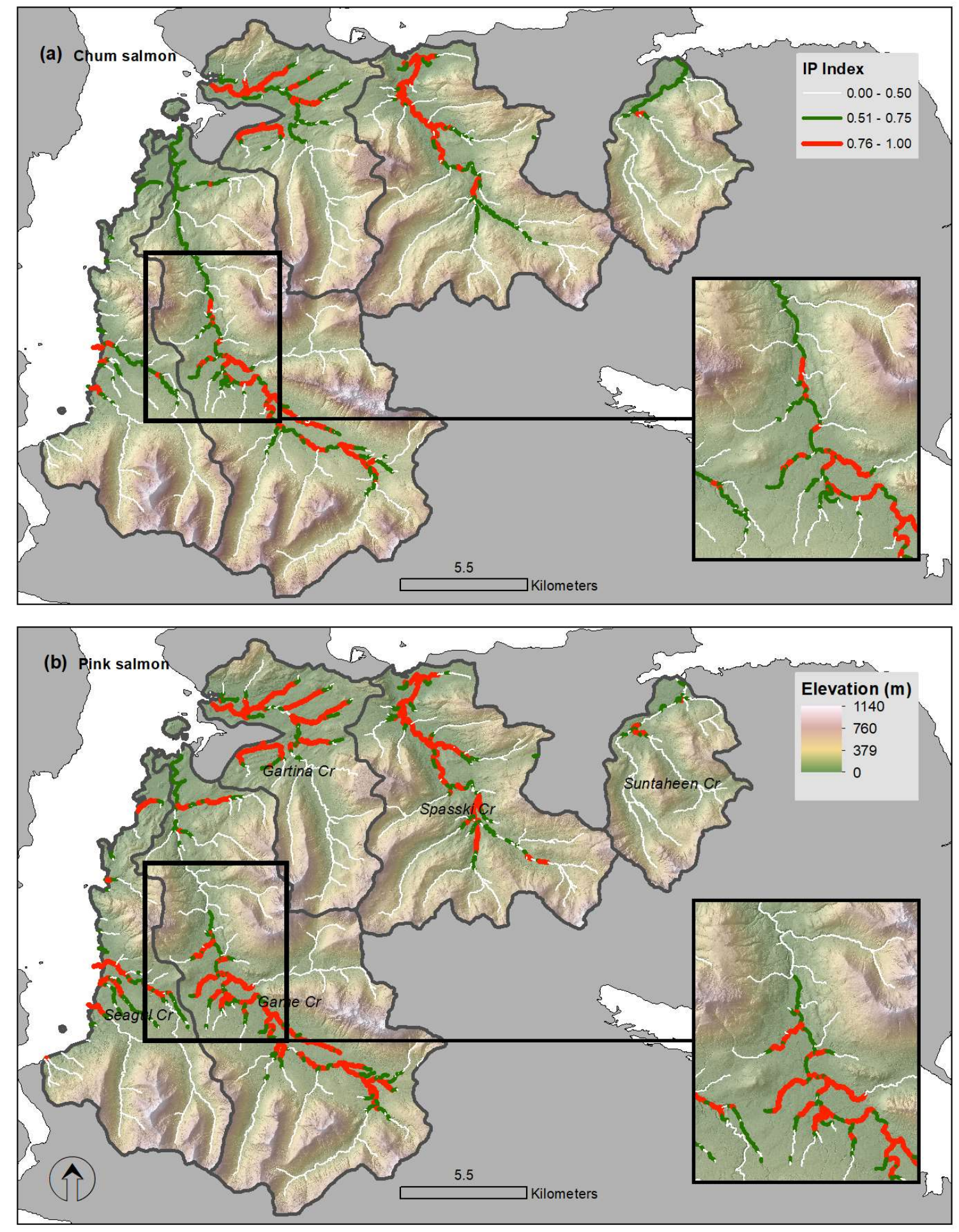

Figure 9. Map showing (a) chum and (b) pink salmon IP modeled reaches across the study area landscape. White lines represent riverscape patterns for stream segments having IP scores $<0.50$ (Low potential), green lines represent IP scores between 0.50 and 0.75 (moderate potential), and red lines represent IP scores $\geq 0.75$ (high potential) for uncorrected channel length. 
Uncertainty Analysis - Analysis of the correlation between field and synthetic channel length revealed a difference in accuracy for the synthetic channel length. Even though there is a significant and strong correlation between the two lengths $\left(\mathrm{p}<0.001, \mathrm{R}^{2}\right.$ $=0.99$ ), the data suggests that synthetic channel lengths tend to be longer than field measured channel length by approximately $12 \%$ (Figure A-4). Subtracting $12 \%$ from the high IP synthetic channel length in the study area for both species reduces to an estimated $40.3 \mathrm{~km}$ for chum salmon and $69.5 \mathrm{~km}$ for pink salmon. Applying the same $12 \%$ reduction to the total synthetic stream network in the study area reduces the total stream length by $241 \mathrm{~km}$. 


\section{Discussion}

\section{Fish-Habitat Relationship}

One of the most important aspects of salmonid conservation is the understanding of habitat diversity across a landscape required for a particular life history, including the abundance and distribution of adults during spawning (Benda et al. 2004; Flitcroft et al. 2012; Steel et al. 2016). This study determined how persistent watershed characteristics, run size, and environmental change influenced riverscape distribution patterns of adult chum and pink salmon in five drainage basins that are typical of coastal Southeast Alaska.

Reach Type Persistent Habitat Selection - Adult chum and pink salmon selected for specific reach types during spawning. For both species, the types of reach selected varied among the two years of the study (rainy and dry field seasons). Both species underutilized confined canyons during both rainy and dry spawning periods, and selected for unconstrained valleys during rainy periods. A similar pattern was observed for both species and for geology types as was expected since channel constraint is a result of the larger geological structure control (Frissell 1992). The findings for chum and pink salmon related to channel constraint types in this study are similar to habitat selection by juvenile chinook and coho salmon for unconstrained channels in Oregon (Burnett 2001).

The study area underlying geology was expressed at the channel interface (lithology) for each study reach contributing to channel morphology via substrate erodibility and sediment loading. Both chum and pink salmon selected unconfined 
channels with alluvial deposits, and underutilized confined channels that were associated with volcanic dolerite. These findings suggest that geology influences habitat use by controlling channel constraint and associated channel characteristics (gradient, substrate composition); similar to findings by Steel (2016) for the Oregon coastal landscape region. Channel constraint is one of the primary reach-scale predictors of spawning chum and pink salmon habitat preferences (Paustian 2010), a result of lithology interacting with channel hydrology. Chum and pink salmon have similar preferences for spawning habitat in low-gradient unconstrained mainstem channel habitat, but pink salmon make more extensive use of tributaries and smaller channels throughout the stream networks. During the two years of redd surveys, chum salmon selected for similar habitat during both rainy and dry periods. Chum salmon selected for large channel habitat and underutilized tributaries and small channels during the low water dry spawning period. The overall pattern of chum salmon selecting larger habitat and underutilizing smaller habitat is consistent with other research on salmonid spawning habitat selection (Quinn 2011; Pess et al. 2014; Mouw et al. 2014). The results from the resource selection ratios show that channel constraint (VWI) and channel size are significant predictors of spawning habitat selection by both chum and pink salmon. These results imply that physical channel constraints set by the valley morphology, and controlled by the underlying geology, help form the patterns of chum and pink salmon persistent habitat use throughout these coastal drainage basins (Frissell et al. 1986; Montgomery and Buffington 1998; Beechie et al. 2008). 
Streamflow and run size during spawning may affect habitat accessibility as well as habitat use by spawning chum and pink salmon. Pink salmon selected for tributaries and small channels more strongly during high flows, and such locations were used less during low flows. The large escapement of adult pink salmon in 2015 (Figure 4), may have prompted spawner-movement into sub-prime habitat in the tributaries as a result of density-dependent competition in the areas with optimal spawning habitat (Fretwell and Calver 1969). Also, selection of smaller channels may be an adaptive trait that promotes pink salmon to utilize smaller habitat not used by larger fish during periods when adequate streamflow allow connectivity to all accessible habitat (Beechie et al. 2008). The overall pattern in the data suggests that chum salmon are generally using the mainstem and larger unconstrained channels either at a higher proportion or at the same proportion to their availability, regardless of flow. Whereas, pink salmon are using the smaller channels at a higher proportion or the same proportion to their availability during periods when adequate flows allow access to these channels. During low flows when access to smaller channels and tributaries are restricted, both species focus their habitat selection for reproductive success in larger low-gradient mainstem habitat.

Persistent Predictors of Redd Presence - My objective was to identify those persistent/immutable landscape features most strongly correlated with reach occupancy for spawning adult chum and pink salmon. I was lucky enough to be able to conduct surveys during a rainy and dry spawning season with corresponding high flows in 2015 and low flows in 2016. Despite disparate differences in flow and run size, the data reveal 
an underlying set of persistent factors influencing spatial patterns of habitat use. Because I was able to document spawning during the rainy 2015 spawning period and the 2016 dry spawning period, two spawning strategies were observed for pink salmon and one for chum salmon through reach-level redd surveys. Pink salmon spawning during the rainy survey period occurred in both the mainstem and tributaries, and primarily low in the basin during the survey period with lack of rainfall (Fukushima and Smoker 1998), which is expected spawning behavior for pink salmon. Chum salmon spawned throughout the mainstem channels, from the lower to upper reaches during both rainy and dry spawning period surveys.

The importance of persistent reach variables for chum salmon spawning indicate landscape interactions primarily with channel size, valley constraint, and gradient. Random forest variable selection for chum salmon spawning primarily described large channel habitat characteristics observed in the study area, due to the association of mean annual flow, channel gradient, and floodplain width (Figure 6). Large low gradient channels are associated with greater spawning habitat heterogeneity and valley floor area (Montgomery and Buffington 1997; Montgomery et al. 1999), features indicative of preferred chum salmon spawning habitat, such as side channels and backwater upwelling areas (Mouw et al. 2014). Regardless of difference in channel flow between the rain and lack of rain spawning seasons, the important predictors for chum salmon redds are relatively the same for both years. Although, when flows in the low gradient floodplain channels are substantially reduced the habitat heterogeneity for chum salmon in these channels is also reduced, as indicated by dewatered side channels and backwater areas 
during the 2016 field surveys that were utilized for spawning by chum salmon during the rainy 2015 spawning season.

The relative importance of persistent reach level variables changed for pink salmon from the rainy 2015 season to lack of rain during the 2016 season. During the first survey season that was rainy, random forest model indicated that persistent reach variable importance for predicting pink salmon redd presence was predominantly channel gradient (Figure 6). Small moderate gradient channels have smaller substrate particle size associated with reduced water depth and velocity, channel features selected for by small bodied pink salmon (Crisp and Carling 1989). Compared to the 2016 adult pink salmon escapement, the 2015 run was much larger and had access to more river kilometers of channel network than the 2016 run. Due to the high spawner density for pink salmon in 2015 it is likely that there was a low degree of segregation in habitat utilization among some reaches of the mainstem suggesting that competitive interaction with the potential for spatial displacement most likely occurred between pink and chum salmon. Although, the degree of influence the pink salmon run has on the chum salmon run spawning success is unknown since both species have overlapping spawning site preferences with segregated peak spawning times. The use of smaller channels and tributaries by pink salmon may reduce competition with chum salmon in main channel habitat when adequate flow allows access and population size is large. However, during direct observations during field surveys for both years, I found that adult chum and pink salmon will at times segregate separately within a reach, with obvious segregation within a habitat unit type between the two species. 
While stream flows during the rainy 2015 spawning period allowed connectivity to a larger stream network, the lack of rain during the 2016 season reduced habitat connectivity and decreased the available habitat size. These results from the field indicate that chum salmon may find more habitat diversity associated with mainstem channel reaches, such as side channels, backwater, and gravel bar upwelling areas during adequate flow, whereas pink salmon will utilize habitat heterogeneity in smaller channel reaches and tributaries when accessible. This indicates that a reduction in flow reduces the available habitat heterogeneity for both species and these two salmonids will respond by seeking core channel habitat with the associated body size environmental window of available favorable conditions (e.g., flow, substrate) to maximize each species spawning success.

The lack of rainfall in 2016 hindered upstream migration of pink salmon and, to a lesser extent, chum salmon, thus spawning duration was much shorter in 2015. Synthetic variable importance for pink salmon shifted to reach elevation as the primary predictor of redd presence during the dry season survey (Figure A-2) indicating that the threshold elevation for redd presence was primarily low in the drainage basins and therefore associated with larger mainstem reaches near the estuary. During this dry period, channel flow was substantially diminished resulting in reduced water depth and velocity in these larger mainstem channels located lower in these drainage basins making spawning conditions more favorable to the smaller pink salmon (Fukushima and Smoker 1997, 1998). Because spawner density was low for both species in 2016 there was a high degree of habitat segregation in habitat utilization suggesting that habitat overlap with 
associated superimposed redds and competitive interaction with the potential for spatial displacement was most likely low.

Pink and chum salmon have adapted species-specific spawning habitat selection strategies that are sustainable for each species. As adult escapement increased, fish expanded into portions of the drainage network that were unoccupied during low adult escapement or low flows, and regardless of the escapement size or channel flow, the distribution of redds remained clustered with a limited portion of the channel network containing the majority of redds for both chum and pink salmon (Figure 4). Similar patterns of clustered spawning habitat use by Chinook salmon was also observed by Isaak and Thurow (2006) in central Idaho. These species specific patterns are thus long-term adaptations relating body size to immutable habitat characteristics at the reach scale (Beechie et al. 2008). Consequently, the persistent nature of these channel features as a result of valley geomorphic controls creates the habitat diversity template unique for each species survival, and survival translates to heritability, which translates to spatial patterns of continued and persistent utilization (adaptive) of immutable habitat characteristics.

\section{Habitat Intrinsic Potential}

The findings from this study corroborate with the working hypothesis set forth by Steel (2003) and Ward (1998) that landscape characteristics affect stream habitat and thus affect salmonid populations. Beechie (2008) proposed that these persistent habitat characteristics, a result of the larger channel forming processes, are a reflection of species specific adaptive traits rather than phenotype plasticity response to short term changes at 
the habitat unit scale. Therefore, the methods I used to develop individual intrinsic potential models for chum and pink salmon spawning habitat follow those methods developed and applied by Burnett $(2003,2007)$ to evaluate habitat potential specifically for an individual salmonid species.

The field-derived habitat curves for chum and pink salmon were similar to other Pacific salmon intrinsic potential modeling efforts (Burnett et al. 2003, 2007; Busch et al. 2011; Bidlack et al. 2014), and were in agreement with research regarding salmon-habitat use at the reach scale (Montgomery et al. 1999; Beechie et al. 2008). Although, where other have used juvenile rearing fish-habitat information to create their models, these models are the first to use adult fish-habitat information to develop the habitat suitability curves. The persistent habitat characteristics chosen as indicators that encompass landform and hydrology, and represent the potential for a reach of stream to produce suitable habitat conditions for both species, were channel constraint in the form of valley width index, gradient, and mean annual flow. The selection of these persistent synthetic characteristics was informed by field observation and analysis included in this study.

The general correspondence between chum and pink salmon distributions and gradient indicated that both species utilize reaches with slopes $<4 \%$ (Figure 8). This corroborates with the Montgomery (1999) hypothesis that fall-spawning salmonids in rain-dominated systems are primarily restricted to channels with gradient $<0.03$. The field data suggests that chum salmon tolerate a wider range of flows than pink salmon, and chum salmon preferred channels with a wider floodplain. These differences in persistent spawning habitat characteristics between the two species indicate an 
evolutionary preference by chum salmon for medium-to-large channels with lowgradient, and pink salmon for small-to-medium sized channel with low-to-medium gradient.

The field data from this study shows that seasonal changes in environmental factors such as flow, and population dynamic factors such as population size, can have a widespread effect on species distribution in a drainage basin (Figure 4). Unlike redd abundance for chum salmon, the numbers associated with the pink salmon redds are from two distinct populations with a dominant odd year population, and this difference may have consequences related to distributions and density differences between the two years. It has been postulated that only high IP habitat would be occupied when population abundance is low (Sheer et al. 2009). Flitcroft (2014) tested this hypothesis for juvenile coho salmon in Oregon and found that larger spawning run sizes corresponded with an expansion of habitat use out of core areas. Changes in redd density at the reach level over multiple spawning seasons emphasizes the importance of using multiple years of survey data to create suitability index curves for an IP model so that habitat heterogeneity a species will encounter across the landscape is well represented within the model (Burnett 2001).

\section{Management Implications}

The data and findings from this study demonstrate the usefulness of IP modeling for investigating redd presence and abundance correlated with persistent habitat attributes. Similar to the uses implied from other IP models (Burnett et al. 2003; Agrawal 
2005; Burnett et al. 2007; Sheer et al. 2009, 2009; Busch et al. 2011; Bidlack et al. 2014), these chum and pink salmon spawning habitat IP models for Southeast Alaska can be used as a first-step approach for identifying the potential extent, distribution and quality of habitat among all coastal streams. Further, these models can be used to inform conservation or restoration areas of potential high-quality habitat critical for the longterm sustainability for chum and pink salmon populations. In addition, these IP models can serve as an initial assessment to identify and prioritize field research areas for fishhabitat use or abundance. However, IP model estimates as a management tool for populations in Southeast Alaska should be viewed cautiously, especially if the model is preliminary and has not been validated.

Results from IP models can be used as habitat predictors in other models, or comparatively with management decisions or land use. For example, IP scores can be used as a predictor in fish-habitat models (Steel et al. 2012, 2016) to explain variation in species abundance. Although, most IP models are used comparatively. Burnett (2003, 2007) compared a steelhead and coho salmon IP models with land use practices in the coastal range of Oregon, while Bidlack (2014) developed a Chinook salmon IP model to identify rearing habitat in advance of land use changes in a large drainage basin in Alaska. Furthermore, May (2016) compared length of high IP habitat for coastal cutthroat trout above and below waterfall nick points to evaluate habitat connectivity.

Even though the resolution of the remotely sensed data used to develop these IP models is high $(1 \mathrm{~m})$, I caution against using results from these models to estimate habitat potential for specific stream reaches without knowing the accuracy of the model at the 
reach scale. Instead, model results should be considered for a group of reaches at a larger scale as an aggregate, and can then be used to compare portions of a population for conservation or recovery related to stream restoration (Busch et al. 2011). Used in this context, IP modeling becomes a powerful tool providing a means to specify areas of the stream networks from the entire pool of potential stream reaches across the landscape that could be evaluated for species specific distribution or abundance surveys.

Some synthetic variables were more accurate than others when compared with field observations. Synthetic channel width and depth are calculated as a function of drainage basin area, and both showed a non-linear relationship when compared with field measured channel width and depth (Figure A-5, Figure A-6). This indicates that the basin area to channel width and depth relationship in the study area is not the same as the relationship represented by the functions used in NetMap, and should be corrected based on field observations for the region. In addition, some variables measured in the field are more prone to observer error. For example, the difficulties associated with identifying channel bank full in the field leads to a larger error when compared with other field channel morphology measurements (Archer et al. 2004; Roper et al. 2010). These sources of error should be taken into consideration when selecting persistent variables for an IP model.

It is important to not overestimate the amount of potential habitat for achieving objectives related to salmonid habitat restoration and species conservation strategies so that unrealistic goals are not set. Field morphology data from this study compared with synthetic channel attributes suggest that IP models based on 1-m resolution LiDAR 
derived DEMs overestimate channel length mostly for large channels by approximately $12 \%$ (Figure A-4), implying that results for total potential habitat should be evaluated with caution.

Finally, this research highlights the importance of modeling potential spawning habitat for chum and pink salmon across coastal landscapes in Southeast Alaska to provide the necessary information to fill the gaps for estimating the fish-habitat distribution and potential for a species. Identifying areas with high IP, regardless of fish presence, allows decision makers the capacity to better balance ecosystem services with salmon conservation for maintaining sustainable populations of salmonids.

\section{Study Limitations and Uncertainties}

IP modeling was originally developed for the heterogeneous drainage basins along the Oregon coastal landscape. This study suggests that the methodology is a good fit for coastal landscapes in Southeast Alaska. Furthermore, most IP models use 10-m to 30-m DEMs (e.g., Burnett et al. 2007; Sheer et al. 2009; Busch et al. 2011; Bidlack et al. 2014) while this IP model is the first to use a 1-m DEM derived from LiDAR remote sensing imagery. From the current published literature regarding IP modeling, these two models are the first for chum and pink salmon, and the first to use redd density to develop the habitat suitability curves for the IP index.

Since few of the peer-reviewed pacific salmon IP models have been validated an attempt should be made to validate the models from this study by applying these models to riverscapes not modeled in this study, and spatially random redd surveys conducted for 
a range of IP index reaches, so that modeled IP can be tested against redd surveys. The results of this proposed test could then be used to quantitatively calibrate these IP models and strengthen the relationship between predicted habitat and fish distribution, increasing the confidence in the fish-habitat suitability curves. 


\section{References}

ADFG. 1985. Alaska habitat management guide, southcentral region, Volume 1: Life histories and habitat requirements of fish and wildlife. Alaska Department of Fish and Game, Division of Habitat.

ADFG. 2008. The Catalog of Waters Important for the Spawning, Rearing or Migration of Anadromous Fishes. Found at https://www.adfg.alaska.gov/sf/SARR/AWC/.

Agrawal, A. 2005. Predicting the potential for historical coho, chinook and steelhead habitat in northern California. Santa Cruz Laboratory Southwest Fisheries Science Center NOAA National Marine Fisheries Service 110 Shaffer Road Santa Cruz, CA 95060.

Archer, E. K., B. B. Roper, R. C. Henderson, N. Bouwes, S. C. Mellison, and J. L. Kershner. 2004. Testing common stream sampling methods for broad-scale, longterm monitoring. Page 15. USDA Forest Service, General Technical Report RMRS-GTR-122.

Bakkala, R. G. 1970. Synopsis of biological data on the chum salmon, Oncorhynchus keta (Walbaum) 1792. US Fish and Wildlife Service.

Beechie, T., H. Moir, and G. Pess. 2008. Hierarchical physical controls on salmonid spawning location and timing. Pages 000-000 American Fisheries Society Symposium.

Beeson, H. 2014. The Influence of Deep-Seated Landslides on Topographic Variability and Salmon Habitat in the Oregon Coast Range, USA.

Benda, L., D. Miller, K. Andras, P. Bigelow, G. Reeves, and D. Michael. 2007. NetMap: a new tool in support of watershed science and resource management. Forest Science 53(2):206-219.

Benda, L., N. L. Poff, D. Miller, T. Dunne, G. Reeves, G. Pess, and M. Pollock. 2004. The network dynamics hypothesis: how channel networks structure riverine habitats. BioScience 54(5):413-427.

Bidlack, A. L., L. E. Benda, T. Miewald, G. H. Reeves, and G. McMahan. 2014. Identifying Suitable Habitat for Chinook Salmon across a Large, Glaciated Watershed. Transactions of the American Fisheries Society 143(3):689-699.

Bjornn, T. C., and D. W. Reiser. 1991. Habitat requirements of salmonids in streams. American Fisheries Society Special Publication 19:83-138.

Breiman, L. 2001. Random forests. Machine learning 45(1):5-32.

Bue, B. G., S. M. Fried, S. Sharr, D. G. Sharp, J. A. Wilcock, and H. J. Geiger. 1998. Estimating salmon escapement using area-under-the-curve, aerial observer efficiency, and stream-life estimates: The Prince William Sound pink salmon example. North Pacific Anadromous Fish Commission Bulletin 1:240-250. 
Buffington, J. M., D. R. Montgomery, and H. M. Greenberg. 2004. Basin-scale availability of salmonid spawning gravel as influenced by channel type and hydraulic roughness in mountain catchments. Canadian Journal of Fisheries and Aquatic Sciences 61(11):2085-2096.

Bunte, K., and S. R. Abt. 2001. Sampling surface and subsurface particle-size distributions in wadable gravel-and cobble-bed streams for analyses in sediment transport, hydraulics, and streambed monitoring.

Burner, C. J. 1951. Characteristics of spawning nests of Columbia River salmon. U.S Fish and Wildlife Service.

Burnett, K. M. 2001. Relationships among juvenile anadromous salmonids, their freshwater habitat, and landscape characteristics over multiple years and spatial scales in the Elk River, Oregon.

Burnett, K. M., G. H. Reeves, D. J. Miller, S. Clarke, K. Vance-Borland, and K. Christiansen. 2007. Distribution of salmon-habitat potential relative to landscape characteristics and implications for conservation. Ecological Applications 17(1):66-80.

Burnett, K. M., G. Reeves, D. Miller, S. Clarke, K. Christiansen, and K. Vance-Borland. 2003. A first step toward broad-scale identification of freshwater protected areas for Pacific salmon and trout in Oregon, USA. Aquatic protected areas: what works best and how do we know:144-154.

Busch, D. S., M. Sheer, K. Burnett, P. McElhany, and T. Cooney. 2011. Landscape-level Model to Predict Spawning Habitat for Lower Columbia River Fall Chinook Salmon (Oncorhynchus tshawytscha). River Research and Applications 29(3):297-312.

Canty, A. J. 2002. Resampling Methods in R: The boot Package. Clarendon Press ; Oxford University Press, Oxford: New York.

Chapman, D. W. 1988. Critical Review of Variables Used to Define Effects of Fines in Redds of Large Salmonids. Transactions of the American Fisheries Society 117(1):1-21.

Crance, J. H. 1987. Guidelines for Using the Delphi Technique to Develop Habitat Suitability Index Curves. U.S. Fish Wildl. Serv. Biol. Rep. 82 10(134):21.

Crisp, D. T., and P. A. Carling. 1989. Observations on siting, dimensions and structure of salmonid redds. Journal of Fish Biology (34):119-134.

Davies, J. R., K. M. Lagueux, B. Sanderson, and T. J. Beechie. 2007. Modeling stream channel characteristics from drainage-enforced DEMs in Puget Sound, Washington, USA. Journal of the American Water Resources Association 43(2):414-426. 
Dickerson, B. R., K. W. Brinck, M. F. Willson, P. Bentzen, and T. P. Quinn. 2005. Relative importance of salmon body size and arrival time at breeding grounds to reproductive success. Ecology 86(2):347-352.

Dickerson, B. R., T. P. Quinn, and M. F. Willson. 2002. Body size, arrival date, and reproductive success of pink salmon, (Oncorhynchus gorbuscha). Ethology Ecology \& Evolution 14(1):29-44.

Dittman, A. H., G. S. Brown, and C. J. Foote. 1998. The role of chemoreception in salmon-egg predation by coastrange (Cottus aleuticus) and slimy (C. cognatus) sculpins in Iliamna Lake, Alaska. Canadian Journal of Zoology 76(3):405-413.

Dunham, J., B. Rieman, and K. Davis. 2001. Sources and magnitude of sampling error in redd counts for bull trout. North American Journal of Fisheries Management 21(2):343-352.

Firman, J. C., E. A. Steel, D. W. Jensen, K. M. Burnett, K. Christiansen, B. E. Feist, D. P. Larsen, and K. Anlauf. 2011. Landscape Models of Adult Coho Salmon Density Examined at Four Spatial Extents. Transactions of the American Fisheries Society 140(2):440-455.

Flitcroft, R., K. Burnett, J. Snyder, G. Reeves, and L. Ganio. 2014. Riverscape patterns among years of juvenile coho salmon in midcoastal Oregon: implications for conservation. Transactions of the American Fisheries Society 143(1):26-38.

Flitcroft, R. L., K. M. Burnett, G. H. Reeves, and L. M. Ganio. 2012. Do network relationships matter? Comparing network and instream habitat variables to explain densities of juvenile coho salmon (Oncorhynchus kisutch) in mid-coastal Oregon, USA. Aquatic Conservation: Marine and Freshwater Ecosystems 22(3):288-302.

Fretwell, S. D., and J. S. Calver. 1969. On territorial behavior and other factors influencing habitat distribution in birds. Acta biotheoretica 19(1):37-44.

Frissell, C. A. 1992. Cumulative effects of land use on salmon habitat in southwest Oregon coastal streams.

Frissell, C. A., W. J. Liss, C. E. Warren, and M. D. Hurley. 1986. A hierarchical framework for stream habitat classification: viewing streams in a watershed context. Environmental management 10(2):199-214.

Frontier, S. 1976. Étude de la décroissance des valeurs propres dans une analyse en composantes principales: Comparaison avec le moddle du bâton brisé. Journal of Experimental Marine Biology and Ecology 25(1):67-75.

Fukushima, M., and W. W. Smoker. 1997. Determinants of stream life, spawning efficiency, and spawning habitat in pink salmon in the Auke Lake system, Alaska. Can. J. Fish. Aquatic. Sci. (54):96-104. 
Fukushima, M., and W. W. Smoker. 1998. Spawning Habitat Segregation of Sympatric Sockeye and Pink Salmon. Transactions of the American Fisheries Society 127(2):253-260.

Gallagher, S. P., and C. M. Gallagher. 2005. Discrimination of Chinook Salmon, Coho Salmon, and Steelhead Redds and Evaluation of the Use of Redd Data for Estimating Escapement in Several Unregulated Streams in Northern California. North American Journal of Fisheries Management 25(1):284-300.

Gehrels, G. E., and H. C. Berg. 1992. Geologic map of southeastern Alaska. US Geological Survey Denver.

Grant, G. E., and F. J. Swanson. 1995. Morphology and processes of valley floors in mountain streams, western Cascades, Oregon. Natural and anthropogenic influences in fluvial geomorphology:83-101.

Groot, C., and L. Margolis. 1991. Pacific salmon life histories. UBC press.

Guy, C. S., and M. L. Brown. 2007. Analysis and interpretation of freshwater fisheries data. American Fisheries Society.

Hair, J. F., Jr, R. E. Anderson, and R. L. Tatham. 1987. Multivariate data alalysis, 2nd edition. Mcmillan, New York.

Hale, S. S., T. E. McMahon, and P. C. Nelson. 1985. Habitat Suitability Index Models and Instream Flow Suitability Curves: Chum Salmon. Page 48. U.S. Fish and Wildlife Service, Biological report 82(10.108), Department of Fisheries and Oceans, Pacific Biological Station, Nanaimo, B.C. Canada V9R-5K6.

Hall, J. E., D. M. Holzer, and T. J. Beechie. 2007. Predicting River Floodplain and Lateral Channel Migration for Salmon Habitat Conservation1.

Harrelson, C. C., C. L. Rawlins, and J. P. Potyondy. 1994. Stream Channel Reference Sites: An Illustrated Guide to Field Technique.

Hastie, T., R. Tibshirani, and J. H. Friedman. 2009. The elements of statistical learning: data mining, inference, and prediction2nd ed. Springer, New York, NY.

Heard, W. R. 1991. Life history of pink salmon (Oncorhynchus gorbuscha), In: Groot C. \& Margolis L., Edits. Pacific salmon life histories. University of British Columbia Press., Vancouver, British Columbia.

Heinl, S. C., E. L. Jones III, A. W. Piston, P. J. Richards, and L. D. Shaul. 2014. Review of salmon escapement goals in southeast Alaska, 2014. Page 77. Alaska Departmen of Fish and Game, Fishery manuscript series 14-07.

Isaak, D. J., and R. F. Thurow. 2006. Network-scale spatial and temporal variation in Chinook salmon (Oncorhynchus tshawytscha) redd distributions: patterns inferred from spatially continuous replicate surveys. Canadian Journal of Fisheries and Aquatic Sciences 63(2):285-296.

Johnson, D. H. 1981. The use of multivariate statistics in studies of wildlife habitat. Pages 11-19. U.S. Forest Service general technical report RM-87. 
Kondolf, G. M., and M. G. Wolman. 1993. The sizes of salmonid spawning gravels. Water Resources Research 29(7):2275-2285.

Liaw, A., and M. Wiener. 2002. Classification and regression by randomForest. R news 2(3):18-22.

Manhard, C. V., J. E. Joyce, W. W. Smoker, and A. J. Gharrett. 2017. Ecological factors influencing lifetime productivity of pink salmon (Oncorhynchus gorbuscha) in an Alaskan stream. Canadian Journal of Fisheries and Aquatic Sciences e-First Article:1-12.

Manly, B. F. J. 2006. Randomization, bootstrap and Monte Carlo methods in biology. CRC Press.

Manly, B. F. J., L. L. McDonald, and D. L. Thomas. 2002. Resource Selection by Animals: Statistical Design and Analysis for Field Studies, 2nd edition. Journal of Animal Ecology.

Martin, D. J., and A. Shelly. 2017. Temporal Trends in Stream Habitat on Managed Forestlands in Coastal Southeast Alaska. North American Journal of Fisheries Management.

May, C., J. Roering, K. Snow, K. Griswold, and R. Gresswell. 2016. The waterfall paradox: How knickpoints disconnect hillslope and channel processes, isolating salmonid populations in ideal habitats. Geomorphology.

McElhany, P., M. H. Ruckelshaus, M. J. Ford, T. C. Wainwright, and E. P. Bjorkstedt. 2000. Viable salmonid populations and the recovery of evolutionarily significant units. US Dept. Commer. NOAA Tech. Memo. NMFS-NWFSC 42:156.

McNeil, W. J. 1964. Redd Superimposition and Egg Capacity of Pink Salmon Spawning Beds. J.Fish, Res. Bd. Canada, 21(6):1385-1396.

McNeil, W. J. 1966, September. Distribution of Spawning Pink Salmon in Sashin Creek, Southeastern Alaska, and Survival of Their Progeny. United States Deparment of the Interior.

Miller, D. J. 2003. Programs for DEM analysis. Landscape dynamics and forest management. Gen. Tech. Rep. RMRSGTR-101CD. USDA Forest Service, Rocky Mountain Research Station, Fort Collins, Colorado, USA. [CD-ROM].

Miller, D. J., K. Burnett, and L. Benda. 2008. Factors Controlling Availability of Spawning Habitat for Salmonids at the Basin Scale. American Fisheries Society (65):103-120.

Montgomery, D. R. 1999. Process Domains and the River Continuum. Journal of the American Water Resources Association 35(2):397-410.

Montgomery, D. R., E. M. Beamer, G. R. Pess, and T. P. Quinn. 1999. Channel type and salmonid spawning distribution and abundance. Canadian Journal of Fisheries and Aquatic Sciences 56(3):377-387. 
Montgomery, D. R., and J. M. Buffington. 1997. Channel-reach morphology in mountain drainage basins. Geological Society of America Bulletin 109(5):596-611.

Montgomery, D. R., and J. M. Buffington. 1998. River Ecology and Management: Channel Processes, Classification, and Response. Springer-Verlag New York, Inc.

Montgomery, D. R., J. M. Buffington, N. P. Peterson, D. Schuett-Hames, and T. P. Quinn. 1996. Stream-bed scour, egg burial depths, and the influence of salmonid spawning on bed surface mobility and embryo survival. Canadian Journal of Fisheries and Aquatic Sciences 53(5):1061-1070.

Moore, K., K. Jones, and J. Dambacher. 2002, May. Methods for Stream Habitat Surveys Aquatic Inventories Project Natural Production Program: Oregon Department of Fish and Wildlife. Oregon Department of Fish and Wildlife.

Mouw, J. E. B., T. H. Tappenbeck, and J. A. Stanford. 2014. Spawning tactics of summer chum salmon Oncorhynchus keta in relation to channel complexity and hyporheic exchange. Environmental Biology of Fishes 97(10):1095-1107.

Muhlfeld, C. C., M. L. Taper, D. F. Staples, and B. B. Shepard. 2006. Observer Error Structure in Bull Trout Redd Counts in Montana Streams: Implications for Inference on True Redd Numbers. Transactions of the American Fisheries Society 135(3):643-654.

Murphy, M. L. 1995. Forestry impacts on freshwater habitat of anadromous salmonids in the Pacific Northwest and Alaska: requirements for protection and restoration.

NOAA. 2016. Climate Data Online. National Centers for Environmental Information. Available from https://www.ncdc.noaa.gov/cdo-web/.

Overstreet, B. T., C. S. Riebe, J. K. Wooster, L. S. Sklar, and D. Bellugi. 2016. Tools for gauging the capacity of salmon spawning substrates. Earth Surface Processes and Landforms 41(1):130-142.

Parks, B., and R. J. Madison. 1985. Estimation of Selected Flow and Water-quality Characteristics of Alaska Streams. Page 64. USGS, Water-resource Investigation 84-4247.

Pauley, G. B., K. L. Bowers, and G. L. Thomas. 1988. Species Profiles: Life Histories and Environmental Requirements of Coastal Fishes and Invertebrates (Pacific Northwest) - chum salmon. Page 17. U.S Fish and Wildl. Serv. Biol. Rep., Species Profile 82(11.81).

Paustian, S. J. 2010. A Channel Type User Guide for the Tongass National Forest, Southeast Alaska. Page 179. USDA Forest Service, Alaska Region, R10-TP-26, Juneau, Alaska.

Pess, G. R., T. P. Quinn, D. E. Schindler, and M. C. Liermann. 2014. Freshwater habitat associations between pink (Oncorhynchus gorbuscha), chum (O. keta) and Chinook salmon (O. tshawytscha) in a watershed dominated by sockeye salmon (O.nerka) abundance. Ecology of Freshwater Fish 23(3):360-372. 
Piston, A. W., and S. C. Heinl. 2011. Pink salmon stock status and escapement goals in southeast Alaska. Page 37. Alaska Department of Fish and Game, Special Publication 11-18.

Piston, A. W., and S. C. Heinl. 2014. Chum salmon stock status and escapement goals in Southeast Alaska. Page 84. Alaska Departmen of Fish and Game, Special Publication 14-13.

Quinn, T. P. 2011. The Behavior and Ecology of Pacific Salmon and Trout. UBC Press.

R Core Team. 2017. R: A Language and Environment for Statistical Computing. R Foundation for Statistical Computing, Vienna, Austria.

Raleigh, R. F., and P. C. Nelson. 1985. Habitat Suitability Index Models and Instream Flow Suitability Curves: Pink Salmon. Page 36. U.S. Fish and Wildlife Service, Biol. Rep. 82(10.109) 82/10.109.

Reed, R. J. 1967. Observation of Fishes Associated with Spawning Salmon. Transactions of the American Fisheries Society 96(1):62-67.

Riebe, C. S., L. S. Sklar, B. T. Overstreet, and J. K. Wooster. 2014. Optimal reproduction in salmon spawning substrates linked to grain size and fish length. Water Resources Research 50(2):898-918.

Roper, B. B., J. M. Buffington, S. Bennett, S. H. Lanigan, E. Archer, S. T. Downie, J. Faustini, T. W. Hillman, S. Hubler, K. Jones, C. Jordan, P. R. Kaufmann, G. Merritt, C. Moyer, and A. Pleus. 2010. A Comparison of the Performance and Compatibility of Protocols Used by Seven Monitoring Groups to Measure Stream Habitat in the Pacific Northwest. North American Journal of Fisheries Management 30(2):565-587.

Ruggerone, G. T., B. A. Agler, and J. L. Nielsen. 2012. Evidence for competition at sea between Norton Sound chum salmon and Asian hatchery chum salmon. Environmental Biology of Fishes 94(1):149-163.

Ruggerone, G. T., R. M. Peterman, B. Dorner, and K. W. Myers. 2010. Magnitude and Trends in Abundance of Hatchery and Wild Pink Salmon, Chum Salmon, and Sockeye Salmon in the North Pacific Ocean. Marine and Coastal Fisheries 2(1):306-328.

Sheer, M. B., D. S. Busch, E. Gilbert, J. Bayer, S. Lanigan, J. Schei, K. Burnett, and D. Miller. 2009. Development and Management of Fish Intrinsic Potential Data and Methodologies: State of the IP 2008 Summary Report. Page 56. NOAA, State of the IP 2008 summary report 2009-004.

Sloat, M. R., G. H. Reeves, and K. R. Christiansen. 2016. Stream network geomorphology mediates predicted vulnerability of anadromous fish habitat to hydrologic change in southeast Alaska. Global Change Biology.

Steel, E. A., D. W. Jensen, K. M. Burnett, K. Christiansen, J. C. Firman, B. E. Feist, K. J. Anlauf, and D. P. Larsen. 2012. Landscape characteristics and coho salmon 
(Oncorhynchus kisutch) distributions: explaining abundance versus occupancy. Canadian Journal of Fisheries and Aquatic Sciences 69(3):457-468.

Steel, E. A., L. Johnston, B. E. Feist, G. R. Pess, R. E. Bilby, D. Jensen, T. J. Beechie, and J. M. Myer. 2003. Pacific salmon recovery planning and the salmonid watershed analysis model (SWAM): a broad-scale tool for assisting in the development of habitat recovery plans. Endangered Species Update 20(1):3-15.

Steel, E. A., A. Muldoon, R. L. Flitcroft, J. C. Firman, K. J. Anlauf-Dunn, K. M. Burnett, and R. J. Danehy. 2016. Current landscapes and legacies of land-use past: understanding the distribution of juvenile coho salmon (Oncorhynchus kisutch) and their habitats along the Oregon Coast, USA. Canadian Journal of Fisheries and Aquatic Sciences:1-16.

Stevens, D. L., and A. R. Olsen. 2004. Spatially Balanced Sampling of Natural Resources. Journal of the American Statistical Association 99(465):262-278.

Strahler, A. N. 1957. Quantitative Analysis of Watershed Geomorphology. Transactions. American Geophysical Union 38(6):913-920.

Strobl, C., J. Malley, and G. Tutz. 2009b. An introduction to recursive partitioning: Rationale, application, and characteristics of classification and regression trees, bagging, and random forests. Psychological Methods 14(4):323-348.

Strobl, C., A. Zeileis, and T. Hothorn. 2009a. Party on!-A new, conditional variable importance measure for random forests available in the party package. R J.:14-17.

Taylor, E. B. 1991. A review of local adaptation in Salmonidae, with particular reference to Pacific and Atlantic salmon. Aquaculture 98(1-3):185-207.

USFWS. 1981. Standards for the development of habitat suitability index models. U.S. Fish and Wildlife Service, Division of Ecological Services, ESM 103, Washington, D.C.

Van Horne, B., and J. A. Wiens. 1991. Forest bird habitat suitability models and the development of general habitat models. DTIC Document.

Ward, J. 1998. Riverine landscapes: biodiversity patterns, disturbance regimes, and aquatic conservation. Biological conservation 83(3):269-278.

WDFW. 2009. Fish Passage and Surface Water Diversion Screening Assessment and Prioritization Manual. Washington Department of Fish and Wildlife. Olympia, Washington. WDFW.

Wickett, W. P. 1958. Review of Certain Environmental Factors Affecting the Production of Pink and Chum Salmon. Journal of the Fisheries Research Board of Canada 15(5):1103-1126.

Wolman, M. G. 1954. A method of sampling coarse river-bed material. EOS, Transactions American Geophysical Union 35(6):951-956. 
Wright, K. A. 2011. Escapement, migration timing, and spatial distribution of adult chinook and coho salmon in Prairie Creek, California. Masters of Science, In Natural Resources: Fisheries, Humboldt State University.

Zarnetske, P. L., B. Baiser, A. Strecker, S. Record, J. Belmaker, and M.-N. Tuanmu. 2017. The Interplay Between Landscape Structure and Biotic Interactions. Current Landscape Ecology Reports 2(1):12-29. 
Appendix A: $\quad$ Supporting data 
Table A-1. Pearson's correlation coefficients among redd densities, and 26 reach scale synthetic channel geomorphic habitat variables used in initial analyses. An asterisk next to the correlation coefficient indicates significance at the alpha $=0.05$ level while bold indicates significant correlations $>$ absolute value of 0.80 (See Methods section Table 1 for variable description).

\begin{tabular}{|c|c|c|c|c|c|c|c|c|c|c|}
\hline & & \multicolumn{4}{|c|}{ Redd density $\left(100 \mathrm{~m}^{\wedge} 2\right)$} & \multicolumn{5}{|c|}{ Habitat size } \\
\hline \multirow{5}{*}{ 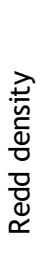 } & & cr15 & cr16 & $\operatorname{pr} 15$ & $\operatorname{pr} 16$ & AREA_SQKM & OUT_DIST & SRC_DIST & WIDTH_M & DEPTH_M \\
\hline & $\operatorname{cr} 15$ & 1 & & & & & & & \multirow[b]{8}{*}{1} & \multirow[b]{9}{*}{1} \\
\hline & cr16 & $0.39 *$ & 1 & & & & & & & \\
\hline & $\operatorname{pr} 15$ & $0.35 *$ & 0.0 & 1 & & & & & & \\
\hline & $\operatorname{pr} 16$ & 0.26 & $0.53 *$ & -0.02 & 1 & & & & & \\
\hline 3 & AREA_SQKM & -0.12 & 0.42 * & -0.23 & 0.32 * & 1 & & & & \\
\hline$\frac{\pi}{\pi}$ & OUT_DIST & 0.40 * & 0.08 & 0.49 * & $-0.43 *$ & -0.12 & 1 & & & \\
\hline$\underset{\widetilde{\tau}}{\complement}$ & SRC_DIST & -0.05 & $0.43 *$ & -0.21 & $0.33 *$ & $0.97 *$ & -0.13 & 1 & & \\
\hline 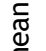 & WIDTH_M & -0.07 & $0.51 *$ & $-0.36 *$ & 0.29 * & $0.93 *$ & -0.12 & 0.91 * & & \\
\hline \multirow{4}{*}{ 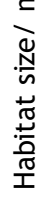 } & DEPTH_M & -0.06 & 0.52 * & $-0.41 *$ & 0.28 & $0.88 *$ & -0.14 & $0.87 *$ & $0.99 *$ & \\
\hline & MEANANNCMS & -0.1 & $0.41 *$ & -0.2 & 0.29 * & $1.0 *$ & -0.08 & $0.98 *$ & $0.93 *$ & $0.88 *$ \\
\hline & MNANPRC_M & $0.33 *$ & 0.13 & 0.38 * & -0.19 & 0.2 & 0.66 * & $0.30 *$ & 0.19 & 0.17 \\
\hline & BFQ & $-0.34^{*}$ & 0.08 & $-0.53 *$ & -0.1 & $0.46 *$ & -0.15 & 0.47 * & $0.58 *$ & $0.61 *$ \\
\hline \multirow{6}{*}{ 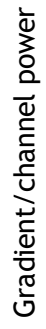 } & GRADIENT & -0.27 & $-0.51 *$ & -0.06 & -0.28 & $-0.64 *$ & -0.17 & $-0.63 *$ & $-0.72 *$ & $-0.71 *$ \\
\hline & GRAD_D & $-0.28 *$ & $-0.39 *$ & -0.12 & -0.15 & $-0.58 *$ & -0.21 & -0.70 * & $-0.55^{*}$ & $-0.52 *$ \\
\hline & FlowVel & -0.27 & -0.56 * & 0.0 & $-0.4^{*}$ & $-0.72 *$ & -0.07 & $-0.69 *$ & $-0.76 *$ & $-0.73 *$ \\
\hline & StrmPow & $-0.34 *$ & -0.48 * & -0.19 & $-0.31 *$ & $-0.53 *$ & -0.18 & $-0.51 *$ & $-0.54 *$ & $-0.51 *$ \\
\hline & $\mathrm{d} 50$ & -0.28 & $-0.57 *$ & 0.03 & $-0.37 *$ & $-0.73 *$ & -0.09 & $-0.71 *$ & -0.79 * & $-0.77 *$ \\
\hline & Shear & $-0.29 *$ & $-0.54 *$ & 0.0 & $-0.32 *$ & $-0.67 *$ & -0.13 & $-0.66 *$ & $-0.75^{*}$ & -0.74 * \\
\hline \multirow{8}{*}{ 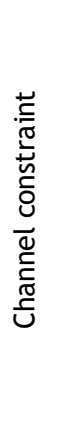 } & FP_WIDTH & 0.09 & 0.50 * & 0.05 & 0.47 * & $0.49 *$ & -0.02 & $0.42 *$ & $0.48 *$ & $0.45^{*}$ \\
\hline & VAL_WIDTH & 0.24 & $0.60 *$ & 0.19 & $0.36 *$ & $0.38 *$ & 0.23 & $0.31 *$ & $0.40 *$ & 0.38 * \\
\hline & VWI_Floor & 0.26 & 0.29 * & 0.54 * & 0.16 & -0.02 & 0.46 * & -0.1 & -0.10 & -0.16 \\
\hline & ValCnstrnt & 0.18 & 0.26 & $0.35 *$ & 0.32 * & 0.11 & 0.15 & 0.02 & 0.03 & 0.0 \\
\hline & GEP & $-0.42 *$ & $-0.47 *$ & -0.37 * & $-0.29 *$ & 0.01 & -0.26 & 0.07 & 0.0 & 0.01 \\
\hline & GEP_Cum & 0.12 & -0.02 & 0.14 & -0.09 & 0.02 & 0.20 & 0.11 & 0.10 & 0.13 \\
\hline & GEP_DEL & $-0.39 *$ & -0.39 * & -0.36 * & -0.22 & 0.0 & $-0.30 *$ & 0.05 & 0.0 & 0.01 \\
\hline & SINUOSITY & 0.02 & 0.34 * & -0.1 & 0.07 & 0.2 & -0.06 & 0.15 & 0.27 & 0.27 \\
\hline \multirow{4}{*}{ 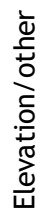 } & ELEV_M & 0.18 & -0.24 & 0.42 * & $-0.54 *$ & $-0.44 *$ & 0.84 * & -0.44 * & $-0.44^{*}$ & $-0.45^{*}$ \\
\hline & FitElev & 0.17 & -0.25 & 0.42 * & $-0.54 *$ & $-0.45^{*}$ & 0.84 * & $-0.45 *$ & $-0.45^{*}$ & $-0.46 *$ \\
\hline & AZIMTH_DEG & 0.22 & -0.08 & 0.05 & -0.04 & $-0.37^{*}$ & 0.18 & $-0.31 *$ & $-0.35 *$ & $-0.33 *$ \\
\hline & P_trib & -0.20 & 0.13 & 0.0 & 0.15 & 0.26 & -0.03 & 0.21 & 0.2 & 0.18 \\
\hline
\end{tabular}


Table A-1 (cont'd)

\begin{tabular}{|c|c|c|c|c|c|c|c|c|c|}
\hline & & & & & Gradient & & & & \\
\hline \multirow{5}{*}{ 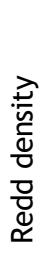 } & & MEANANNCMS & MNANPRC_M & BFQ & GRADIENT & GRAD_D & FlowVel & StrmPow & d50 \\
\hline & cr15 & & & & & & & & \\
\hline & cr16 & & & & & & & & \\
\hline & pr15 & & & & & & & & \\
\hline & pr16 & & & & & & & & \\
\hline \multirow{8}{*}{ 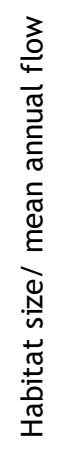 } & AREA_SQKM & & & & & & & & \\
\hline & OUT_DIST & & & & & & & & \\
\hline & SRC_DIST & & & & & & & & \\
\hline & WIDTH_M & & & & & & & & \\
\hline & DEPTH_M & & & & & & & & \\
\hline & MEANANNCMS & 1 & & & & & & & \\
\hline & MNANPRC_M & 0.26 & 1 & & & & & & \\
\hline & $\mathrm{BFQ}$ & 0.47 * & 0.17 & 1 & & & & & \\
\hline \multirow{6}{*}{ 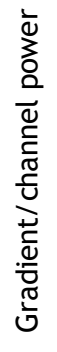 } & GRADIENT & $-0.65^{*}$ & -0.27 & -0.14 & 1 & & & & \\
\hline & GRAD_D & $-0.61 *$ & $-0.58 *$ & -0.24 & $0.65 *$ & 1 & & & \\
\hline & FlowVel & -0.70 * & -0.15 & 0.03 & 0.88 * & $0.56^{*}$ & 1 & & \\
\hline & StrmPow & $-0.52 *$ & -0.14 & 0.18 & 0.88 * & 0.59 * & 0.92 * & 1 & \\
\hline & d50 & $-0.72 *$ & -0.2 & -0.07 & $0.95 *$ & 0.61 * & 0.98 * & $0.91 *$ & 1 \\
\hline & Shear & -0.67 * & -0.23 & -0.1 & 0.98 * & 0.65 * & 0.94 * & $0.92 *$ & 0.98 * \\
\hline \multirow{7}{*}{ 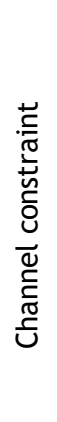 } & FP_WIDTH & $0.47^{*}$ & -0.04 & 0.09 & $-0.42 *$ & -0.12 & $-0.48 *$ & $-0.38 *$ & -0.47 * \\
\hline & VAL_WIDTH & 0.36 * & 0.13 & -0.01 & $-0.45 *$ & -0.12 & $-0.49 *$ & $-0.43^{*}$ & -0.48 * \\
\hline & VWI_Floor & -0.03 & 0.16 & -0.39 * & -0.18 & 0.06 & -0.18 & -0.29 & -0.15 \\
\hline & ValCnstrnt & 0.09 & -0.08 & -0.25 & -0.18 & 0.10 & -0.22 & -0.25 & -0.19 \\
\hline & GEP & 0.03 & 0.1 & 0.39 * & $0.38 *$ & 0.01 & 0.38 * & 0.50 * & 0.37 * \\
\hline & GEP_Cum & 0.05 & $0.70 *$ & 0.33 * & 0.02 & -0.2 & 0.09 & 0.22 & 0.06 \\
\hline & GEP_DEL & 0.01 & 0.09 & $0.41^{*}$ & $0.31 *$ & 0.0 & 0.36 * & 0.49 * & 0.33 * \\
\hline \multirow{5}{*}{ 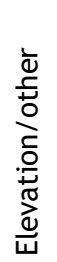 } & SINUOSITY & 0.17 & -0.17 & -0.05 & -0.19 & 0.0 & -0.41 * & $-0.36 *$ & -0.34 * \\
\hline & ELEV_M & $-0.4^{*}$ & 0.56 * & -0.15 & 0.22 & 0.11 & 0.36 * & 0.24 & 0.34 * \\
\hline & FitElev & $-0.4^{*}$ & $0.56^{*}$ & -0.15 & 0.24 & 0.11 & 0.38 * & 0.25 & 0.35 * \\
\hline & AZIMTH_DEG & $-0.35^{*}$ & 0.11 & -0.16 & 0.14 & 0.01 & 0.24 & 0.10 & 0.2 \\
\hline & P_trib & 0.25 & -0.08 & 0.01 & -0.03 & -0.05 & -0.15 & -0.07 & -0.12 \\
\hline
\end{tabular}


Table A-1 (cont'd)

\begin{tabular}{|c|c|c|c|c|c|c|c|c|c|c|}
\hline \multicolumn{11}{|c|}{ Channel constraint } \\
\hline \multirow{5}{*}{ 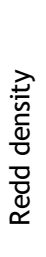 } & & Shear & FP_WIDTH & VAL_WIDTH & VWI_Floor & ValCnstrnt & GEP & GEP_Cum & GEP_DEL & SINUOSITY \\
\hline & $\operatorname{cr} 15$ & & & & & & & & & \\
\hline & cr16 & & & & & & & & & \\
\hline & pr15 & & & & & & & & & \\
\hline & pr16 & & & & & & & & & \\
\hline \multirow{8}{*}{ 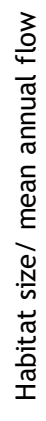 } & AREA_SQKM & & & & & & & & & \\
\hline & OUT_DIST & & & & & & & & & \\
\hline & SRC_DIST & & & & & & & & & \\
\hline & WIDTH_M & & & & & & & & & \\
\hline & DEPTH_M & & & & & & & & & \\
\hline & MEANANNCMS & & & & & & & & & \\
\hline & MNANPRC_M & & & & & & & & & \\
\hline & BFQ & & & & & & & & & \\
\hline \multirow{6}{*}{ 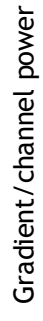 } & GRADIENT & & & & & & & & & \\
\hline & GRAD_D & & & & & & & & & \\
\hline & FlowVel & & & & & & & & & \\
\hline & StrmPow & & & & & & & & & \\
\hline & $\mathrm{d} 50$ & & & & & & & & & \\
\hline & Shear & 1 & & & & & & & & \\
\hline \multirow{8}{*}{ 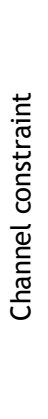 } & FP_WIDTH & $-0.44 *$ & 1 & & & & & & & \\
\hline & VAL_WIDTH & $-0.46 *$ & 0.87 * & 1 & & & & & & \\
\hline & VWI_Floor & -0.15 & 0.59 * & 0.80 * & 1 & & & & & \\
\hline & ValCnstrnt & -0.17 & 0.86 * & 0.78 * & 0.80 * & 1 & & & & \\
\hline & GEP & $0.39 *$ & $-0.45 *$ & $-0.56 *$ & $-0.59 *$ & $-0.53 *$ & 1 & & & \\
\hline & GEP_Cum & 0.06 & -0.09 & -0.03 & -0.11 & -0.18 & 0.36 & 1 & & \\
\hline & GEP_DEL & $0.33 *$ & $-0.48 *$ & $-0.60 *$ & $-0.65 *$ & $-0.59 *$ & 0.9 * & $0.42 *$ & 1 & \\
\hline & SINUOSITY & -0.28 & 0.19 & 0.21 & 0.06 & 0.07 & -0.14 & -0.10 & -0.15 & 1 \\
\hline \multirow{4}{*}{ 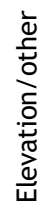 } & ELEV_M & 0.28 * & -0.22 & -0.01 & 0.33 * & 0.04 & 0.0 & $0.35 *$ & -0.01 & -0.25 \\
\hline & FitElev & 0.30 * & -0.22 & -0.01 & $0.33 *$ & 0.04 & 0.01 & $0.35 *$ & -0.01 & -0.25 \\
\hline & AZIMTH_DEG & 0.14 & -0.28 & -0.12 & 0.05 & -0.17 & -0.03 & -0.04 & -0.08 & -0.15 \\
\hline & p_trib & -0.07 & 0.05 & 0.06 & -0.01 & -0.06 & -0.1 & -0.14 & -0.18 & -0.03 \\
\hline
\end{tabular}


Table A-1 (cont'd)

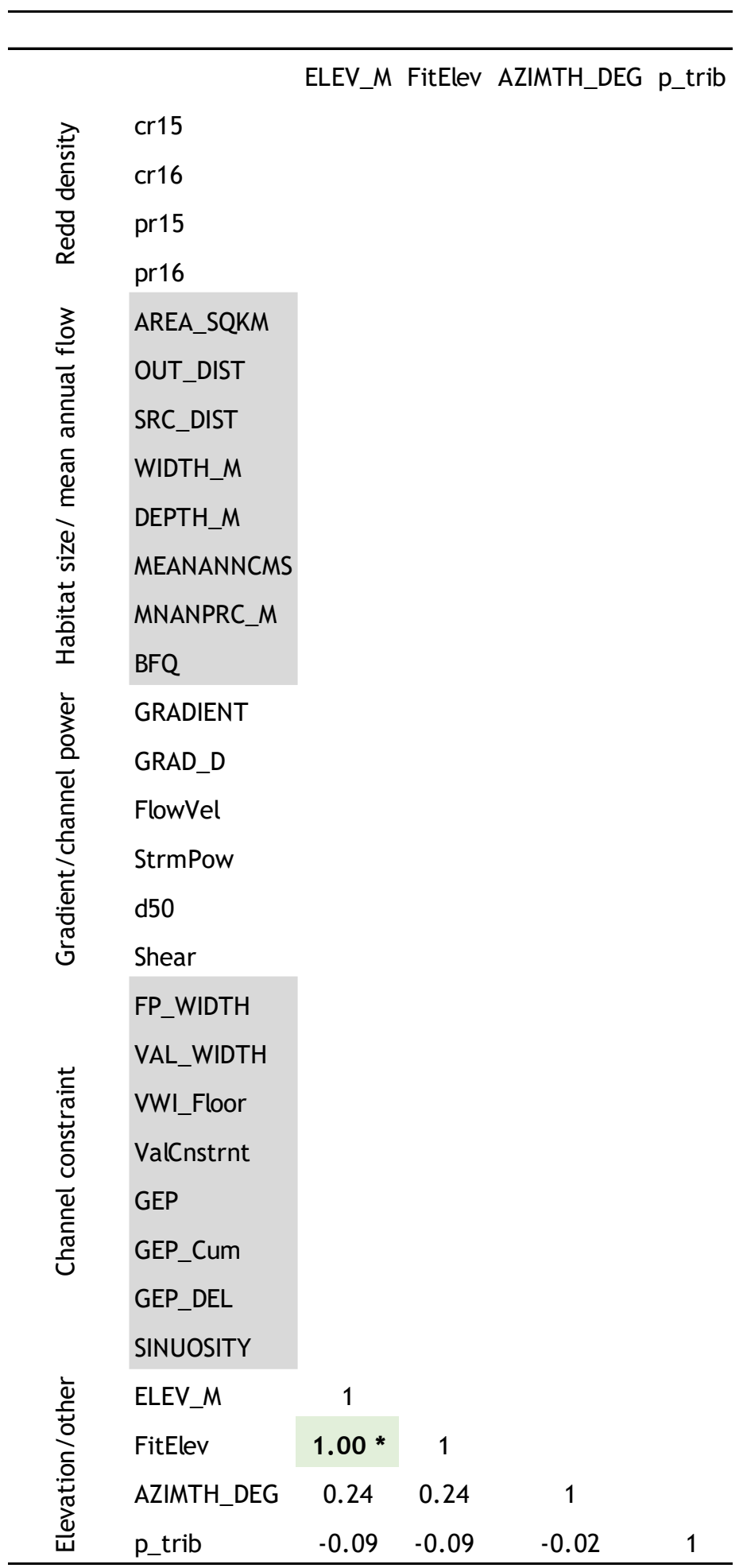


Table A-2. Pearson's correlation coefficients ( $\mathrm{r}$ ) among field $(\mathrm{f})$ and synthetic (modeled $=\mathrm{m}$ ) channel gradient, longitudinal profile length (lpl), bankfull width (bfw), bankfull depth (bfd), and median channel substrate (d50) at 48 channel cross sections surveyed during 2015 field season. An asterisk next the correlation coefficient indicates significance at the alpha $=0.05$ level. Bold coefficients indicate a coefficient with an absolute value correlation $>0.70$ (See Methods section Table 1 for variable description).

\begin{tabular}{|c|c|c|c|c|c|c|c|c|c|c|c|}
\hline & & & & Field & & & & & Model & & \\
\hline \multirow{5}{*}{$\frac{\text { D }}{i \frac{\mathbb{U}}{4}}$} & & f_gradient & f_lpl & f_bfw & f_bfd & f_d50 & m_gradient & m_lpl & m_bfw & m_bfd & m_d50 \\
\hline & gradient & 1 & & & & & & & & & \\
\hline & lpl & $-0.65 *$ & 1 & & & & & & & & \\
\hline & bfw & $-0.64 *$ & 0.99 * & 1 & & & & & & & \\
\hline & bfd & $-0.62 *$ & 0.83 * & 0.82 * & 1 & & & & & & \\
\hline \multirow{6}{*}{$\begin{array}{l}\overline{0} \\
\text { एँ }\end{array}$} & d50 & -0.37 & 0.23 & 0.21 & 0.21 & 1 & & & & & \\
\hline & gradient & 0.97 * & $-0.62 *$ & $-0.61 *$ & $-0.62 *$ & $-0.40 *$ & 1 & & & & \\
\hline & lpl & $-0.63 *$ & $1.0 *$ & 0.99 * & 0.83 * & 0.21 & $-0.61 *$ & 1 & & & \\
\hline & bfw & $-0.74 *$ & 0.95 * & 0.93 * & 0.87 * & 0.31 & $-0.72 *$ & 0.95 * & 1 & & \\
\hline & bfd & $-0.8 *$ & 0.92 * & 0.90 * & 0.85 * & 0.37 & $-0.8 *$ & $0.91 *$ & 0.99 * & 1 & \\
\hline & d50 & 0.95 * & $-0.7 *$ & $-0.69 *$ & $-0.67 *$ & -0.29 & 0.96 * & $-0.70 *$ & $-0.78 *$ & $-0.84 *$ & 1 \\
\hline
\end{tabular}


Table A-3. Summary statistics including mean, standard deviation, median, minimum, maximum, and $25^{\text {th }}$ and 75 quartiles for synthetic variables used to describe the 26 persistent reach habitat conditions for the 49 study reaches. The four main habitat categories indicate strong channel morphology associations or linear combinations (Refer to Methods section Table 1 for variable description).

\begin{tabular}{|c|c|c|c|c|c|c|c|c|}
\hline Category & Code & Mean & Std.Dev & Median & Min & Max & 25th & 75th \\
\hline \multicolumn{9}{|l|}{ Flow } \\
\hline & AREA_SQKM & 3.43 & 1.10 & 3.69 & 0.75 & 4.88 & 2.74 & 4.23 \\
\hline & OUT_DIST (m) & 2.18 & 0.66 & 2.06 & 0.72 & 3.33 & 1.78 & 2.65 \\
\hline & SRC_DIST (m) & 2.60 & 0.60 & 2.65 & 1.15 & 3.57 & 2.27 & 3.03 \\
\hline & WIDTH_M & 18.59 & 5.46 & 19.24 & 5.92 & 26.95 & 14.84 & 22.52 \\
\hline & DEPTH_M & 0.48 & 0.04 & 0.49 & 0.35 & 0.54 & 0.46 & 0.51 \\
\hline & MNANPRC_M & 1.24 & 0.08 & 1.26 & 1.10 & 1.37 & 1.18 & 1.31 \\
\hline & MEANANNCMS & 1.40 & 0.74 & 1.51 & 0.06 & 2.53 & 0.85 & 1.92 \\
\hline & $\mathrm{BFQ}$ & 21.72 & 5.81 & 22.95 & 5.90 & 32.55 & 18.55 & 25.07 \\
\hline & p_trib & 0.16 & 0.11 & 0.16 & 0.00 & 0.41 & 0.06 & 0.24 \\
\hline \multicolumn{9}{|l|}{ Gradient } \\
\hline & GRADIENT & 0.01 & 0.01 & 0.01 & 0.00 & 0.04 & 0.00 & 0.01 \\
\hline & GRAD_D & 0.02 & 0.01 & 0.02 & 0.00 & 0.05 & 0.01 & 0.03 \\
\hline & FlowVel & 1.08 & 0.23 & 1.05 & 0.43 & 1.66 & 0.95 & 1.23 \\
\hline & StrmPow & 7.32 & 0.86 & 7.30 & 3.96 & 9.22 & 6.89 & 7.96 \\
\hline & d50 & 3.39 & 0.47 & 3.32 & 1.87 & 4.42 & 3.10 & 3.78 \\
\hline & Shear & 3.80 & 0.73 & 3.67 & 1.49 & 5.40 & 3.40 & 4.39 \\
\hline \multicolumn{9}{|c|}{ Constraint } \\
\hline & FP_WIDTH & 3.84 & 0.63 & 3.71 & 2.73 & 5.23 & 3.36 & 4.20 \\
\hline & VAL_WIDTH & 4.42 & 0.71 & 4.32 & 3.04 & 5.99 & 3.92 & 4.98 \\
\hline & VWI_Floor & 1.76 & 0.55 & 1.70 & 0.86 & 3.02 & 1.24 & 2.24 \\
\hline & GEP_Cum & 0.30 & 0.04 & 0.29 & 0.22 & 0.39 & 0.28 & 0.32 \\
\hline & GEP & 0.13 & 0.07 & 0.12 & 0.05 & 0.28 & 0.08 & 0.18 \\
\hline & GEP_DEL & 0.05 & 0.05 & 0.03 & 0.00 & 0.23 & 0.01 & 0.07 \\
\hline & ValCnstrnt & 1.30 & 0.41 & 1.24 & 0.73 & 2.17 & 0.94 & 1.68 \\
\hline & SINUOSITY & 0.86 & 0.08 & 0.84 & 0.77 & 1.12 & 0.80 & 0.90 \\
\hline \multicolumn{9}{|l|}{ Elevation } \\
\hline & ELEV_M & 3.42 & 0.85 & 3.64 & 1.56 & 4.75 & 2.78 & 4.00 \\
\hline & FitElev (m) & 3.43 & 0.85 & 3.64 & 1.57 & 4.76 & 2.80 & 4.01 \\
\hline & AZIMTH_DEG & 5.21 & 0.58 & 5.52 & 3.86 & 5.78 & 4.71 & 5.63 \\
\hline
\end{tabular}


Table A-4. Estimated total relative density (number/100 $\mathrm{m}^{2}$ ) of salmon redds, wet usable area $\left(\mathrm{m}^{2}\right)$, and reach type in stream reaches of 5 drainages during 2015-2016.

\begin{tabular}{|c|c|c|c|c|c|c|c|c|c|c|c|}
\hline \multirow[t]{2}{*}{ Basin } & \multirow[t]{2}{*}{ Reach } & \multicolumn{4}{|c|}{ Reach type } & \multicolumn{2}{|c|}{ Surface area $\left(\mathrm{m}^{2}\right)$} & \multicolumn{4}{|c|}{ Redd density (redds $/ 100 \mathrm{~m}^{2}$ ) } \\
\hline & & Constraint & Tributary & Geology & Size & 2015 & 2016 & Chum 2015 & Chum 2016 & Pink 2015 & Pink 2016 \\
\hline Game & 1 & UV & $\mathrm{t}$ & Qs & $s$ & 325.0 & 295.8 & 0.0 & 0.0 & 29.2 & 0.0 \\
\hline Game & 3 & UV & $\mathrm{t}$ & Dv & s & 1016.7 & 783.3 & 0.0 & 0.0 & 0.0 & 0.0 \\
\hline Game & 5 & $\mathrm{CC}$ & $\mathrm{t}$ & Qs & $\mathrm{s}$ & 716.7 & 508.3 & 3.5 & 0.0 & 14.2 & 0.0 \\
\hline Game & 6 & $\mathrm{CC}$ & $\mathrm{t}$ & Dv & $\mathrm{s}$ & 1258.3 & 891.7 & 0.0 & 0.0 & 3.5 & 0.0 \\
\hline Spasski & 8 & $\mathrm{CC}$ & $\mathrm{t}$ & Dv & $\mathrm{s}$ & 2271.4 & 2208.3 & 0.0 & 0.0 & 3.5 & 0.0 \\
\hline Spasski & 9 & $\mathrm{CC}$ & $\mathrm{m}$ & Qs & $\mathrm{s}$ & 1965.0 & 1258.3 & 0.0 & 0.0 & 9.8 & 0.0 \\
\hline Game & 10 & $\mathrm{CC}$ & $\mathrm{t}$ & Dv & s & 1483.3 & 833.3 & 0.0 & 0.0 & 0.0 & 0.0 \\
\hline Spasski & 12 & UV & $\mathrm{t}$ & Dv & $\mathrm{s}$ & 1205.0 & 741.7 & 0.8 & 0.0 & 6.4 & 1.5 \\
\hline Seagul & 13 & $\mathrm{CC}$ & $\mathrm{m}$ & Qs & $\mathrm{s}$ & 1712.5 & 1400.0 & 0.0 & 0.0 & 11.9 & 0.0 \\
\hline Game & 14 & UV & $\mathrm{t}$ & Qs & $\mathrm{s}$ & 825.0 & 475.0 & 1.3 & 0.0 & 28.9 & 0.0 \\
\hline Game & 17 & $\mathrm{CC}$ & $\mathrm{t}$ & Qs & $\mathrm{s}$ & 1506.3 & 625.0 & 0.8 & 0.3 & 4.1 & 0.8 \\
\hline Seagul & 18 & $\mathrm{CC}$ & $\mathrm{m}$ & Qs & $\mathrm{s}$ & 2045.8 & 1483.3 & 0.0 & 0.0 & 0.0 & 0.0 \\
\hline Seagul & 19 & $\mathrm{CC}$ & $\mathrm{t}$ & Ss & $\mathrm{s}$ & 1154.2 & 825.0 & 0.0 & 0.0 & 2.5 & 0.0 \\
\hline Game & 24 & $\mathrm{CC}$ & $\mathrm{t}$ & Dv & $\mathrm{s}$ & 1741.7 & 808.3 & 0.0 & 0.0 & 2.8 & 0.0 \\
\hline Seagul & 25 & $\mathrm{CC}$ & $\mathrm{m}$ & Qs & $\mathrm{s}$ & 2166.7 & 1616.7 & 0.0 & 0.0 & 6.5 & 0.0 \\
\hline Spasski & 28 & $\mathrm{CC}$ & $\mathrm{m}$ & Dv & I & 3241.7 & 3000.0 & 0.1 & 0.1 & 3.5 & 0.0 \\
\hline Suntaheen & 29 & $\mathrm{CC}$ & $\mathrm{m}$ & Ss & $\mathrm{s}$ & 3516.7 & 2833.3 & 0.0 & 0.1 & 1.2 & 1.1 \\
\hline Game & 31 & $\mathrm{CC}$ & $\mathrm{m}$ & Qs & I & 3818.8 & 2562.5 & 0.6 & 0.7 & 3.8 & 0.0 \\
\hline Spasski & 32 & UV & $\mathrm{m}$ & Dv & I & 3426.5 & 2062.5 & 0.1 & 0.0 & 1.5 & 0.0 \\
\hline Seagul & 33 & $\mathrm{CC}$ & $\mathrm{m}$ & Qs & $\mathrm{s}$ & 2925.0 & 1858.3 & 2.3 & 0.2 & 9.3 & 4.3 \\
\hline Gartina & 34 & $\mathrm{CC}$ & $\mathrm{m}$ & Qs & I & 3881.3 & 2500.0 & 0.4 & 0.8 & 1.1 & 0.3 \\
\hline Game & 35 & $\mathrm{CC}$ & $\mathrm{m}$ & Qs & I & 3179.2 & 3266.7 & 2.1 & 1.1 & 6.1 & 0.2 \\
\hline Spasski & 36 & $\mathrm{CC}$ & $\mathrm{m}$ & Dv & I & 4325.4 & 3690.0 & 0.1 & 0.4 & 1.8 & 0.4 \\
\hline Gartina & 37 & $\mathrm{CC}$ & $\mathrm{m}$ & Qs & $\mathrm{s}$ & 3141.7 & 2916.7 & 0.0 & 0.1 & 0.5 & 0.0 \\
\hline Gartina & 38 & $\mathrm{CC}$ & $\mathrm{m}$ & Qs & 1 & 3541.7 & 2833.3 & 0.0 & 0.6 & 1.5 & 0.2 \\
\hline Game & 39 & $\mathrm{CC}$ & $\mathrm{m}$ & Qs & 1 & 3282.7 & 3493.8 & 1.4 & 0.3 & 6.9 & 0.0 \\
\hline Spasski & 40 & $\mathrm{CC}$ & $\mathrm{m}$ & Dv & I & 5641.7 & 4375.0 & 0.1 & 0.3 & 0.8 & 0.3 \\
\hline Seagul & 42 & $\mathrm{CC}$ & $\mathrm{m}$ & Qs & $\mathrm{s}$ & 2800.0 & 2006.3 & 2.0 & 0.7 & 4.6 & 3.6 \\
\hline Game & 43 & UV & $\mathrm{m}$ & Qs & $\mathrm{s}$ & 2568.8 & 2175.0 & 1.5 & 0.4 & 12.1 & 0.0 \\
\hline Suntaheen & 44 & $\mathrm{CC}$ & $\mathrm{m}$ & Ss & $\mathrm{s}$ & 3135.0 & 2875.0 & 0.0 & 0.2 & 2.1 & 1.4 \\
\hline Spasski & 45 & UV & $\mathrm{m}$ & Dv & I & 2808.3 & 2333.3 & 0.0 & 0.3 & 0.8 & 0.0 \\
\hline Game & 46 & UV & $\mathrm{m}$ & Qs & I & 3745.0 & 3450.0 & 0.7 & 0.8 & 9.2 & 0.0 \\
\hline Game & 55 & $\mathrm{CC}$ & $\mathrm{m}$ & Dv & I & 7850.0 & 7062.5 & 0.1 & 0.0 & 1.4 & 0.1 \\
\hline Game & 56 & $\mathrm{CC}$ & $\mathrm{m}$ & Dv & 1 & 6875.0 & 6500.0 & 0.0 & 0.1 & 0.3 & 0.9 \\
\hline Spasski & 57 & UV & $\mathrm{m}$ & Qs & 1 & 4650.0 & 4541.7 & 0.0 & 0.2 & 1.7 & 1.3 \\
\hline Game & 58 & $\mathrm{CC}$ & $\mathrm{m}$ & Qs & 1 & 4183.3 & 3750.0 & 1.6 & 0.7 & 8.4 & 0.1 \\
\hline Game & 59 & $\mathrm{CC}$ & $\mathrm{m}$ & Dv & I & 9275.0 & 9000.0 & 0.1 & 0.2 & 0.8 & 0.8 \\
\hline Spasski & 60 & $\mathrm{CC}$ & $\mathrm{m}$ & Dv & 1 & 7141.7 & 6750.0 & 0.3 & 0.5 & 3.8 & 1.3 \\
\hline Spasski & 61 & UV & $\mathrm{m}$ & Dv & 1 & 3700.0 & 3583.3 & 2.5 & 1.1 & 4.3 & 4.2 \\
\hline Game & 62 & UV & $\mathrm{m}$ & $\mathrm{Sc}$ & 1 & 5990.0 & 4343.8 & 1.2 & 0.4 & 9.2 & 0.0 \\
\hline Game & 63 & UV & $\mathrm{m}$ & Qs & 1 & 4283.3 & 4062.5 & 0.2 & 0.5 & 3.3 & 1.1 \\
\hline Spasski & 65 & UV & $\mathrm{m}$ & Qs & I & 4926.6 & 4825.5 & 0.9 & 1.0 & 6.6 & 3.8 \\
\hline Game & 66 & UV & $\mathrm{m}$ & Qs & I & 4010.9 & 4250.0 & 1.3 & 0.4 & 5.3 & 0.0 \\
\hline Game & 67 & $\mathrm{CC}$ & $\mathrm{m}$ & Dv & 1 & 5350.0 & 4775.0 & 0.3 & 0.3 & 1.1 & 1.2 \\
\hline Spasski & 69 & UV & $\mathrm{m}$ & Dv & 1 & 4903.3 & 3476.7 & 0.3 & 0.5 & 2.6 & 1.3 \\
\hline Game & 70 & UV & $\mathrm{m}$ & Qs & 1 & 3900.0 & 3833.3 & 0.4 & 0.6 & 18.8 & 0.3 \\
\hline Game & 71 & $\mathrm{CC}$ & $\mathrm{m}$ & Dv & 1 & 6258.3 & 4375.0 & 0.0 & 0.1 & 0.2 & 0.1 \\
\hline Game & 72 & UV & $\mathrm{m}$ & Qs & 1 & 7812.5 & 7985.8 & 0.1 & 1.1 & 7.9 & 6.7 \\
\hline Game & 73 & $\mathrm{CC}$ & $\mathrm{m}$ & Qs & I & 4031.3 & 3916.7 & 1.6 & 0.7 & 8.5 & 0.5 \\
\hline
\end{tabular}




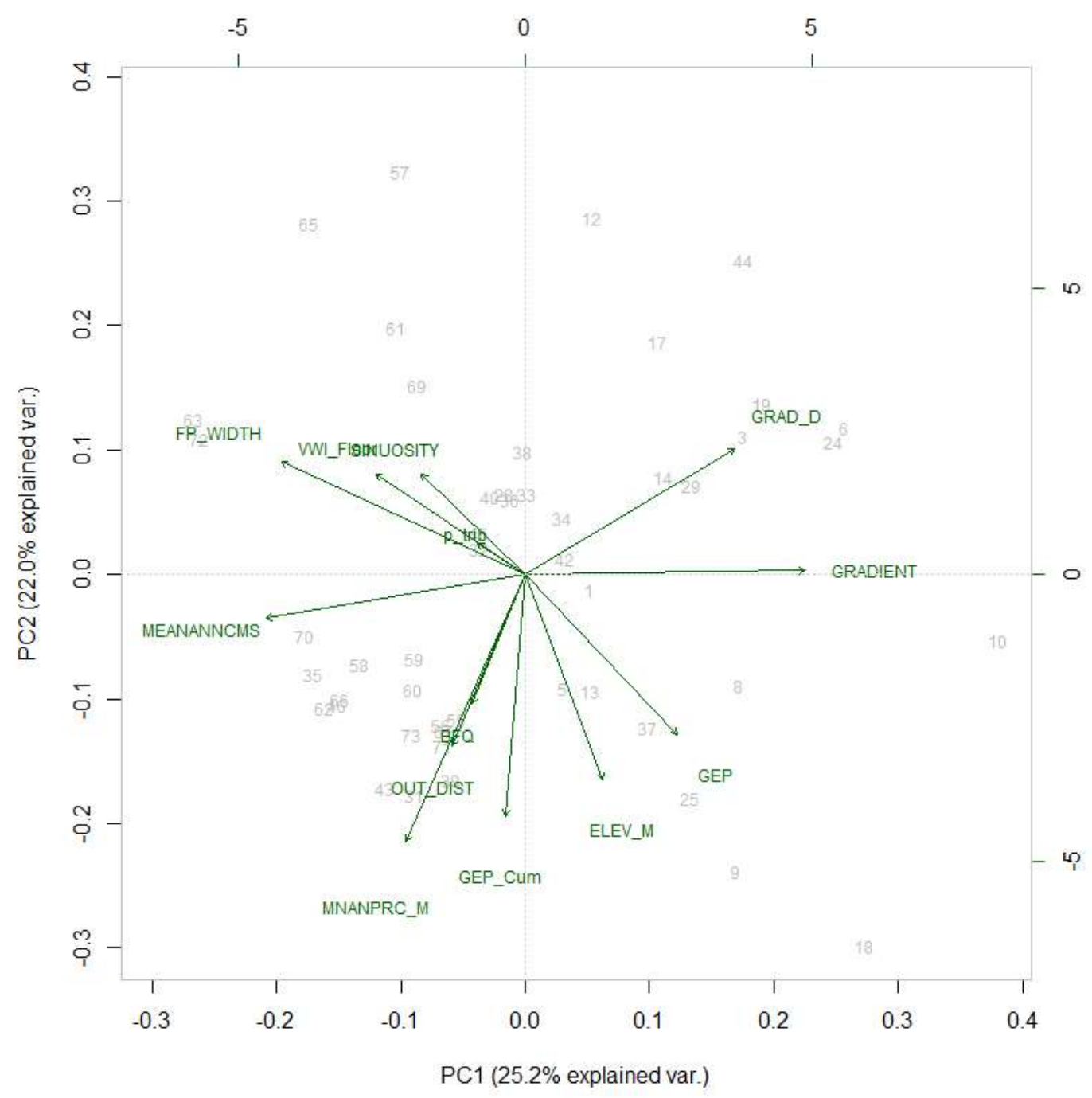

Figure A-1. PCA biplot of standardized PC 1 and PC 2 axis showing study reach number in grey and thirteen $\log$ transformed synthetic reach persistent habitat variables in green. PC 1 is comprised primarily of habitat size and channel gradient, while PC 2 is a channel constraint and debris transport/deposition gradient. Refer to Table 1 for a complete list of variable descriptions. 
2015 Pink Salmon

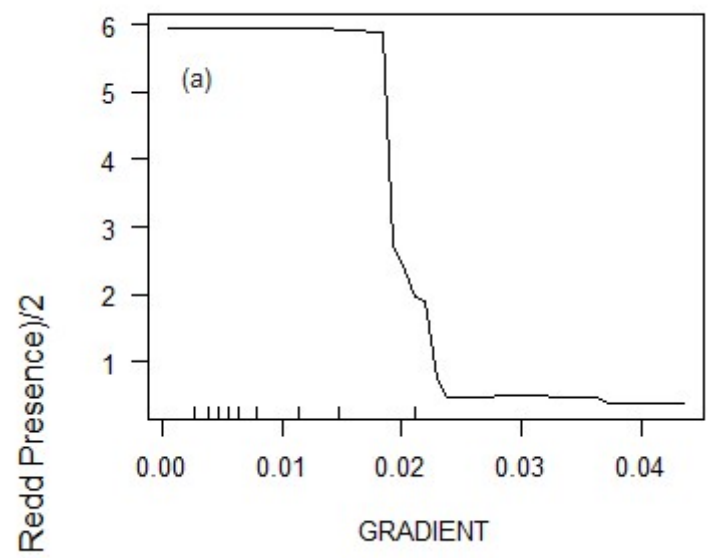

2015 Chum Salmon

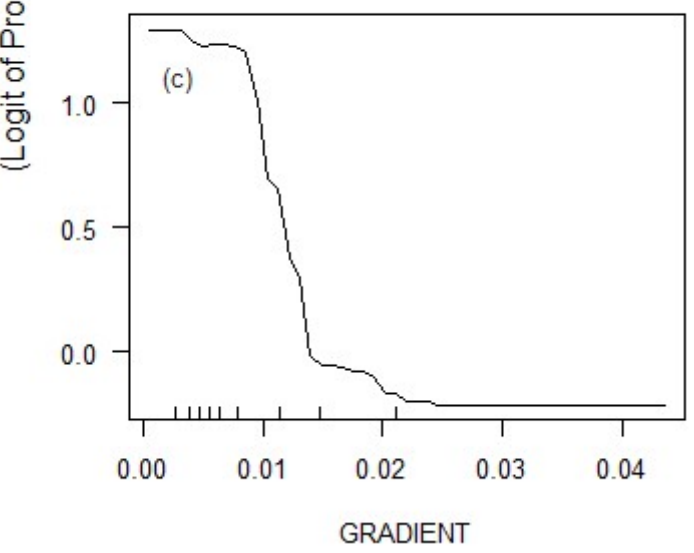

2016 Pink Salmon

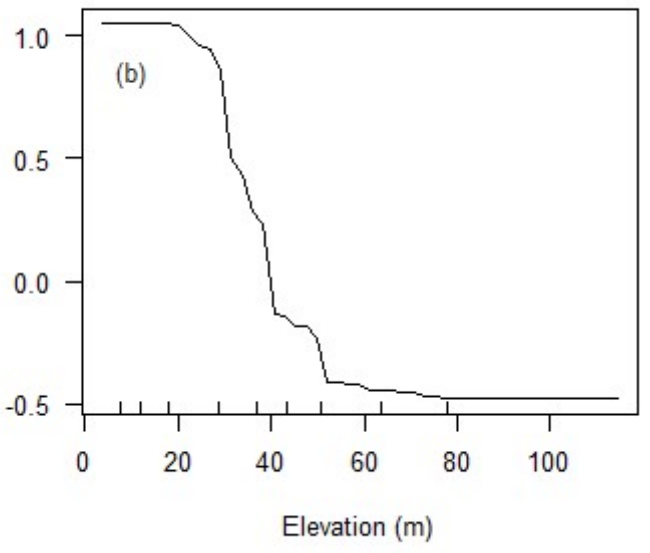

2016 Chum Salmon

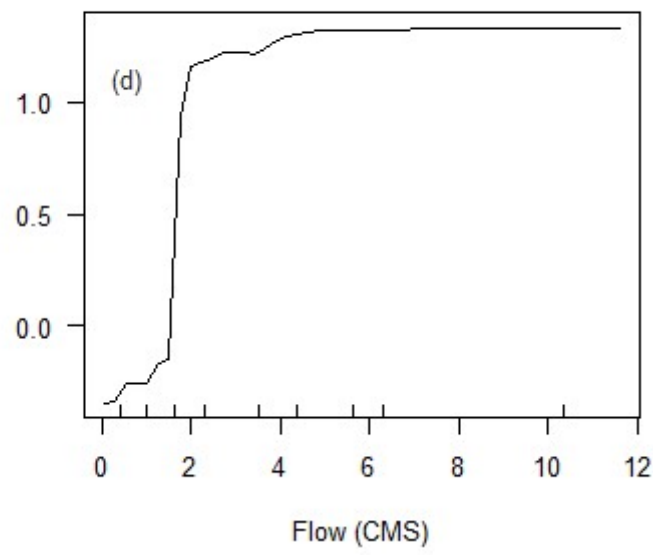

Figure A-2. Partial dependency plots for selected predictor variables from random forest predictions of the presence of chum and pink salmon redds present in the study area. Partial dependence is the dependence of the probability of redd presence on one predictor variable after averaging out the effects of the other predictor variables in the model 


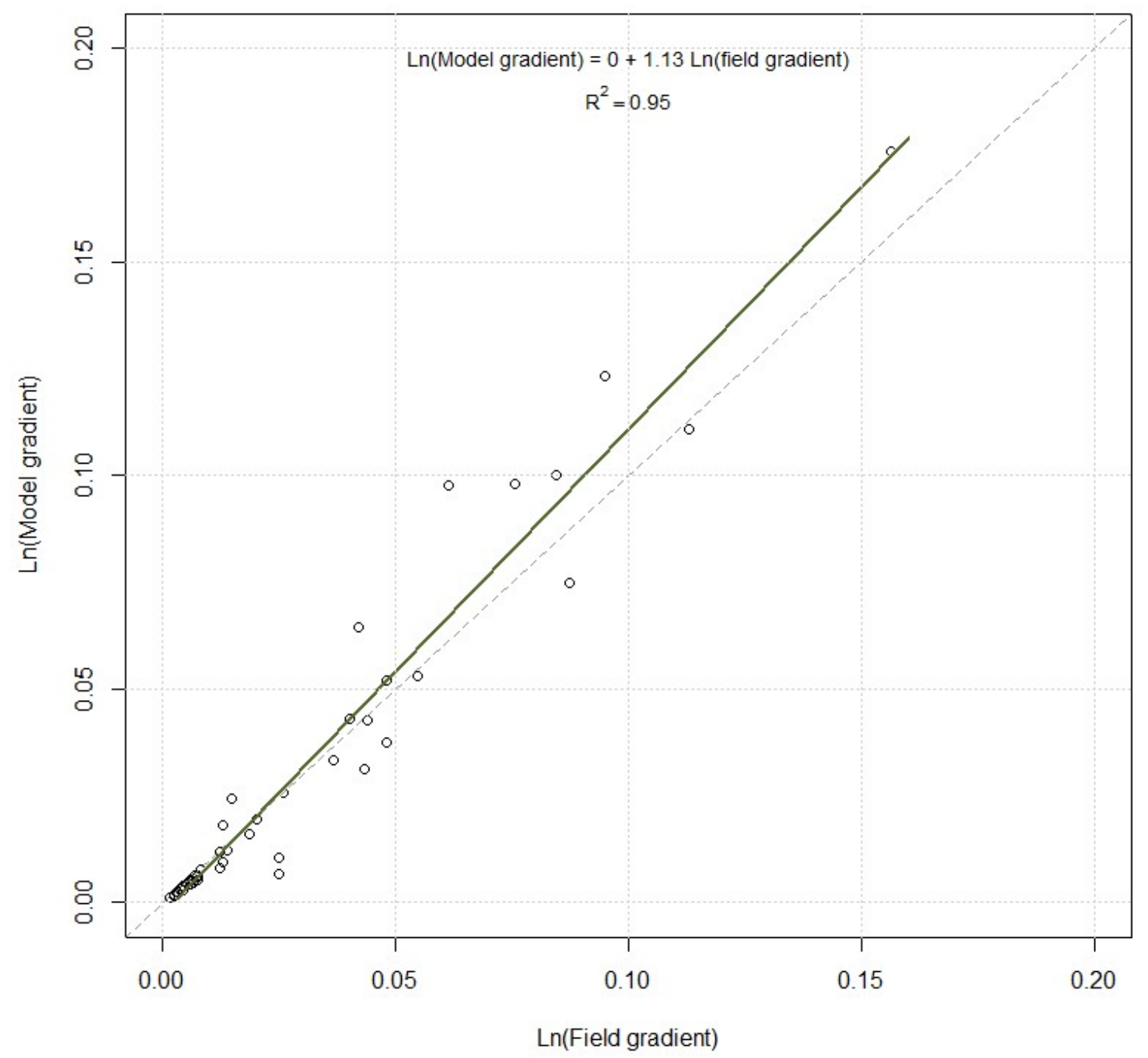

Figure A-3. Regression plot of synthetic vs. field channel gradient surveyed during summer 2015 field season, with 1:1 dashed line for accuracy reference $(n=48)$. 


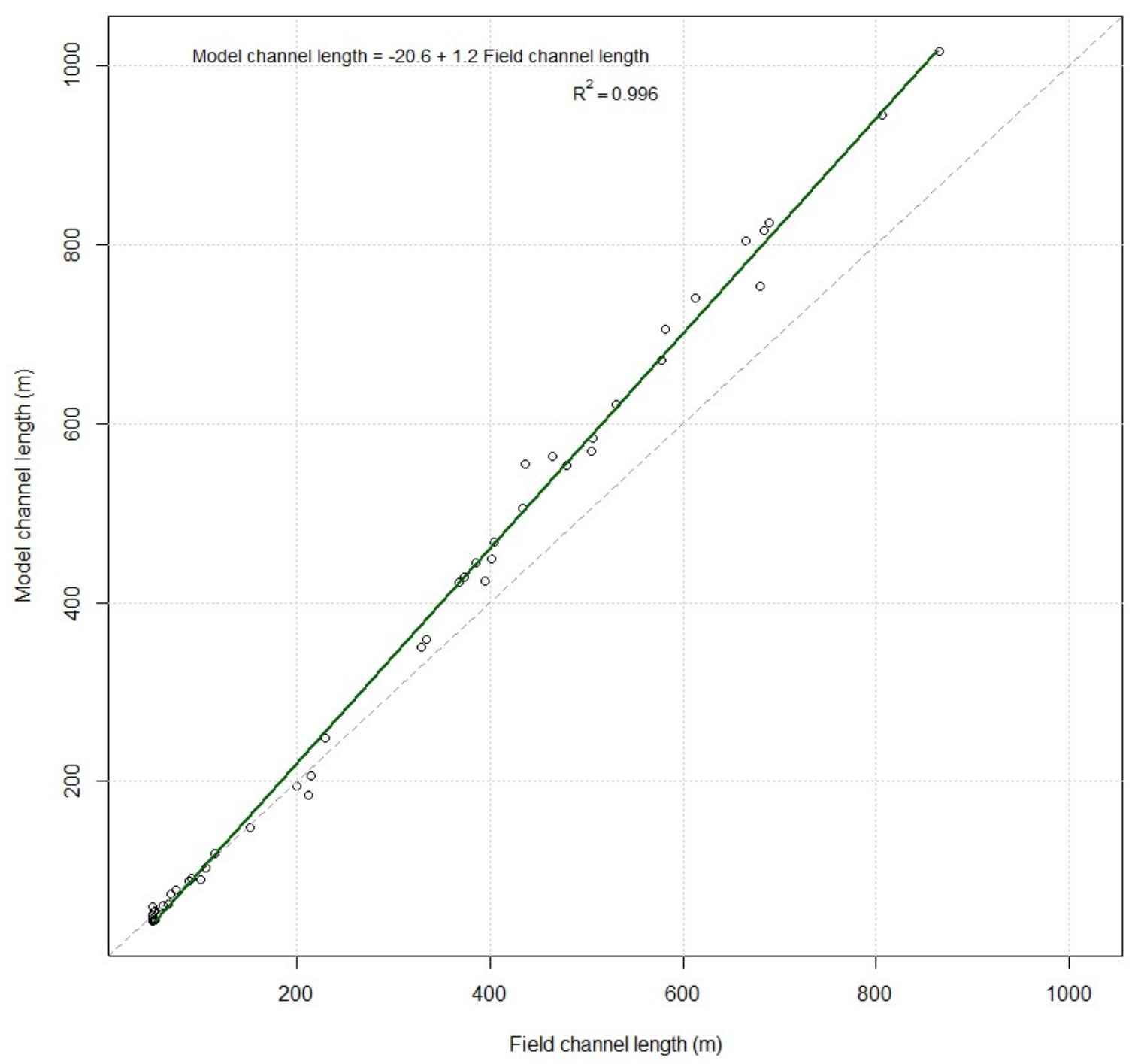

Figure A-4. Regression plot of synthetic channel length vs. field channel length surveyed during summer 2015 field season; 1:1 dashed line for accuracy reference. Field channel length $=20 \mathrm{x}$ bank-full width; comparison based on GPS start and end waypoints for field channel length $(n=48)$. 


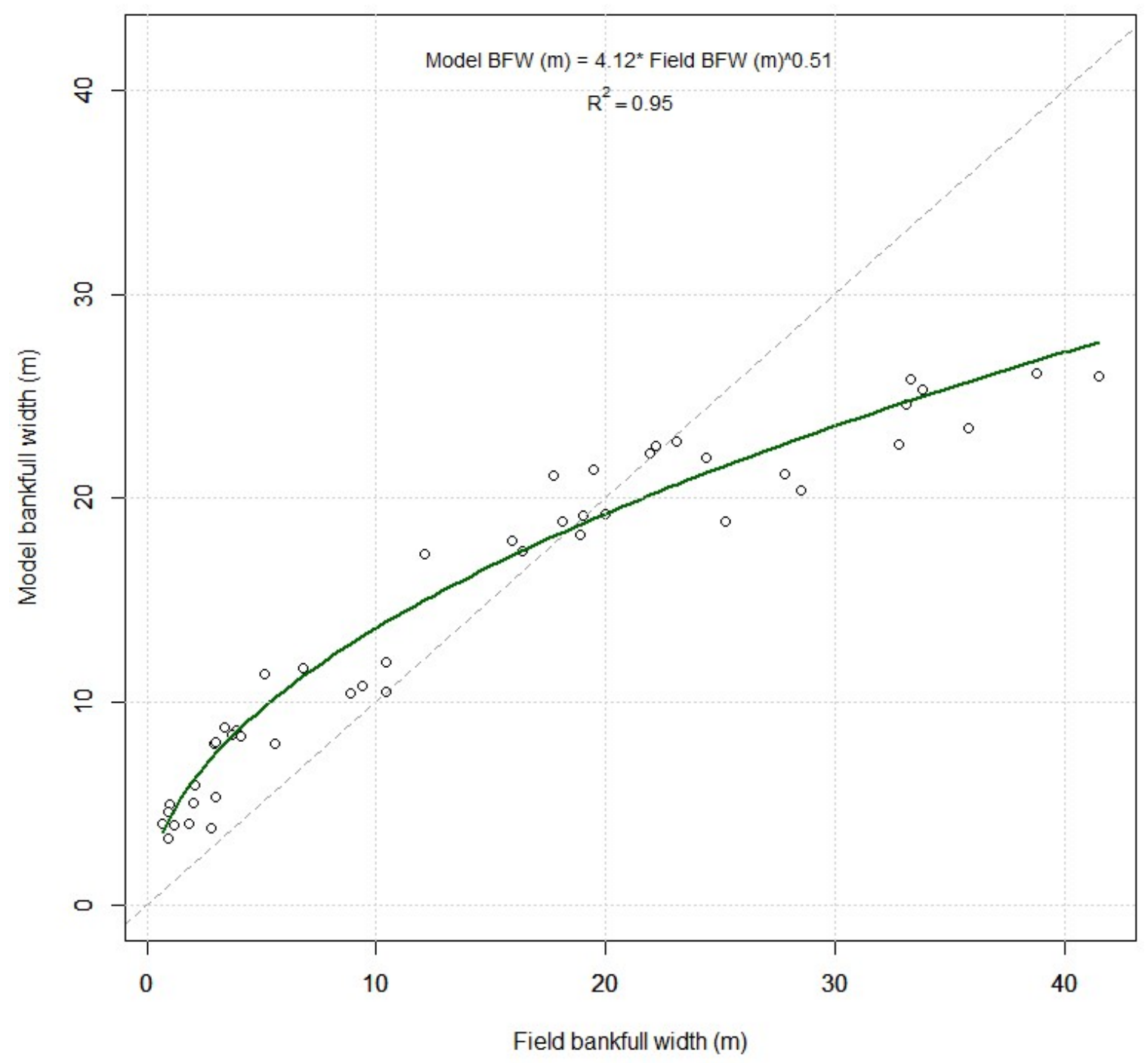

Figure A-5. Polynomial regression plot of synthetic bank-full width vs. field bank-full width during 2015 field season, with 1:1 dashed line for accuracy reference. 


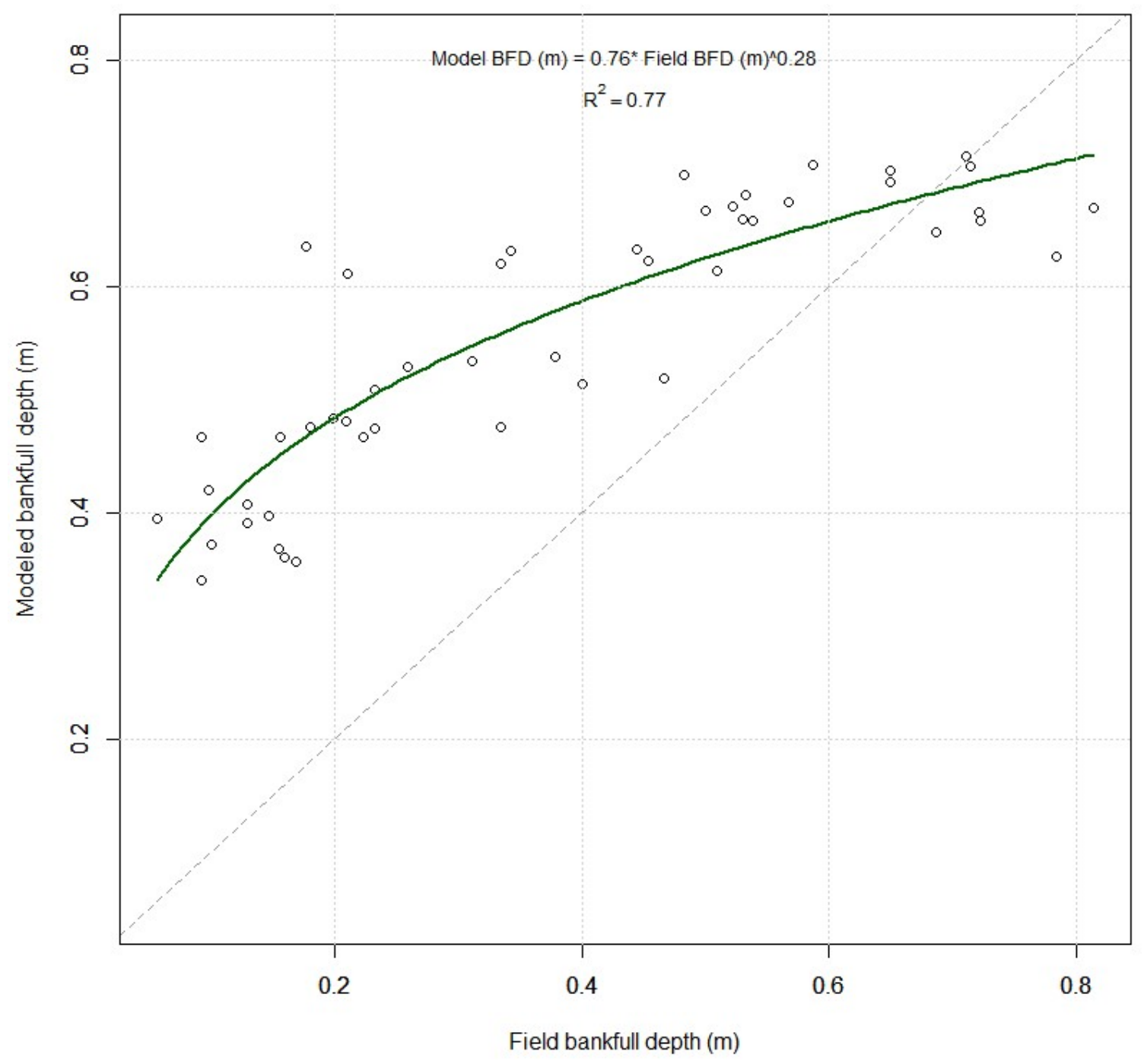

Figure A-6. Polynomial regression plot of synthetic bank-full depth vs field bank-full depth during 2015 field season, with 1:1 dashed line for accuracy reference. 


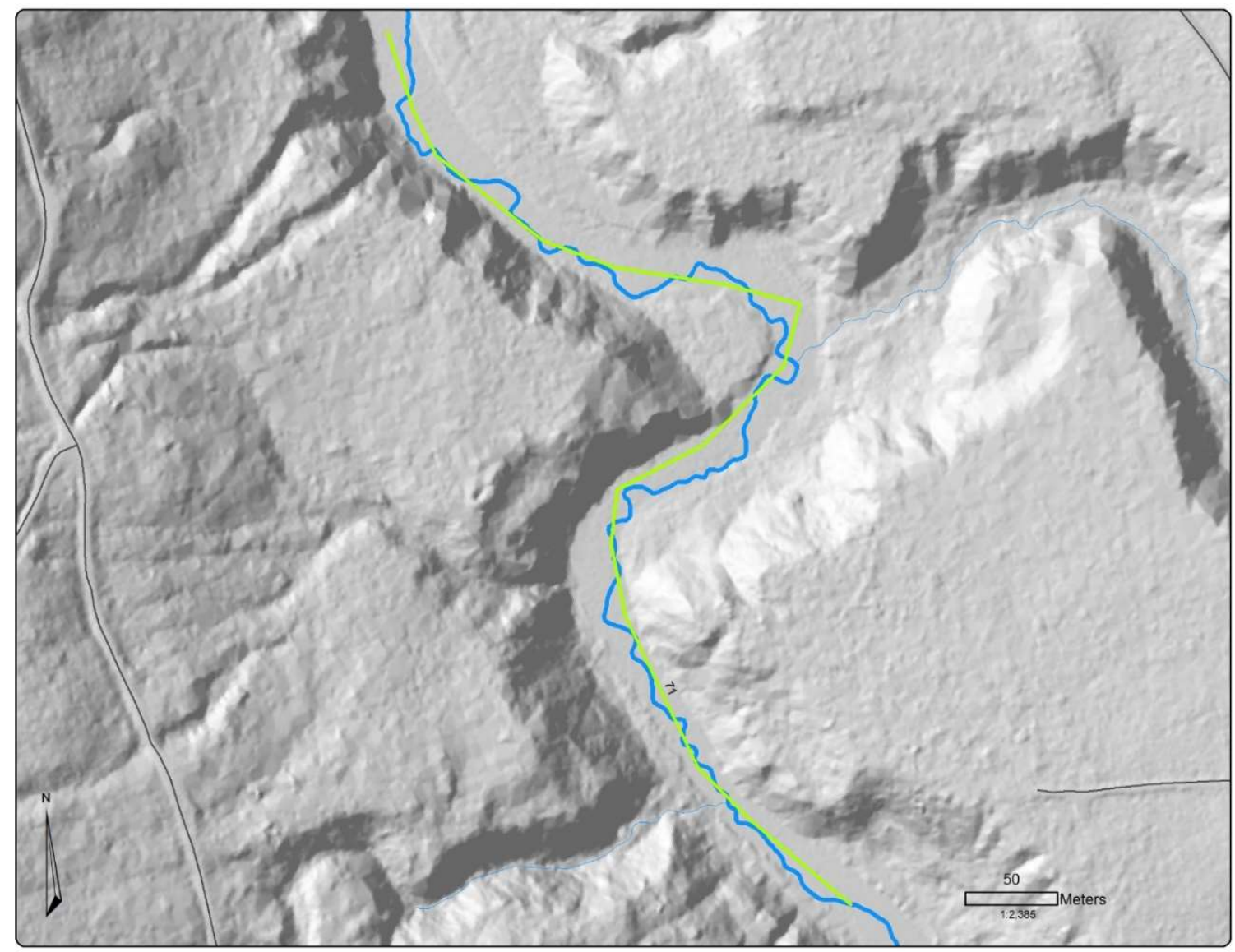

Figure A-7. Mainstem Game Creek channel longitudinal profile length measured in the field (green) compared with syntheticly derived channel (blue) from LiDAR DEM. 